\title{
BIOCATALYSIS OF TYROSINASE IN CHLOROFORM MEDIUM USING SELECTED PHENOLIC SUBSTRATES
}

\author{
by
}

\section{Mara Tse}

A thesis submitted to the Faculty of Graduate Studies and Research in partial fulfilment of the requirements of the degree of Master of Science

\section{- Mara Tse}

Department of Food Science and Agricultural Chemistry

McGill University

Montreal, Québec

November, 1996 
Acquisitions et services bibliographiques

395, rue Wellington Ottawa ON K1A ON4 Canada
The author has granted a nonexclusive licence allowing the National Library of Canada to reproduce, loan, distribute or sell copies of this thesis in microform, paper or electronic formats.

The author retains ownership of the copyright in this thesis. Neither the thesis nor substantial extracts from it may be printed or otherwise reproduced without the author's permission.
L'auteur a accordé une licence non exclusive permettant à la Bibliothèque nationale du Canada de reproduire, prêter, distribuer ou vendre des copies de cette thèse sous la forme de microfiche/film, de reproduction sur papier ou sur format électronique.

L'auteur conserve la propriété du droit d'auteur qui protège cette thèse. $\mathrm{Ni}$ la thèse ni des extraits substantiels de celle-ci ne doivent être imprimés ou autrement reproduits sans son autorisation.

\section{Canadă}




\section{SHORT TITLE}

\section{BIOCATALYSIS OF TYROSINASE IN ORGANIC SOLVENT MEDIA}




\section{M.Se. Mara Tse}

The biocatalytic activity of mushroom tyrosinase was optimized in chloroform medium, using five selected phenolic substrates, including catechin (CT), vanillin (VA), chlorogenic acid (CA), $p$-aminophenol ( $p A P)$ and hydroquinone (HQ). The specific activity (SA) of tyrosinase determined as the change in absorbance at the selected wavelength per $\mu \mathrm{g}$ protein per $\sec (\delta \mathrm{A} / \mu \mathrm{g}$ protein/sec) in chloroform was much higher than that obtained in aqueous media; SA's in chloroform and aqueous media were found to be, respectively, 0.2034 and 0.0102 for CT, 0.0459 and 0.0124 for VA, 0.1529 and $1.257 \times 10^{-3}$ for $\mathrm{CA}, 0.0103$ and $0.2687 \times 10^{-3}$ for $p \mathrm{AP}$ and $0.2595 \times 10^{-3}$ and $2.395 \times 10^{-6}$ for HQ. The values of $V_{\max }$ for tyrosinase in chloroform were $0.1415,0.0250,0.1073,7.9393 \times 10^{-3}$ and $0.1795 \times 10^{-3}(\delta \mathrm{A} / \mu \mathrm{g}$ protein/sec $)$ for CT, VA, CA, $p \mathrm{AP}$ and HQ, respectively, whereas those of $K_{\mathrm{m}}$ were $3.970,0.4125,3.492,0.9495$ and 0.0427 $\mathrm{mM}$, respectively. The optimal amount of enzymatic protein for tyrosinase biocatalysis in chloroform was found to be $44.0 \mathrm{mg}$ protein $/$ for CT and VA, 31.6, 180.5 and $90.3 \mathrm{mg}$ protein/L, respectively, for $\mathrm{CA}, \mathrm{pAP}$ and $\mathrm{HQ}$. The optimal $\mathrm{pH}$ for the oxidative activity of tyrosinase in chloroform was 6.0 for all the substrates; however, the optimal temperature for enzymatic activity was $30^{\circ} \mathrm{C}$ for $\mathrm{CT}$ and $25^{\circ} \mathrm{C}$ for the other four substrates. The use of 1.25 and $6.65 \mathrm{mM}$ catechol in chloroform medium activated the tyrosinase activity maximally by $56.2 \%$ and $267.2 \%$, respectively for CT and CA as substrates; however, no effect from catechol ( 0 to 7 $\mathrm{mM}$ ) was found with VA, pAP or HQ. In addition, the use of $4.25,2.25$ and $5.39 \mathrm{mM}$ ethylenediamine tetraacetic acid (EDTA) in chloroform, with CT, VA and pAP as substrates, inhibited the tyrosinase activity maximally by $44.3,84.7$ and $67.0 \%$, respectively; however, the use of 4.75 and $1.60 \mathrm{mM}$ EDTA activated the enzyme by $101.9 \%$ and $115.9 \%$, respectively, for CA and HQ. The use of high-performance liquid chromatography (HPLC) and capillary electrophoresis (CE) demonstrated the phenolic substrate bioconversion, whereas the spectrophotometric scanning showed the product formation during the enzymatic reaction. HPLC and CE analyses also showed the extent of the substrate bioconversion with respect to the increasing reaction time and suggested that the maximal substrate bioconversion was achieved within the first 10 to $20 \mathrm{sec}$ of the reaction. Fourier transform infrared (FT-IR) spectroscopic analyses suggested that the native mushroom tyrosinase was mainly composed of $\alpha$-helical 
FT-IR analyses provided strong evidence of the formation of o-quinones from the bioconversion in chloroform medium for all the substrates and suggested the possibility of further interaction of these o-quinones with the parent phenolic substrate in the case of vanillin and p-aminophenol while for chlorogenic acid, ring cleavage upon the formation of 0 -quinones might have occurred. 
L'activité biocatalytique de la tyrosinase de champignon a été optimisée dans un milieu de chloroforme, en utilisant cinq substrats phénoliques sélectionnés, la catéchine (CT), la vanilline (VA), l'acide chlorogénique (AC), le p-aminophénol (pAP) et l'hydroquinone (HQ). L'activité spécifique (AS) de la tyrosinase, déterminée par la variation de l'absorbance à une longueur d'onde sélectionnée par $\mu \mathrm{g}$ de protéine et par sec ( $\delta \mathrm{A} / \mu \mathrm{g}$ protéine/sec) dans le chloroforme, a été beaucoup plus élevée que celle obtenue en milieu aqueux; les AS dans le chloroforme et en milieu aqueux ont été, respectivement, de 0,2034 et 0,0102 pour la CT, 0,0459 et 0,0124 pour la VA, 0,1529 et $1,257 \times 10^{-3}$ pour le $\mathrm{AC}, 0,0103$ et $0,2687 \times 10^{-3}$ pour le $p A P$ et $0,2595 \times 10^{-3}$ et $2,395 \times 10^{-6}$ pour l'HQ. Les valeurs du $V_{\max }$ obtenues pour l'activité de la tyrosinase dans le chloroforme ont été respectivement de $0,1415,0,0250,0,1073,7,9393 \times 10^{-3}$ et $0,1795 \times 10^{-3}$ $(\delta \mathrm{A} / \mu \mathrm{g}$ protéine/sec) pour la CT, la VA, le AC, le $p \mathrm{AP}$ et l'HQ, alors que celles obtenues pour le $K_{\mathrm{m}}$ ont été, respectivement, de $3,970,0,4125,3,492,0,9495$ et $0,0427 \mathrm{mM}$. La quantité optimale de protéine enzymatique pour la biocatalyse de la tyrosinase dans le chloroforme a été déterminée à $44,0 \mathrm{mg}$ protéine/L pour la $\mathrm{CT}$ et la VA, et respectivement à 31,6,180,5 et $90,3 \mathrm{mg}$ protéine/L pour le AC, le pAP et l'HQ. Le pH optimal pour l'activité oxydative de la tyrosinase dans le chloroforme a été de 6.0 pour tous les substrats; cependant, la température optimale pour l'activité enzymatique a été de $30^{\circ} \mathrm{C}$ pour la $\mathrm{CT}$ et $25^{\circ} \mathrm{C}$ pour les quatre autres substrats. L'utilisation de catéchol à une concentration de 1,25 et $6,65 \mathrm{mM}$ dans le chloroforme a augmenté l'activité de la tyrosinase respectivement de $56,2 \%$ et $267,2 \%$ pour la CT et le AC; cependant, aucun effet n'a été constaté avec le catéchol (de 0 à $7 \mathrm{mM}$ ) pour la VA, le $p A P$ ou l'HQ. De même, l'utilisation d'acide tétraacétique éthylènediamine (EDTA) à une concentration de 4,25, 2,25 et 5,39 $\mathrm{mM}$ dans le chloroforme a inhibé l'activité de la tyrosinase respectivement de 44,3, 84,7 et $67,0 \%$ pour la CT, la VA et le pAP; cependant, l'utilisation d'EDTA à une concentration de 4,75 et 1,60 mM a augmenté l'activité enzymatique respectivement de $101,9 \%$ et $115,9 \%$ pour la AC et l'HQ. L'utilisation de chromatographie liquide haute-performance (HPLC) et d'électrophorèse capillaire (CE) a mis en évidence la bioconversion des substrats phénoliques, alors que le balayage spectroscopique a montré la formation de produits au cours de la réaction enzymatique. Les analyses d'HPLC et de CE ont aussi montré le degré de bioconversion des 
substrats au cours du temps et suggéré que la bioconversion maximale de substrat avait lieu dans les 10 à 20 premières secondes de la réaction. Les analyses spectroscopiques à transformation de Fourier (FT-IR) ont suggéré que la tyrosinase native de champignon possédait principalement une conformation $\alpha$-hélicoidale alors que dans le chloroforme, l'enzyme possédait une structure à feuillets $\beta$-plissés. De même, pour tous les substrats, les analyses de FT-IR ont mis en évidence la formation de o-quinones résultant de leur bioconversion dans le chloroforme et ont suggéré la possibilité d'interactions secondaires de ces o-quinones avec les substrats phénoliques parentaux dans le cas de la vanilline et du p-aminophénol, alors que pour l'acide chlorogénique, la séparation des cycles pourrait avoir eu lieu au cours de la formation des o-quinones. 
Starting with my supervisor, Dr. Kermasha, I would like to thank him for the initial inspiration to work on this research project and for his intellectual advice and input throughout this entire study. For this, my gratitude is beyond words.

I would like to thank everybody in the lab for giving me a memorable two year in Montreal. I would be remiss if I did not extend my special thanks to three persons on this campus, Mr. Bruce Grainger for his help on the literature searching, Wigdan Madani for her sage advice and friendship, and Xavier Perraud for his help and invaluable opinions on this research project as well as for his humor outside the lab.

Finally, a debt of thanks is owed to my parents for their help and constant support to the decisions that I make in my life and for encouraging me to pursue higher education, especially to my Mother for her love and care which make me realize what is important in life. Also a thank-you to my brother, K.K., I enjoyed his numerous jokes through the $e$-mails very much during these past two years. 


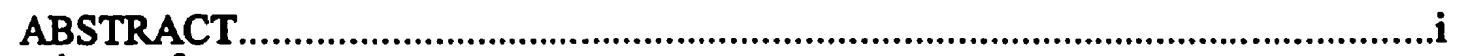

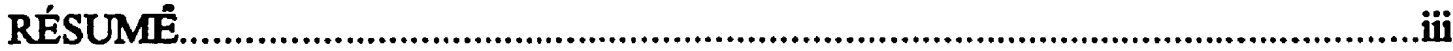

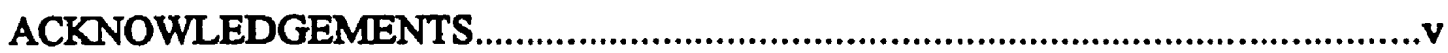

TABLE OF CONTENTS .................................................................................

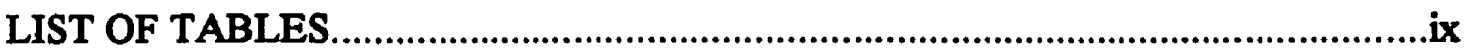

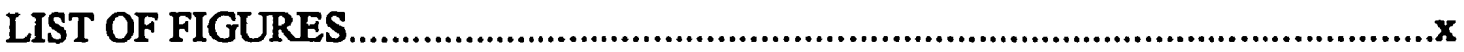

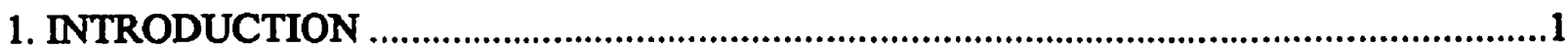

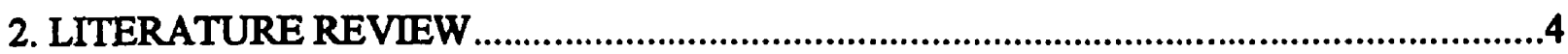

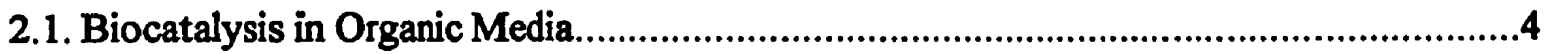

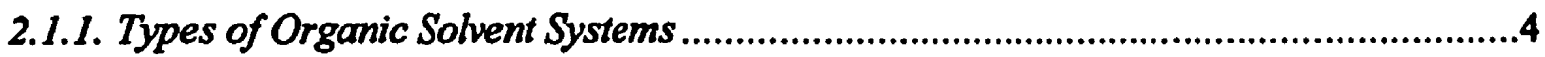

2.1.1.1. Water/Miscible-Organic Solvent Systems .....................................................4

2.1.1.2. Biphasic Organic Solvent Systems...................................................................4

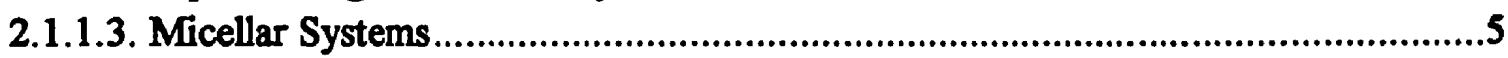

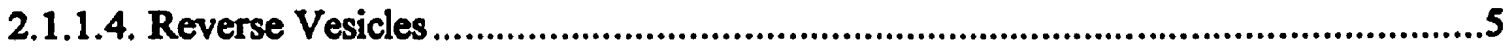

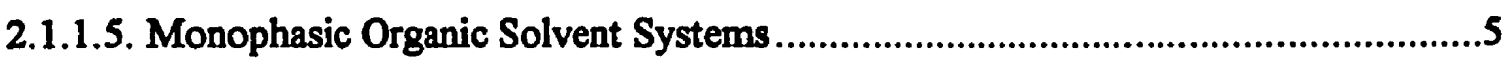

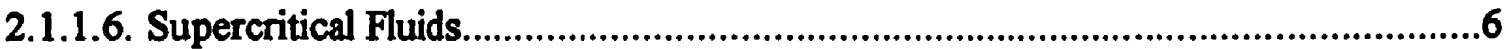

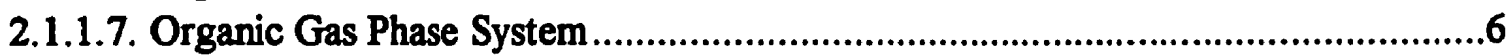

2.1.2. Importance of the Enzyme-Bound Water ................................................................6

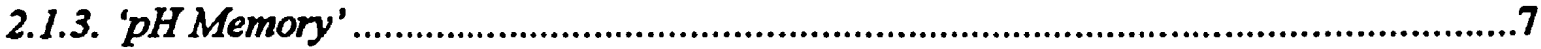

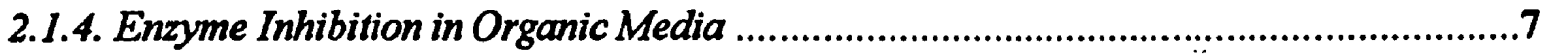

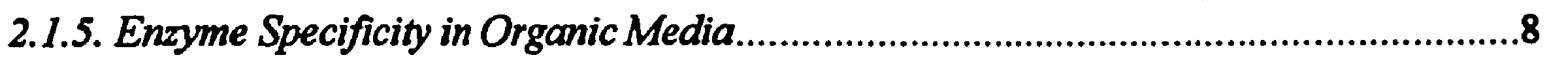

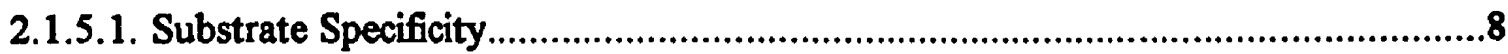

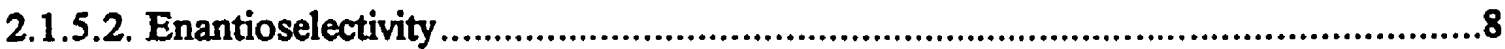

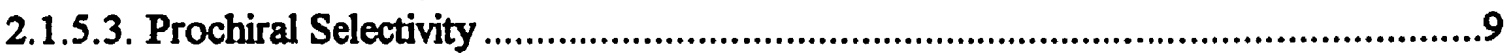

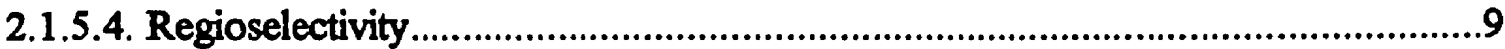

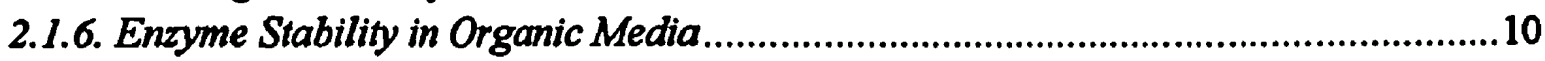

2.1.7. Why Enzymes Do Not Inactivate in Organic Media .................................................10

2.1.8. Enzyme Activation in Organic Media .....................................................................11

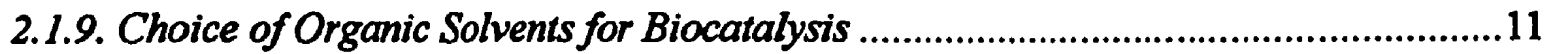

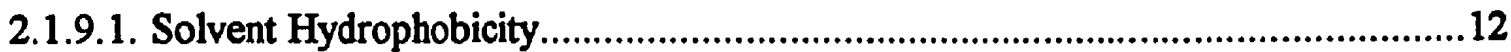

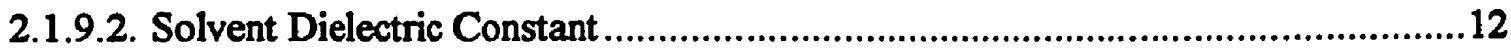

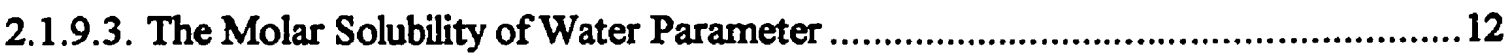

2.2. Biocatalysis of Polyphenol Oxidases in Organic Media..................................................13

2.2.1. Mechanism of PPO Biocatalysis ............................................................................13

2.2.2. Substrate Specificity of $P P O$

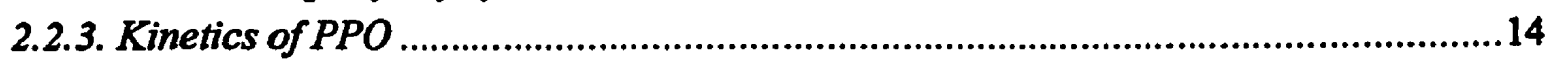


2.2.3.1. Steric Effect. .14

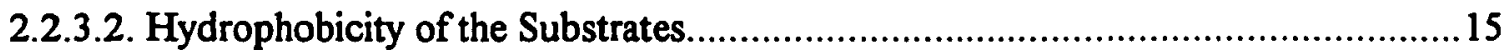

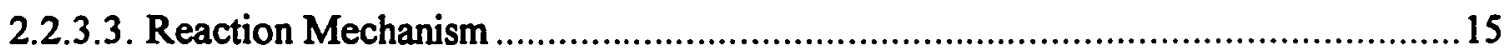

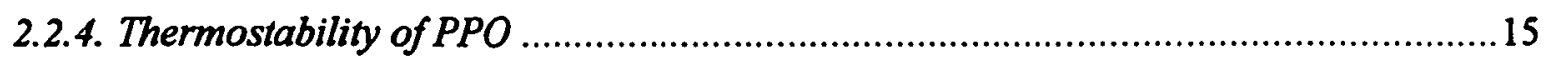

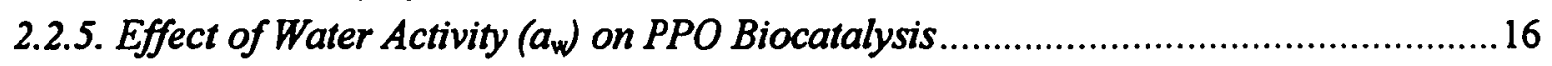

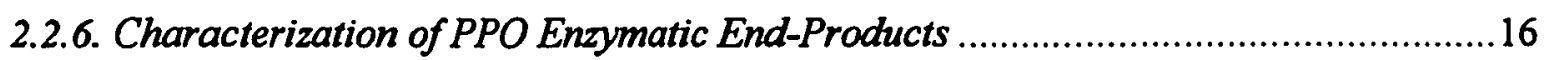

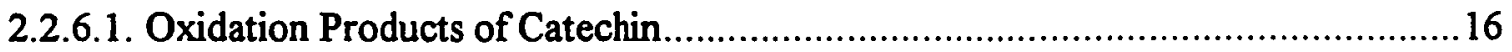

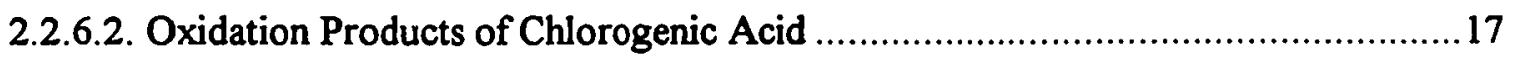

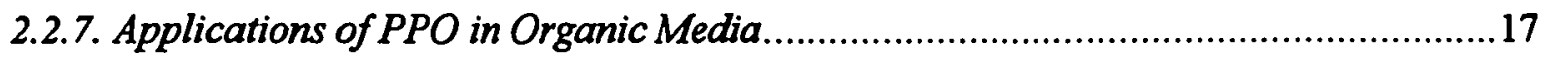

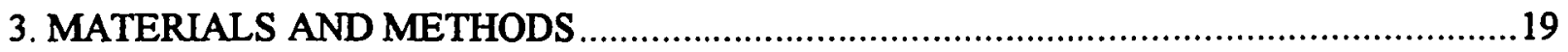

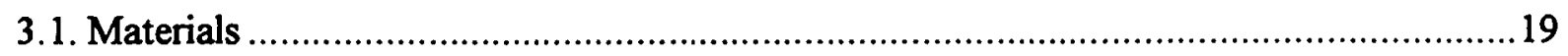

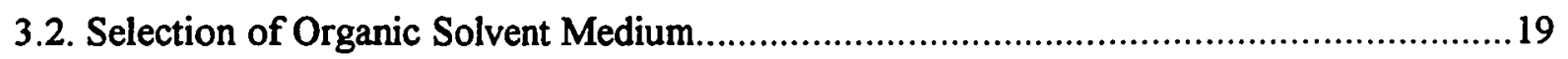

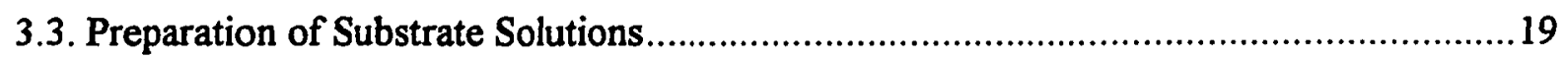

3.4. Determination of Water Activity $\left(a_{w}\right)$ in the Reaction Medium ....................................19

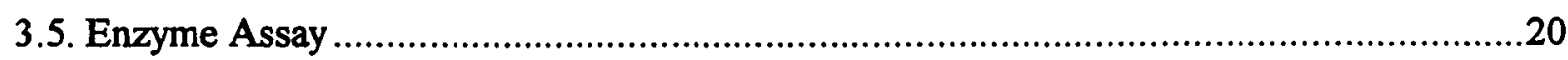

3.6. Effect of Substrate Concentration on Tyrosinase Activity ...........................................20

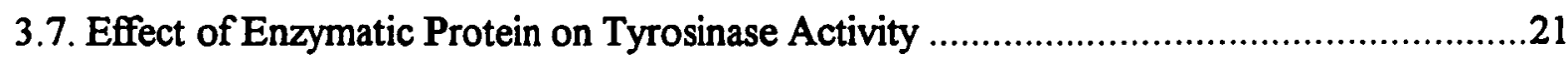

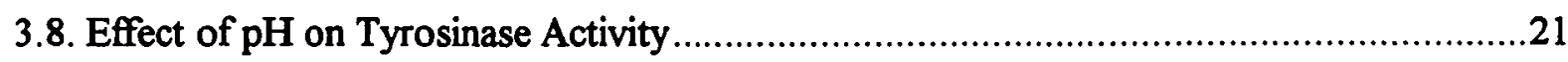

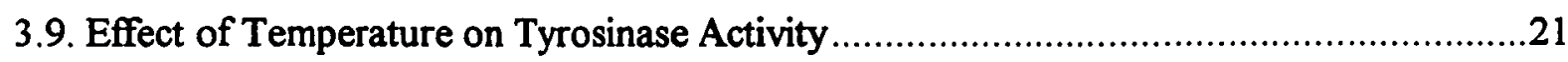

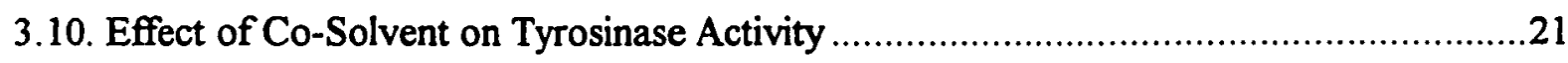

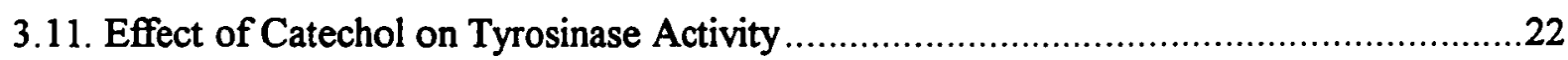

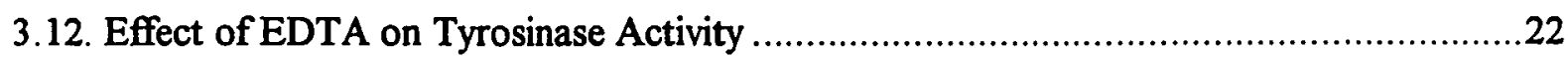

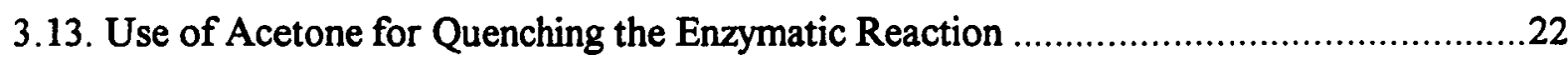

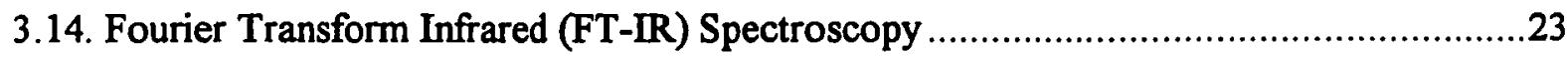

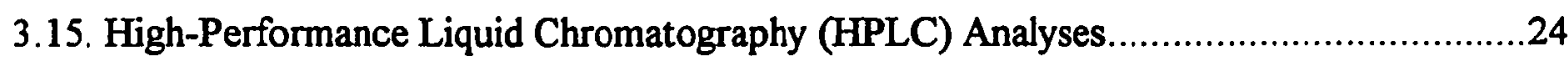

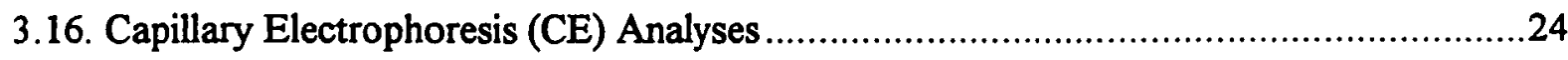

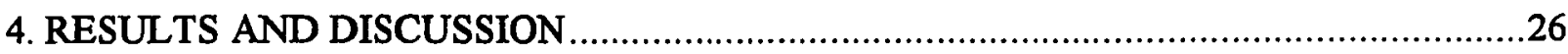

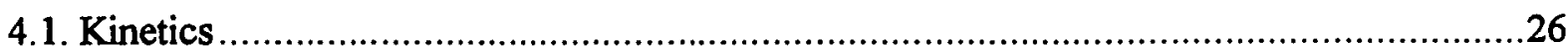

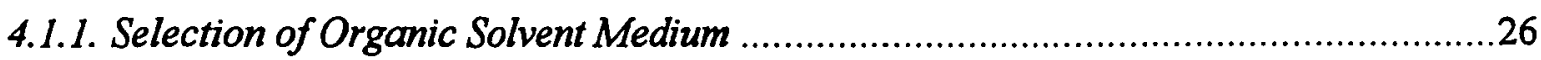

4.1.2. Effect of Enzymatic Protein on Tyrosinase Activity ..............................................28

4.1.3. Determination of Water Activity $\left(a_{w}\right)$ in the Reaction Medium ...............................28

4.1.4. Effect of Substrate Concentration on Tyrosinase Activity ......................................... 11

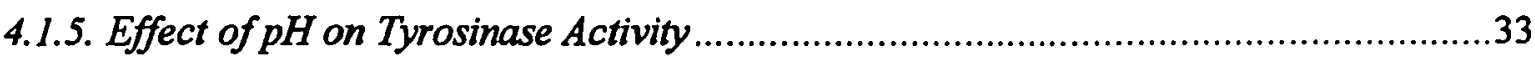

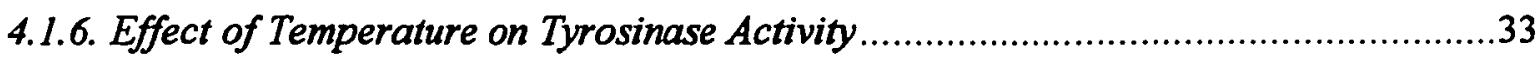

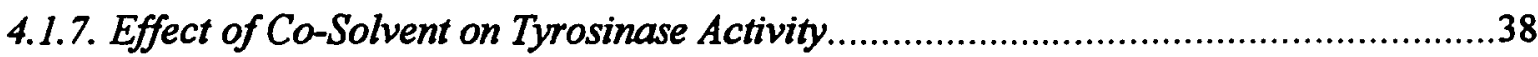




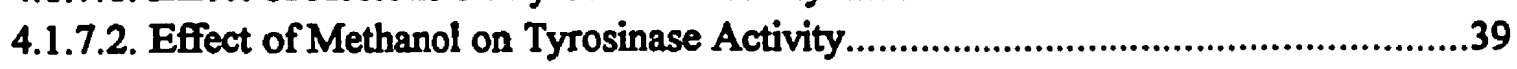

4.1.7.3. Effect of Ethanol on Tyrosinase Activity ..........................................................40

4.1.8. Effect of Catechol on Tyrosinase Activity ...............................................................47

4.1.9. Effect of EDTA on Tyrosinase Activity ...............................................................49

4.1.10. Use of Acetone for Quenching Enzymatic Reaction .............................................52

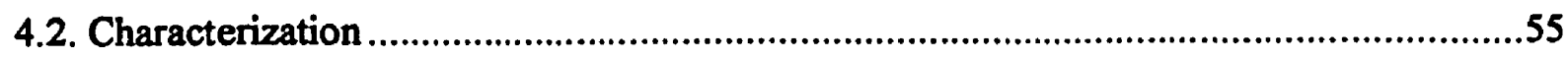

4.2.1. Fourier Transform Infrared (FT-IR) Spectroscopy Study ......................................55

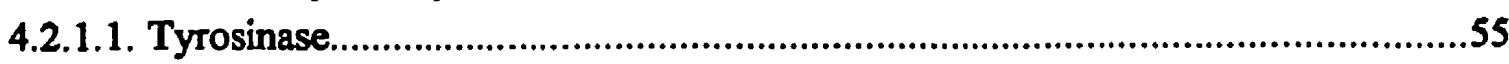

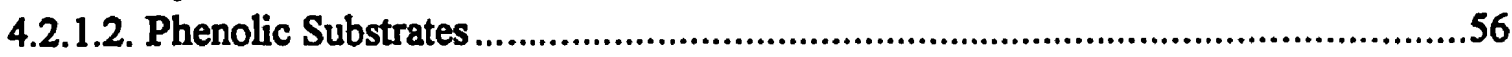

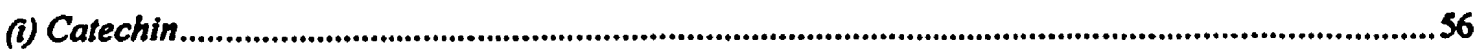

(ii) Vanillin .........................................................................................................................................56

(ii) Chlorogenic Acld ...............................................................................................................64

(iv) p-Aminophenol .............................................................................................................................64

(v) Hydroquinone .............................................................................................................................65

4.2.2. High Performance Liquid Chromatography (HPLC) Analyses ................................65

4.2.2.1. HPLC Scanning of Phenolic Substrates ........................................................65

4.2.2.2. UV Detection of Phenolic Substrates and Their Bioconversion..........................65

4.2.3. Capillary Electrophoresis (CE) Analyses ...............................................................66

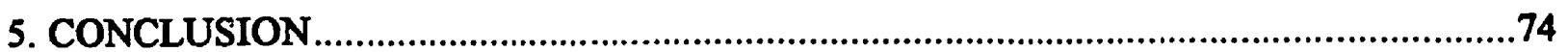

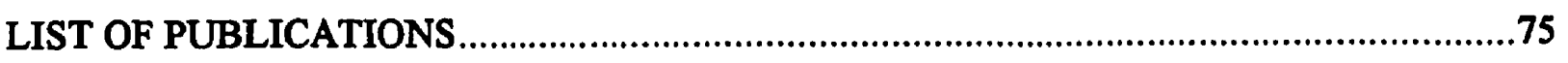

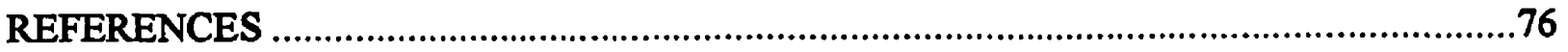




\section{LIST OF TABLES}

Table 1. Water activity measurements and the water content of the chloroform reaction medium

Table 2. Kinetic parameters of tyrosinase biocatalysis in chloroform and aqueous media 35

Table 3. Kinetic parameters of tyrosinase biocatalysis in chloroform with co-solvents as the inhibitor

Table 4. The retention time, migration time and maxima absorbance wavelengths of the five phenolic substrates 


\section{LIST OF FIGURES}

Figure 1. Schematic representation of biocatalysis by polyphenol oxidase. 1

Figure 2. The chemical structures of the five phenolic substrates. .3

Figure 3. Schematic representation of enzymatic synthesis of L-DOPA esters. 18

Figure 4. Spectrophotometric scanning profiles of tyrosinase enzymatic end-products formed in various organic solvent media.

Figure 5. Effect of enzymatic protein concentration on tyrosinase activity in chloroform

Figure 6. Spectrophotometric scanning profiles of tyrosinase biocatalysis in chloroform. .34

Figure 7. The effect of $\mathrm{pH}$ on tyrosinase biocatalysis in chloroform .36

Figure 8. The effect of temperature on tyrosinase biocatalysis in chloroform .37

Figure 9. Effect of the presence of acetone on tyrosinase biocatalysis in chloroform 41

Figure 10. The Lineweaver-Burk plots of tyrosinase biocatalysis in chloroform without inhibitor and with acetone as inhibitor

Figure 11. Effect of the presence of methanol on tyrosinase biocatalysis in chioroform.

Figure 12. The Lineweaver-Burk plots of tyrosinase biocatalysis in chloroform without inhibitor and with methanol as inhibitor

Figure 13. Effect of the presence of ethanol on tyrosinase biocatalysis in chloroform (A) and the Lineweaver-Burk plots of tyrosinase biocatalysis in chloroform without inhibitor and with ethanol as inhibitor (B).

Figure 14. Effect of catechol on tyrosinase biocatalysis in chloroform

Figure 15. Effect of EDTA on tyrosinase biocatalysis in chloroform. 50

Figure 16. Effect of EDTA on tyrosinase biocatalysis in aqueous medium

Figure 17. Use of acetone for quenching the enzymatic reaction .53 
Figure 18. Tyrosinase inhibition by acetone at different water contents in chloroform reaction mixture

Figure 19. Stacked plot of deconvoluted spectra of tyrosinase in $D_{2} O$ in the amide $\mathbf{r}$ region as a function of temperature.

Figure 20. Overlaid spectra of the amide $\mathrm{I}$ band of tyrosinase in $\mathrm{D}_{2} \mathrm{O}$ at $45^{\circ} \mathrm{C}(\mathrm{A})$ and plots of the increase in the intensity of the $1616 \mathrm{~cm}^{-1}(\odot)$ and the decrease in the intensity of the $1550 \mathrm{~cm}^{-1}(+)$ bands (B) as a function of time

Figure 21. ATR/FT-IR spectra of dry films deposited onto the ATR crystal of (A) the catechin substrate, and the enzymatic end-products of tyrosinase biocatalysis in aqueous (B) and chloroform media (C).

Figure 22. ATR/FT-IR spectra of dry films deposited onto the ATR crystal of (A) the vanillin substrate, and the enzymatic end-products of tyrosinase biocatalysis in aqueous (B) and chloroform media (C).

Figure 23. ATR/FT-IR spectra of dry films deposited onto the ATR crystal of (A) the chlorogenic acid substrate, and the enzymatic end-products of tyrosinase biocatalysis in aqueous (B) and chloroform media (C).

Figure 24. ATR/FT-IR spectra of dry films deposited onto the ATR crystal of (A) the paminophenol substrate, and the enzymatic end-products of tyrosinase biocatalysis in aqueous (B) and chloroform media (C)

Figure 25. ATR/FT-IR spectra of dry films deposited onto the ATR crystal of (A) the hydroquinone substrate, and the enzymatic end-products of tyrosinase biocatalysis in aqueous (B) and chloroform media (C).

Figure 26. HPLC chromatograms of the five selected phenolic substrates

Figure 27. Overlaid HPLC chromatograms of the five phenolic substrate bioconversion with respect to reaction time during the biocatalysis.

Figure 28. Substrate bioconversion at various reaction time, measured in the HPLC analyses (A) and CE analyses (B). .70

Figure 29. CE electropherograms of the five selected phenolic substrates.

Figure 30. Overlaid CE electropherograms of the five phenolic substrate bioconversion with respect to reaction time during the biocatalysis. 


\section{INTRODUCTION}

The use of enzymes as catalysts in organic solvent media is gaining substantial interest for their potential applications in industry. Organic solvents, if chosen carefully, not only do not inactivate enzymes, but also preserve the enzymatic activity, i.e. the enzymatic catalytic activity can be of similar magnitude in organic solvents as in aqueous solutions (Zaks and Russell, 1988). The catalytic action of enzymes in organic solvent media can also be described by conventional Michaelis-Menten kinetics. The real concerns are finding the appropriate conditions for the enzymes, such as the recovery of the enzyme from the appropriate $\mathrm{pH}$, sufficiently fine suspension of the enzyme, optimal organic solvent, etc. (Zaks and Klibanov, 1985). Hydrophobicity, designated by $\log \mathrm{P}$ where $\mathrm{P}$ is the measure of the partition coefficient for a given solvent between octanol and water (Rekker and de Kort, 1979) plays an important role in the choice of organic medium for biocatalysis.

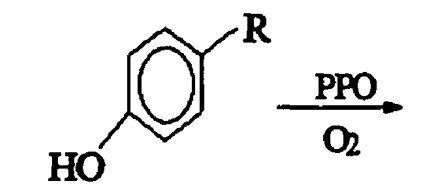

Phenolic substrate<smiles>[R]c1ccc(O)c(O)c1</smiles>

o-Dihydroxy intermediate

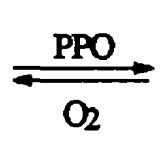

a-Quinone

Figure 1. Schematic representation of biocatalysis by polyphenol oxidase.

Polyphenol oxidases (PPO) (EC 1.14.18.1) are oxido-reductases that catalyze the hydroxylation of monophenols and the subsequent oxidation of $o$-diphenols to o-quinones (Mayer, 1987) (Fig. 1). The enzymatic products, $o$-quinones, are susceptible to further oxidation, leading to polymerization and the formation of brown pigments. The great practical value of $o$ diphenols production plus the fact that $o$-quinones can be polymerized easily in aqueous systems has led to the development of catalysis by PPO in organic media (Kazandjian and Klibanov, 1985). PPO has been reported to inactivate itself through catalysis in aqueous systems. Its utilization in organic media with low water content is designed to minimize the inactivation 
process (Kazanajlan ana Nuoanuv, 170 J).

of aromatic compounds is difficult in aqueous systems and suggested that L-tyrosine ester can be completely converted to the corresponding quinone by $\mathrm{PPO}$ in chloroform followed by reduction with ascorbic acid to L-3,4-dihydroxyphenylalanine (L-DOPA) ester, a drug used in treatment of Parkinson's disease. Another bonus of conducting enzymatic oxidation of phenolic compounds in organic solvents by PPO is that the solubility of the co-substrate, $\mathrm{O}_{2}$, is nearly an order of magnitude higher than that in aqueous solutions, thus speeding up the reaction (Klibanov, 1986).

Polyphenol oxidase has in fact been shown by Kazandjian and Klibanov (1985) to vigorously function in chloroform whereby a number of phenols can be quantitatively converted to stable $o$-quinones. Chloroform is a particularly suitable medium for this enzyme since oxygen has a high solubility and thus the availability of oxygen for the reaction need not be a limiting factor (Linke, 1958). The o-quinones formed are very reactive entities and are subjected to further secondary reactions, both enzymic and non-enzymic, leading to the formation of pigments. The mechanism of the formation of the pigments from o-quinones has been well proposed in the literature (Cheynier et al., 1986; Richard-Forget $e t$ al., 1992; Nicolas et al., 1994).

In this research work, mushroom (Agaricus bispora) tyrosinase was used as the biocatalyst in chloroform medium, the objectives of this research were:

(I) To optimize the activity of a commercially purified mushroom tyrosinase in chloroform, using five selected phenolic compounds as substrates, including catechin, vanillin, chlorogenic acid, $p$-aminophenol acid and hydroquinone (Fig. 2).

(II) To characterize the reaction, in terms of water activity, enzymatic protein, kinetic parameters, including specific activity, $V_{\max }, K_{\mathrm{m}}$ the catalytic efficiency, the acceleration factor, optimal $\mathrm{pH}$ and temperature, effects of co-solvents on the enzymatic reaction, and enzymatic activation as well as inhibition.

(III) To study the effect of temperature on the secondary structure of the enzyme tyrosinase by using Fourier Transform Infrared (FT-IR) spectroscopy.

(IV) To study the effect of reaction media (chloroform and aqueous) on the secondary structure of the enzyme tyrosinase by using FT-IR spectroscopy. 
(V) To characterize tyrosinase biocatalysis using FT-IR spectroscopy, high-performance liquid chromatography (HPLC) and capillary electrophoresis (CE).<smiles>Oc1cc(O)c2c(c1)OC(c1ccc(O)c(O)c1)C(O)C2</smiles>

Catechin<smiles>COC1=C(O)C=CC(C=O)C1</smiles>

Vanillin

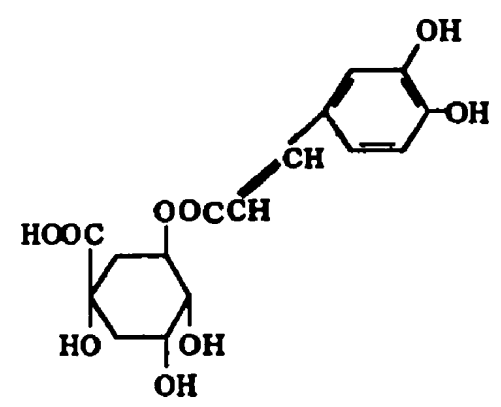

Chlorogenic Acid<smiles>Nc1ccc(O)cc1</smiles>

p-Aminophenol<smiles>Oc1ccc(O)cc1</smiles>

Hydroquinone

Figure 2. The chemical structures of the five selected phenolic substrates. 


\subsection{Biocatalysis in Organic Media}

Water plays a central role in biocatalysis and is a ubiquitous component in all biological processes such as biosynthesis, photosynthesis, metabolism and catalysis (Zaks and Russel, 1988). It is, therefore, not surprising that almost all studies in enzymology thus far have only been conducted in aqueous solutions. Zaks and Klibanov (1985) reported that aqueous environment does, however, exert some restrictions on biocatalysis such as limited solubility of organic compounds in aqueous media, instability of enzymes, impossibility of novel reactions in water because of kinetic or thermodynamic restrictions and the difficult product recovery from aqueous media as well as the recovery and reuse of enzymes in aqueous media.

\subsubsection{Types of Organic Solvent Systems}

\subsubsection{Water/Miscible-Organic Solvent Systems}

Water mixed with miscible-organic solvent system creates a homogeneous reaction mixture (Lilly et al., 1987). Such water-miscible organic solvents that are commonly employed are methanol, ethanol, $N, N$-dimethyl formamide, dimethyl sulphoxide. The inclusion of watermiscible organic solvents raise the solubility of many organic compounds to a limited extent in the aqueous phase (Lilly et al., 1987). The direct interaction of organic solvent and the enzyme poses a major problem in this system (Marini and Martin, 1971).

\subsubsection{Biphasic Organic Solvent Systems}

Biphasic organic solvent system is simply a two-phased mixture of water and a waterimmiscible organic solvent (Carrea, 1984), in which the enzymes or cells and hydrophilic cofactors are dissolved in water phase and the hydrophobic substrates are solubilized in organic phase (Carrea, 1987). On stirring and shaking, substrates are transferred from the organic to aqueous phase, where they undergo an enzyme-catalyzed transformation and the products return to the organic phase (Carrea, 1984). Biocatalysis in biphasic systems do not change the catalytic properties of the enzymes as much since water still remains a major component of the system 
(Lilly et al., 1987). The concentration of organic solvents in water is low, and hence the inhibitory or denaturing effects are much less than those induced in the water/miscible organic solvent systems (Carrea, 1984). The advantages of this system include high ratio of reactant to product concentration in reactor (Lilly, 1982), reduction of product inhibition (Klibanov et al., 1977; Schwartz and McCoy, 1977) and the ease of product recovery (Carrea, 1984). Potential disadvantages, on the other hand, include catalyst denaturation at the liquid-liquid interface and/or enzyme inhibition by organic solvent dissolved in the aqueous phase (Marini and Martin, 1971).

\subsubsection{Micellar Systems}

There are two main types of micelles (Stenius, 1984), namely normal micelles designated as oil-in-water $(\mathrm{O} / \mathrm{W})$ which exist in water at low concentrations of organic solvents, and reversed micelles $(\mathrm{W} / \mathrm{O})$ that form in organic solvents at a moderate water content. Reversed micelles are limiting example of the ternary system of surfactant/water/apolar solvent which forms an aggregate called microemulsion (Overbeek et al., 1984), a clear, translucent, and thermodynamically stable homogeneous dispersion of two immiscible liquids in the presence of surfactants (Reed and Healy, 1977). The basic components, hydrocarbon, surfactant and water, are sufficient to form the micellar solutions.

\subsubsection{Reverse Vesicles}

Reverse vesicles are self-closed spherical structures where surfactant inverted bilayers (head-to-head) separate well-defined interior and exterior apolar phases (Sanchez-Ferrer et al., 1992). Playing an essential role in many physiologic and biological membranes, vesicles are also employed in industrial processes. Most importantly, reverse vesicles are capable of entrapping enzymes without losing their activity (Sanchez-Ferrer et al., 1992).

\subsubsection{Monophasic Organic Solvent Systems}

In monophasic organic systems, enzymes are employed as insoluble catalysts in nearly anhydrous media (Klibanov, 1986). Enzymes in this system are not in direct contact with a bulk water phase and exist in an environment vastly different from aqueous milieu (Dordick, 1989). 
This novel medium gives rise to the alteration of enzyme properties, such as alteration of catalytic properties, solubility enhancements (Brink and Tramper, 1986), suppression of hydrolysis and shifting of thermodynamic equilibrium to favor synthetic reaction (Fukui et al., 1980), enhancement of thermostability (Zaks and Klibanov, 1984) and alteration of substrate specificity (Margolin and Klibanov, 1987).

\subsubsection{Supercritical Fluids}

Enzymatic transformations in non-aqueous media, and supercritical fluids are now commonplace. Supercritical fluids (e.g. carbon dioxide, fluoroform, ethylene, ethane) are materials above their critical point with certain appealing characteristics such as miscibility with low molecular weight hydrocarbons, high volatility, low viscosity, high diffusion coefficients, good thermal transport properties (Kamat et al., 1995). Many enzymes, in particular lipases, are active and stable in supercritical fluids. In addition, the unique pressure dependence of supercritical fluid physical properties presents opportunities for rational control of enzyme activity, specificity and stability (Kamat et al., 1995). Hammond et al. (1985) showed that polyphenol oxidase remained active in the presence of supercritical carbon dioxide or fluoroform.

\subsubsection{Organic Gas Phase System}

Biocatalysis with gas phase substrates is emerging as a technology with applications in organic gas analysis (Hwang and Park, 1994). The use of a solid enzyme to accept gaseous substrates, with a carrier gas of controlled humidity passing over the biocatalysis, and convert them to releasable products presents an ideal system to study to role of protein hydration on biocatalyst function. Alcohol dehydrogenase has been used as biocatalyst in such system (Yang and Russell, 1996).

\subsubsection{Importance of the Enzyme-Bound Water}

Water is required for enzyme action to maintain the native, catalytically active enzyme conformation (Zaks and Klibanov, 1985). This 'essential' water is thought to act as a lubricant giving the enzyme molecule with flexibility necessary for enzymatic catalysis (Poole and Finney, 1983). The role of water as a lubricant stems from its ability to form hydrogen bonds with 
'unlocking' the structure. Removal of water should therefore drastically distort that conformation and inactivate the enzyme. As long as this 'essential' water is localized about enzyme molecules, or at least localized about the active center region, the rest (i.e. the bulk) of water can probably be replaced with an organic solvent without adversely affecting the enzyme.

\subsection{3. 'pH Memory'}

One of the interesting phenomena that enzymes exhibit only in organic media is the " $\mathrm{pH}$ memory'. When recovered from an aqueous solution of a particular $\mathrm{pH}$, the enzyme in organic solvent will show its catalytic activity characteristic of that $\mathrm{pH}$ because the enzyme's ionogenic groups acquire the corresponding ionization states at that particular $\mathrm{pH}$ which will then remain in the solid state (as suspension) or in organic solvents. The catalytic activity of the enzymes in aqueous solution is, however, independent of its previous pH history (Zaks and Klibanov, 1985). Therefore, it became routine to prepare the enzyme solution in buffer at the enzyme optimal pH, followed by freeze-drying or solvent precipitation before placing it in organic solvent. Another alternative is to saturate a water-immiscible organic solvent with an aqueous buffer at the appropriate $\mathrm{pH}$, instead of plain water, prior to the addition of the enzyme powder (Klibanov, 1986).

\subsubsection{Enzyme Inhibition in Organic Media}

Interestingly, the inhibitive effect on enzymes in aqueous and organic media are very different. To illustrate, chymotrypsin in aqueous environments was reversibly and competitively inhibited by numerous aromatic compounds, with the more hydrophobic compounds being more potent inhibitors (Zaks and Klibanov, 1988b). An increase in hydrophobicity from such inhibitors as benzene to toluene to naphthalene resulted in higher inhibitor affinity to enzyme. Furthermore, the introduction of a carboxyl group to each inhibitory compound diminished inhibition. This phenomenon could be due to the fact that the addition of a hydrophilic moiety reduced the incentive for the inhibitor to leave water and partition into the active center of chymotrypsin (Zaks and Klibanov, 1988b). However, the effect of inhibitors on chymotrypsin in octane was exactly opposite. An increase in hydrophobicity of inhibitor should no longer result in a higher 
inhibitor affinity to the enzyme, as hydrophobic interactions, the driving force of the enzymeinhibitor binding in water, would not exist in octane. Also the introduction of a carboxyl group should enhance the inhibition, since the inhibitor would tend to 'hide' from octane by partitioning into the active center of the enzyme. Zaks and Klibanov (1988b) concluded that better enzyme inhibitors in water became poorer in octane and vice versa. This effect is both phenomenologically and mechanistically similar to the reversal of substrate specificity of enzymes upon replacement of water with organic solvent as the reaction medium (Zaks and Klibanov, 1986).

\subsubsection{Enzyme Specificity in Organic Media}

The ultimate challenge in the area of biocatalysis is the alteration of enzyme specificity at will (Zaks and Klibanov, 1986). Recently, it has become apparent that through prudent choice of the solvent, the substrate specificity, enantioselectivity, prochiral selectivity and regioselectivity of enzymes can be profoundly manipulated (Wescott and Klibanov, 1994).

\subsubsection{Substrate Specificity}

Zaks and Klibanov (1984) observed that the structure of dry porcine pancreatic lipase, although similar to that of its wet counterpart (Careri et al., 1980), appeared to be more rigid. The wet lipase, which is an enzyme known for its wide substrate specificity (Desnuelle, 1972), will accept nearly any alcohol as a nucleophile in the transesterification reaction; the dry lipase, on the other hand, will perhaps be unreactive toward bulky alcohols because it lacks the conformational mobility needed to accommodate the bulky substrate in the active center. Upon increase in size from primary to secondary alcohol, the reactivities of the wet and dry enzyme remained comparable; however, with tertiary alcohols the dry lipase, in contrast to the wet, was completely inactive (Zaks and Klibanov, 1984).

\subsubsection{Enantioselectivity}

The discovery that enantioselectivity can be changed or even inverted by the reaction medium greatly enhances the utility of enzyme-catalyzed reactions in the field of organic synthesis. Subtilisin Carlsberg can synthesize peptides containing D-amino acid residues in 
organic solvents, but not in water (Margolin et al., 1987). Sakurai et al. (1988) discovered a strong solvent dependence of enantioselectivity in the transesterification of $N$-Ac-(L or D)-Ala$\mathrm{OEtCl}$ with propanol catalyzed by the same enzyme. Since the binding of the ester to the enzyme displaced water from the active site, as the solvent hydrophobicity increased, more energy was required to transfer water from the active site into the solvent. The D-enantiomer bound to the enzyme differently than the L-enantiomer to form a reactive complex and then displaced less water from the active site, hence the D-enantiomer was less hindered by the hydrophobic solvents than its counterpart (Wescott and Klibanov, 1994).

\subsubsection{Prochiral Selectivity}

The ability of enzymes to selectively catalyze the conversion of a prochiral substrate to a single enantiomer of a chiral product provides a valuable alternative to enantioselective resolutions for the preparation of optically active compounds. Hirose et al. (1992) reported that Pseudomonas sp. lipase catalyzed the hydrolysis of achiral bis-(alcoxymethyl)-1,4-dihydro-3,5pyridine dicarboxylates to produce optically active monoesters. When the reaction was performed in water-saturated isopropanol, the $S$-product was recovered with an enantiomeric excess of $99 \%$. In contrast, in cyclohexane saturated with water, the prochiral substrate was preferentially converted to the $R$-enantiomer, with an $e e$ of $89 \%$.

\subsubsection{Regioselectivity}

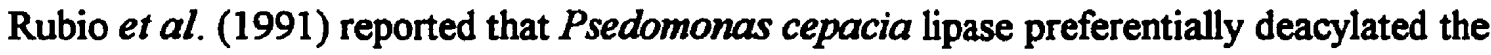
substrate 1,4-dibutyryloxy-2-octylbenzene at the 4-position in toluene, whereas in acetonitrile, the deacylation was made at 1-position. The regioselectivity was found to correlate roughly with the $\log P$ value of the solvent.

In addition to the above phenemona, enzyme specificity towards inhibitor (Zaks and Klibanov, 1988b), as well as the antigen specificity of an antibody (Russell et al., 1989) are also found to be strongly dependent on the solvent. 
Stability, in particular thermostability, is an important functional characteristic of an enzyme (Klibanov, 1983). It has been reported that lipases (Zaks and Klibanov, 1984), terpene cyclase (Wheeler and Croteau, 1986), and cytochrome oxidase and ATPase (Ayala et al., 1986) are much more thermostable in organic solvents than in water. The 'pH-memory' of chymotrypsin applies not only to its catalytic activity but also to thermal stability. At $100^{\circ} \mathrm{C}$, chymotrypsin in octane at $\mathrm{pH} 7.8$ (the optimum $\mathrm{pH}$ ) and $\mathrm{pH} 3.0$ exhibited a drastic difference in the half-lives $(4.5 \mathrm{~h} v \mathrm{~s} .30 \mathrm{~min})$. Furthermore, the thermostability of chymotrypsin strongly depended on the nature of the solvents and was higher in hydrophobic than in hydrophilic ones. Even in such unfavorable solvents as dioxane and pyridine, the enzyme was, however, still far more stable than in water (Zaks and Klibanov, 1988b). In addition to the thermostability, Zaks and Klibanov (1988b) also studied the storage stability of chymotrypsin in octane versus water. At $20^{\circ} \mathrm{C}$, chymotrypsin, dissolved in phosphate buffer at $\mathrm{pH} 7.8$, lost half of its catalytic activity after 1 week while full enzymatic activity was retained even after 6 months of incubation at the same temperature when the same enzyme was suspended in dry octane. Hence Zaks and Klibanov (1988b) concluded that replacement of water with organic solvents greatly enhanced enzymatic stability both at elevated and ambient temperatures.

\subsubsection{Why Enzymes Do Not Inactivate in Organic Media}

Zaks and Klibanov (1988b) suggested that the enzyme structure in organic medium is kinetically trapped which explains why most enzymes remain active in organic solvents. Three pieces of evidence were used to support. First is the 'pH-memory' phenomenon which exists because the enzyme cannot radically change their native conformation upon the transition from water to organic solvent due to high kinetic barriers. Second is the observation that addition of a high concentration (up to $0.1 \mathrm{M}$ ) of strong acids to lipase in hexane did not appreciably inactivate the enzyme (Kirchner et al., 1985). Furthermore the greatly enhanced thermostability of the enzyme in organic solvent is due to the high rigidity of the structure (Zaks and Klibanov, 1988b). 
It has been reported that the lyophilization of biocatalyst from aqueous solutions containing ligands (e.g. inhibitors) had significant positive effects on enzymatic activity in organic media. Indeed, the activity of chymotrypsin lyophilized in the presence of $N$-acetyl-Lphenylalanine was 35 times greater than that of the enzyme lyophilized in the absence of the ligand (Zaks and Klibanov, 1988b). The activation was the result of the ligand 'locking' the enzyme into a more active conformation due to the substitution of water molecules from the active site by the ligand. Since the greatest obstacle to substrate binding in organic solvents was the replacement of water by the substrate, it is reasonable to assume that the removal of water by ligands from the active site, prior to being placed in the organic solvent, would result in a more active enzyme (Zaks and Russel, 1988).

Almarsson and Klibanov (1996) demonstrated that the addition of denaturing organic cosolvent, such as formamide and dimethyl sulfoxide (DMSO), could actually dramaticaly raise enzymatic activity in anhydrous media. They observed that the rates of transesterification reactions catalyzed by the protease subtilisin Carlsberg suspended in various anhydrous solvents could be increased more than 100-fold by the addition of such denaturing organic co-solvent as DMSO; in water the same co-solvent exerted no enzyme activation. This phenomenon is most likely the denaturant-induced enhancement of conformational flexibility of enzymes in anhydrous media. However, high concentrations of the denaturing organic co-solvents offered diminished activation or even inhibition. The denaturant concentrations should be, therefore, selected judiciously to ensure the maximum positive effect (Almarsson and Klibanov, 1996).

\subsubsection{Choice of Organic Solvents for Biocatalysis}

Gorman and Dordick (1992) studied the desorption of water into organic solvents by radioactively labelling the enzyme-bound water $\left(\mathrm{T}_{2} \mathrm{O}\right)$ of three different enzymes (chymotrypsin, subtilisin and horseradish peroxidase) and they observed that the most appropriate organic solvent as the reaction medium for an enzyme depends on the following factors: 


\subsubsection{Solvent Hydrophobicity}

Hydrophobicity of the solvent is represented as $\log P$ where $P$ is the measure of partitioning of a given solvent between 1-octanol and water (Rekker and de Kort, 1979). Generally as solvent hydrophobicity increases, less water is desorbed from an enzyme.

Other research groups such as Estrada et al. (1991) observed that, for mushroom PPO, organic solvents with $\log \mathrm{P}$ between 2 and 2.5 (e.g. dichloroethane, dichloromethane, chloroform, and toluene) gave higher conversions of polyphenol oxidase, using phenol as the substrate, with chloroform as the highest. The result obtained by Estrada et al. coincided with the rule proposed by Laane et al. (1987) which states that solvents with $\log \mathrm{P}<2$ are not suitable for biocatalytic processes. The behavior of PPO was, however, different than other described enzymes since its activity was very low in solvents with $\log \mathrm{P}>2.5$ (Estrada et al., 1991). This fact, explained by Estrada et al. (1991), may be due to the effect of the solvents polarity not only on the enzyme but also on the solubility of substrate and/or product.

\subsubsection{Solvent Dielectric Constant}

Solvent dielectric constant, represented as $\varepsilon$, is a good indication of the power of solvents to strip away water bound to an enzyme. In general, solvents with high dielectric constants support the essential water desorption into the solvent. Water is bound to polar and charged residues of proteins through mainly electrostatic forces. Increased solvent dielectric constant weakens these electrostatic forces and thus enables water to desorb off the enzyme and into the solvent.

\subsubsection{The Molar Solubility of Water Parameter}

The molar solubility of water parameter, $\mathbf{S}_{\mathrm{w} / \mathrm{o}^{\circ}}$ is also an accurate indicator of the waterdesorption phenomenon. $S_{\mathrm{w} / \mathrm{o}}$ parameter is valid only for water-immiscible solvents. In more polar solvents, such as ethyl acetate and hexanol, the ability of the solvent to solubilize water increase. Non-polar solvents, such as toluene and hexane, are incapable of containing large amounts of soluble water and are, therefore, unable to strip away substantial amounts of water from enzymes. 


\subsection{Biocatalysis of Polyphenol Oxidases in Organic Media}

Polyphenol oxidases, abbreviated as PPO (EC 1.14.18.1), are copper-containing monooxygenases, found abundant in fruits such as grapes, apples, peaches, bananas, and in vegetables such as potatoes, mushroom and lettuce. PPO is responsible for the browning observed in cut or injured fruits or vegetables. In addition to its direct effect in the modification of color considered as a negative feature in food, browning also affects the sensory and nutritive qualities of the food by interacting with proteins, thus reducing the digestibility and palatability of proteins and decreasing their nutritional value (Mathesis and Whitaker, 1984). On the other hand, PPO activity of plants is desirable in the processing of certain foods such as prunes, black raisins, black figs, zapote, tea, coffee, and cocoa, and it probably protects plants against attack from insects and microorganisms (Lee and Whitaker, 1995).

\subsubsection{Mechanism of PPO Biocatalysis}

PPO first catalyzes, in the presence of oxygen, the hydroxylation of the phenolic compounds at ortho position followed by the dehydrogenation of the dihydroxy intermediates by PPO in the presence of $\mathrm{O}_{2}$ again to form o-quinones (Fig. 1). PPO is regioselective enzyme in the sense that the substituent in the phenolic substrates, if present, must be at para position, hence 0 and $m$-phenolic compounds are unreactive towards PPO. The enzymatic products, o-quinones, are colored substances whose strongly electrophilic natures make them very susceptible to nucleophilic attack (Cabanes et al., 1987). Reactive oquinones in aqueous environments polymerize rapidly to form high molecular-weight (MW) polyaromatic brown colored compounds (Kazandjian and Klibanov, 1985) and may combine with amino sulfhydryl groups of protein (Cheynier et al., 1989) to form relatively insoluble brown polymers. There are numerous advantages of performing PPO biocatalysis in organic as opposed to aqueous media such as reduced solubility of the phenolic substrates in water, thus necessitating dilute solutions leading to low productivity (Zaks and Klibanov, 1985), higher stability of the products o-quinones in organic solvents, greater thermal stability of the enzyme, alteration of substrate specificity which leads to the possibility of novel reactions, higher solubility of oxygen, which is an essential component in PPO enzymatic oxidation, in organic (e.g. chloroform) than in aqueous media (Kazandjian and Klibanov, 1985). 


\subsubsection{Substrate Specificity of PPO}

In aqueous systems, PPO is known to be capable of hydroxylating molecules of considerable size (e.g. steroids); but in chloroform, the accessibility of bulky substrates (e.g. ptert-butylphenol) to the active site of the enzyme may be restricted by the rigidity of the protein pocket of the enzyme (Burton et al., 1993). The effects of hydrophobic solvents on enzymes are therefore a reduction in conformational flexibility and hence reduction in substrate specificity. Reduction of substrate specificity is expected to be general since water plays a critical role in all types of enzyme-substrate interactions and therefore its substitution should have a major impact on substrate specificity of enzymes (Zaks and Klibanov, 1986).

\subsubsection{Kinetics of PPO}

PPO shows substantial enzymatic activity in various organic solvents. By varying the $p$ substituted phenolic substrates, Burton and his collaborators (1993) studied the steric and electronic effects of the substrate on the kinetics of PPO in chloroform, using three parameters to describe the kinetic behavior. $K_{\mathrm{m}}$ reflects the ability of an enzyme to bind a substrate. $E_{S}$ is indicative of steric size of the substrates; a large negative $E_{s}$ value correlates with a large steric volume. $V_{\max } / K_{\mathrm{m}}$, the catalytic efficiency, indicates the ability of the enzyme to transform the substrate and also reflects the hydrophobicity of the solvents. Burton and co-workers (1993) observed the following:

\subsubsection{Steric Effect}

As the steric size of the alkyl group in $p$-alkylphenolic substrate increased from methyl to tert-butyl, the $V_{\max } / K_{\mathrm{m}}$ values decreased. Similarly, for the remaining phenolic substrates, taken in the order fluro-, methoxy-, chloro-, and bromo-, there was a decrease in $V_{\max } / K_{\mathrm{m}}$ as the steric size increased. 
The hydrophobicity of the phenolic substrates may well affect the substrate partitioning between the chloroform and the enzyme active site, decreasing the amount of substrate available to the active site, and hence giving rise to the high apparent $K_{\mathrm{m}}$ values.

\subsubsection{Reaction Mechanism}

Although the mechanism of the PPO enzymatic reaction is generally regarded as a nucleophilic attack by the phenolic aromatic ring on a polarized peroxide bridge in the enzyme active center (Solomon, 1990), this mechanism has not been fully established, and it is a matter for conjecture as to whether or not electron donation by $p$-substituents facilitates the reaction.

\subsubsection{Thermostability of $P P O$}

From an industrial point of view, operational stability of biocatalysts must be achieved and since elevated temperatures are desirable, thermal stabilization of enzymes becomes very crucial (Estrada et al., 1993). Yang and co-workers (1992) examined the effect of organic solvents on PPO thermostability and found that although the optimal temperature of the tyrosinase-catalyzed reaction in water-saturated chloroform $\left(20^{\circ} \mathrm{C}\right)$ was lower than that in aqueous medium $\left(45^{\circ} \mathrm{C}\right)$, the half-life of the enzyme $\left(t_{1 / 2}\right)$ in water-saturated chloroform was about 10-fold higher. The dehydration drastically hindered the thermoinactivation of the enzyme and maintained its conformational rigidity (Yang et al., 1992).

Using mushroom tyrosinase immobilized on "organo-gels" obtained by adding gelatine to the reverse micelles followed by the complete evaporation of the organic solvent, Crecchio et al. (1995) reported that such enzyme preparation was much more thermal stable than the "free" ones. For example, at $50^{\circ} \mathrm{C}$, the activity of the free enzyme was only $30 \%$ of the maximum activity while that of the entrapped enzyme was kept about $60 \%$. The results obtained by Crecchio et al. (1995) indicate that by entrapping enzymes, microemulsion gels preserved the protein structure from thermal inactivation; this resistance to temperature is an important potential advantage for practical applications of enzymes. 
6ince Zaks and Klibanov (1988a) revealed that enzyme activity depends only on the amount of water adsorbed on the enzyme rather than on the water content of the whole solvent system; and depending on the hydrophobicity of the solvent, the same water content may result in entirely different amounts of water associated with enzyme, it is important to compare the enzyme activity in organic media when the hydration of enzyme is kept constant. Since there is a proportional relationship between water activity and water content of the enzyme, water activity provides a convenient means of controlling the amount of water adsorbed on the enzyme. Yang et al. (1992) observed that when chloroform was used as solvent, tyrosinase had no activity with an $a_{\mathrm{w}}$ lower than 0.7 ; but its activity increased dramatically and reached the maximum at $a_{\mathrm{w}}$ of 0.96 which corresponded to a water content of $0.45 \% \mathrm{v} / \mathrm{v}$ for chloroform, then the reaction rate declined; which might be due to the catalyst particles becoming clumped together, reducing interfacial area and limiting mass transfer. Earlier work by Kazandijan and Klibanov (1985) revealed that tyrosinase required more extensive hydration $\left(a_{\mathrm{w}}=0.7-1\right)$ than certain lipases $\left(a_{\mathrm{w}}\right.$ $=0.13-0.89)$ and thermolysin $\left(a_{w}=0.3-1\right)$.

\subsubsection{Characterization of PPO Enzymatic End-Products}

PPO enzymatic products, o-quinones, are very reactive entities and are subjected to further secondary reactions, both enzymic and non-enzymic, leading to pigments. Different degradation pathways of $o$-quinones involving phenolic or non-phenolic compounds have been well proposed in the literature (Cheynier et al., 1986; Singleton, 1987; Rouet-Mayer et al., 1990; Richard-Forget et al., 1992; Nicolas et al., 1994).

\subsubsection{Oxidation Products of Catechin}

Oszmianski and Lee (1990) observed that enzymatic oxidation of catechin prepared in $0.02 \mathrm{M}$ acetic acid buffer solution at $\mathrm{pH} 3.5$ produced several compounds that had longer elution times than that of catechin. In addition, a couple of reaction products that had shorter elution times than catechin were observed, namely procyanidin B3 (dimer of catechin). Spectroscopic 
analyses show that the oxidation products of catechin demonstrated a maximum absorbance at $380 \mathrm{~nm}$ and $420 \mathrm{~nm}$.

\subsubsection{Oxidation Products of Chlorogenic Acid}

For the separation of chlorogenic acid and its oxidation products formed in Mcllvaine buffer at $\mathrm{pH} 4.5$ and $30^{\circ} \mathrm{C}$ by the purified apple PPO, Richard-Forget et al. (1995) employed a Chromspher (Chrompack) C18 reversed-phase column, using high-performance liquid chromatography (HPLC) with ultraviolet (UV) detection at $280 \mathrm{~nm}$ and obtained four initial oxidation product peaks (CG1, CG2, CG3, QCG) that were more polar than that the parent chlorogenic acid. More apolar oxidation products were then formed as the reaction time increased. The QCG spectrum exhibited three maxima close to 255, 325 and $400 \mathrm{~nm}$, consistent with the presence of an o-quinone structure. Three maxima $(255,300$ and $400 \mathrm{~nm})$ were also observed in the CG3 spectrum. The CG2 spectrum with two maxima at 300 and $340 \mathrm{~nm}$ displayed a bathochromic shift compared to that of chlorogenic acid, which showed a maximum at $325 \mathrm{~nm}$ characteristic of a cinnamic structure.

Similar to the observation of Richard-Forget et al. (1995), Oszmianski and Lee (1990) observed six product peaks, from the enzymatic oxidation of chlorogenic acid prepared in $0.02 \mathrm{M}$ acetic acid buffer solution at $\mathrm{pH} 6.5$, that had longer elution times than that of chlorogenic acid, indicating that these oxidation products had higher molecular weights and/or they were less polar than the substrate. All of the oxidation products show a maximum absorbance at or near $320 \mathrm{~nm}$, a value that is significantly different from $420 \mathrm{~nm}$, which is the maximum absorbance for brown color.

\subsubsection{Applications of PPO in Organic Media}

PPO offers great versatility in applications. For example, PPO is of great preparative interest because it can regioselectively oxidize aromatic compounds which is often desirable but difficult in aqueous solutions (Klibanov, 1986). To illustrate, tyrosinase can catalyze tyrosine ester to form a range of alkyl- or aryl-esters of L-3,4-dihydroxyphenylalanine (L-DOPA) which have been tested as potential drugs for the treatment of Parkinson's disease (Cooper et al., 1987) (Fig. 3). 
Other remarkable selective reaction catalyzed by PPO is, for instance, the exchange of the side chains of D, L-serine to L-DOPA (Yamada and Kumagai, 1978). This exchange reaction is pyridoxal phosphate coenzyme-dependent and proceeds via a Schiff-base intermediate (Jones, 1986). Many side chain groups can be introduced in this way, including unnatural ones such as selenomethyl (Esaki et al., 1983).

Phenols and aromatic amines entering from the environment from various sources pose a major pollution problem especially in soil and drinking water. Degradation of such toxic compounds by PPO could represent an innovative and valuable technology for the bioremediation of contaminated aqueous environment (Crecchio et al., 1995). This biodegradation appears to be more promising than conventional physical and chemical technologies (Bretscher, 1981) as well as the direct use of microorganisms (Kearney et al., 1987).<smiles>[R]OC(=O)C(N)Cc1ccc(O)c(O)c1</smiles>

Tyrosine ester
L-DOPA ester<smiles>[R]OC(=O)C(N)CC1=CC(=O)C(=O)C=C1</smiles>

Quinone

Figure 3. Schematic representation of enzymatic synthesis of L-DOPA esters. 


\section{MATERIALS AND METHODS}

\subsection{Materials}

Commercially purified mushroom tyrosinase, catechin, vanillin, chlorogenic acid, $p$ aminophenol, hydroquinone, catechol and anhydrous sodium sulfate were all obtained from Sigma Chemicals Co. (St. Louis, MO). Chloroform, methanol, ethanol, acetone, heptanol, acetonitrile and sodium dodecyl sulfate were purchased from Fisher Scientific Co. (Pittsburgh, PA). Ethylenediamine tetraacetic acid (EDTA), sodium phosphate monobasic and dibasic crystals were purchased from ACP Chemicals Co. (Montreal, Québec). Prior to use, all organic solvents used throughout this study were dried overnight with anhydrous sodium sulfate.

\subsection{Selection of Organic Solvent Medium}

Five organic solvents, with increasing hydrophobicities as indicated by their $\log \mathrm{P}$ values, including methanol $(-0.76)$, ethanol $(-0.24)$, acetone $(-0.23)$, chloroform $(2.00)$ and heptanol (2.40) were used separately as the reaction medium for tyrosinase biocatalysis.

\subsection{Preparation of Substrate Solutions}

Stock solution of catechin (100 mM), chlorogenic acid (10 mM) and hydroquinone (20 $\mathrm{mM}$ ) were prepared in methanol by sonication whereas that of vanillin (5 $\mathrm{mM})$ was prepared in chloroform and p-aminophenol (100 $\mathrm{mM})$ in ethanol.

\subsection{Determination of Water Activity $\left(a_{w}\right)$ in the Reaction Medium}

Water activity $\left(a_{\mathrm{w}}\right)$ in the reaction system was measured with a hygrometer (Hanna Instruments, Fisher Scientific, Pittsburgh, PA). The hygrometer was calibrated successively, prior to use, with saturated solutions of $\mathrm{LiCl}$ and $\mathrm{NaCl}$ in an effort to maximize the accuracy of the measurements. The equilibrium relative humidity (ERH in \%) was measured by the hygrometer and determined as the water activity or $a_{\mathrm{W}}=\mathrm{ERH} / 100$ (Fennema, 1996). The enzymatic reaction mixture was placed in the chamber provided and the hygrometer probe was inserted into the chamber, 2 inches above the surface. Measurement was stabilized for at least $\mathbf{2} \mathbf{~ h}$. 
Tyrosinase activity in chloroform was assayed using one of the following substrate solutions, $5 \mu$ l of $100 \mathrm{mM}$ catechin, $10 \mu \mathrm{l}$ of $5 \mathrm{mM}$ vanillin, $5 \mu \mathrm{l}$ of $10 \mathrm{mM}$ chlorogenic acid, $5 \mu \mathrm{l}$ of $100 \mathrm{mM} p$-aminophenol solution or $5 \mu \mathrm{l}$ of $20 \mathrm{mM}$ hydroquinone. The substrate solution was added $200 \mu \mathrm{l}$ of reaction mixture and incubated at $30^{\circ} \mathrm{C}$ for catechin or $25^{\circ} \mathrm{C}$ for vanillin, chlorogenic acid, $p$-aminophenol and hydroquinone. The enzymatic reaction was initiated by the addition of $1.1 \mu \mathrm{l}$ tyrosinase suspension (8.8 $\mu \mathrm{g}$ protein prepared in $0.1 \mathrm{M}$ phosphate citrate buffer at $\mathrm{pH}$ 6.0) for catechin and vanillin, $0.7 \mu \mathrm{l}$ (6.3 $\mu \mathrm{g}$ protein) for chlorogenic acid, $4.0 \mu \mathrm{l}$ (36.1 $\mu \mathrm{g}$ protein) for $p$-aminophenol or $2.0 \mu \mathrm{l}$ (18.1 $\mu \mathrm{g}$ protein) for hydroquinone to the chloroform reaction mixture. The reaction mixtures were vigorously shaken for $3 \mathrm{sec}$ to $5 \mathrm{~min}$. The enzymatic reaction was then quenched after the appropriate time by the addition of acetone at $24.5,20.0,25.9,24.5$ and $24.5 \%(v / v)$ for catechin, vanillin, chlorogenic acid, $p$-aminophenol and hydroquinone, respectively. A blank trial, containing all components except the enzyme, was also performed concurrently. The enzyme activity was determined spectrophotometrically, using a Beckman DU-650 spectrophotometer, by measuring the color intensity of the reaction products at $372 \mathrm{~nm}$ (catechin), $332 \mathrm{~nm}$ (vanillin), $372 \mathrm{~nm}$ (chlorogenic acid), $394 \mathrm{~nm}$ (p-aminophenol) and $338 \mathrm{~nm}$ (hydroquinone). One unit of enzyme was defined as an increase in absorbance of 0.001 at a defined wavelength per $\mathrm{sec}$ at $\mathrm{pH} 6.0$, using the selected substrate. Specific activity of tyrosinase was expressed as the change in absorbance unit at the selected wavelength per $\mu \mathrm{g}$ enzyme protein per sec.

\subsection{Effect of Substrate Concentration on Tyrosinase Activity}

The effect of substrate concentration on tyrosinase activity in chloroform was assayed according to the procedure described above, using a range of substrate concentrations, 0.5 to 3.0 $\mathrm{mM}$ for catechin, 0.05 to $1.0 \mathrm{mM}$ for vanillin, 0.1 to $1.0 \mathrm{mM}$ for chlorogenic acid, 0.25 to 6.25 $\mathrm{mM}$ for $p$-aminophenol, and 0.05 to $5.0 \mathrm{mM}$ for hydroquinone.

The effect of substrate concentration on tyrosinase activity in aqueous medium was also investigated, using a range of substrate concentrations, 0.25 to $4.0 \mathrm{mM}$ for catechin, 0.07 to 0.50 $\mathrm{mM}$ for vanillin, 0.25 to $4.0 \mathrm{mM}$ for chlorogenic acid, 0.33 to $4.0 \mathrm{mM}$ for $p$-aminophenol, and 
substrate solution was added to the aqueous medium ( $0.1 \mathrm{M}$ phosphate citrate buffer, $\mathrm{pH} 6.0)$ of $1 \mathrm{~mL}$ total reaction volume and the enzymatic reaction was initiated by the addition of preincubated $1.40,1.40,1.20,41.8$ and $24.6 \mu \mathrm{g}$ of tyrosinase protein $(20 \mu \mathrm{l})$ to the reaction mixture. A blank assay, containing all components except the enzyme, was also conducted concurrently. The enzyme activity was determined spectrophotometrically, using a Beckman DU650 spectrophotometer, by measuring the color intensity of reaction products at $420 \mathrm{~nm}$ for catechin, $332 \mathrm{~nm}$ for vanillin, $392 \mathrm{~nm}$ for chlorogenic acid, $364 \mathrm{~nm}$ for $p$-aminophenol and 328 $\mathrm{nm}$ for hydroquinone.

\subsection{Effect of Enzymatic Protein on Tyrosinase Activity}

The effect of enzymatic protein on tyrosinase activity was determined by varying the amount of protein, suspended in phosphate citrate buffer $(0.1 \mathrm{M}, \mathrm{pH} 6.0)$, from 1.60 to $54.2 \mu \mathrm{g}$ per $200 \mu$ assay (or 8.0 to $271.0 \mathrm{mg}$ protein/L), while the volume of suspension added to the reaction medium was maintained constant.

\subsection{Effect of $\mathrm{pH}$ on Tyrosinase Activity}

The effect of $\mathrm{pH}$ on tyrosinase activity in chloroform was determined by preparing the enzyme-buffer suspension over a range of different $\mathrm{pHs}$, from 4.5 to 7.5 , in $0.1 \mathrm{M}$ phosphate citrate buffer.

\subsection{Effect of Temperature on Tyrosinase Activity}

The effect of temperature on tyrosinase activity in chloroform was determined by incubating the enzymatic reaction at a wide range of temperatures, from 5 to $40^{\circ} \mathrm{C}$.

\subsection{Effect of Co-Solvent on Tyrosinase Activity}

The effect of acetone as a co-solvent on tyrosinase biocatalysis was examined. Acetone, from 0 to $30 \%(v / v)$ for catechin, 0 to $60 \%(v / v)$ for vanillin, 0 to $77.5 \%(v / v)$ for chlorogenic acid, 0 to $95.0 \%(\mathrm{v} / \mathrm{v})$ for $p$-aminophenol and 0 to $95.0 \%(\mathrm{v} / \mathrm{v})$ for hydroquinone, was added prior to the enzymatic reaction under the identical experimental conditions described previously. 
The concentration of the co-solvent was expressed as the ratio of the volume of co-solvent (in $\mu l)$ to the total assay volume $(200 \mu \mathrm{l})$.

The effect of methanol as a co-solvent, from 0 to $100.0 \%(v / v)$ for catechin, 0 to $50.0 \%$ (v/v) for vanillin, 0 to $80.0 \%$ (v/v) for chlorogenic acid, 0 to $92.5 \%(v / v)$ for $p$-aminophenol and 0 to $90.0 \%$ for hydroquinone, on enzyme activity was also determined.

Since $p$-aminophenol was prepared in ethanol, the effect of ethanol, from 0 to $95 \%(\mathrm{v} / \mathrm{v})$, on tyrosinase activity with p-aminophenol as substrate was determined.

\subsection{Effect of Catechol on Tyrosinase Activity}

Stock solution of $7 \mathrm{mM}$ catechol was prepared in chloroform. The effect of catechol concentration, from 0 to $7 \mathrm{mM}$, on tyrosinase activity was investigated, using the phenolic substrates.

\subsection{Effect of EDTA on Tyrosinase Activity}

A range of ethylenediamine tetraacetic acid (EDTA) concentrations, from 0.90 to 6.15 $\mathrm{mM}$ for catechin assay, 0.01 to $4.50 \mathrm{mM}$ for vanillin, 0 to $4.75 \mathrm{mM}$ for chlorogenic acid, 0 to $5.39 \mathrm{mM}$ for $p$-aminophenol and 0 to $4.25 \mathrm{mM}$ for hydroquinone, was prepared in the enzymebuffer suspension to study the effect of EDTA on tyrosinase activity in chloroform.

The effect of EDTA on tyrosinase in aqueous solution was also investigated. Stock solution of EDTA (1.5 mM) was prepared in phosphate citrate buffer $(0.1 \mathrm{M}, \mathrm{pH} 6.0)$. A range of EDTA concentrations, 0 to $1.30 \mathrm{mM}$ for catechin, 0 to $1.35 \mathrm{mM}$ for vanillin, 0 to $1.43 \mathrm{mM}$ for chlorogenic acid, 0 to $80.0 \mathrm{mM}$ for $p$-aminophenol and 0 to $1.43 \mathrm{mM}$ for hydroquinone, was added to the reaction mixture of $200 \mu$ l total volume.

\subsection{Use of Acetone for Quenching the Enzymatic Reaction}

The reaction-quenching ability of acetone, 0 to $66.7 \%(\mathrm{v} / \mathrm{v})$ for catechin and vanillin, 24.5 to $33.3 \%(v / v)$ for chlorogenic acid, 16.7 to $33.3 \%$ (v/v) for $p$-aminophenol and 23.1 to $28.6 \%(v / v)$ for hydroquinone, was investigated. The reference reaction was quenched with deionized water instead of acetone. A blank reaction, containing all components except the 
reaction was defined as:

$$
v=\frac{\text { Abs }_{\text {ref }} \times \text { Initial reaction volume }(\mu l)}{\text { Total reaction volume }(\mu l)}
$$

where, $\mathrm{Abs}$ Tef was the absorbance of the water-quenched reference reaction mixture at a specific wavelength, the initial reaction volume was equal to $200 \mu \mathrm{l}$ and the total reaction volume was the assay volume after the addition of acetone used for quenching the reaction.

To investigate the relationship between the water content in the reaction medium and the acetone inhibitory effect on tyrosinase activity, the enzyme was prepared in three different water contents in phosphate citrate buffer $(0.1 \mathrm{M}, \mathrm{pH} 6.0)$ while the amount of enzymatic protein was maintained constant, $0.50,0.55$ and $0.65 \%$ for catechin and vanillin, $0.35,0.45$ and $0.65 \%$ for chlorogenic acid, 1.0, 2.0 and $2.5 \%$ for p-aminophenol and $0.75,1.0$ and $2.0 \%$ for hydroquinone. The acetone inhibitory effect was measured in the same way as described above. The water content was defined as the percent ratio $(v / v)$ of the volume of the enzyme-buffer suspension (in $\mu$ l) to the total reaction volume $(200 \mu \mathrm{l})$.

\subsection{Fourier Transform Infrared (FT-IR) Spectroscopy}

Infrared spectroscopic analyses were performed, using a Nicolet model 8210 Fourier transform infrared spectroscopy (FT-IR) spectrometer (Nicolet Instrument Corp., Madison, WI) equipped with a deuterated triglycine sulfate (DTGS) detector. The spectrometer was purged with dry air from a Balston dryer (Balston, Lexington, MA). Aliquots $(0.5 \mathrm{ml})$ of tyrosinase (in chloroform), catechin, vanillin, chlorogenic acid, $p$-aminophenol and hydroquinone (all in acetone), and their enzymatic end-products (both formed in aqueous and chloroform media, as described previsouly in Enzyme Assay) were deposited separately on the surface of a horizontal zinc selenide ( $\mathrm{ZnSe}$ ) attenuated total reflectance (ATR) sampling accessory and the solvent was allowed to evaporate completely to dryness to form a dried film. For end-products in aqueous medium, the reaction mixture was first freeze-dried for $24 \mathrm{~h}$ and then solubilized in acetone and the mixture was centrigued at $5000 \mathrm{rpm}$ for $10 \mathrm{~min}$. Only the end-products were soluble in acetone and thus taken for the measurement while the phosphate citrate crystals from the buffer 
variable-temperature transmission FT-IR studies, a $10 \%$ solution of tyrosinase was prepared in $\mathrm{D}_{2} \mathrm{O} .7 \mu \mathrm{l}$ of the solution was placed between two $\mathrm{CaF}_{2}$ windows separated by a $50 \mu \mathrm{m}$ spacer. The IR cell was placed in the FT-IR instrument and the cell temperature was controlled within \pm $0.5^{\circ} \mathrm{C}$ using an Omega temperature controller (Stamford, CT). The temperature of the cell was increased by $5^{\circ} \mathrm{C}$ and allowed to equilibrate for $15 \mathrm{~min}$. After 15-min interval at each temperature setting, the FT-IR spectrum of the sample was recorded ( 512 scans at $4 \mathrm{~cm}^{-1}$ resolution).

\subsection{High-Performance Liquid Chromatography (HPLC) Analyses}

Stock solutions of the five phenolic substrates were prepared in acetonitrile at $20 \mathrm{~g} / \mathrm{L}$. The end-products, first formed in chloroform as previously described in Enzyme Assay, were dried under a gentle stream of nitrogen and solubilized in acetonitrile (stock concentration 20 $g / L)$. Both the substrates and the end-products were then filtered, using $0.45 \mu \mathrm{m}$ PVDF syringe filter, prior to the injection for HPLC analyses.

Each phenolic substrate and the mixture of the end-products were separated on the CSCSperisorb-pH stable C18 $(5 \mu \mathrm{m})$ column ( $25 \times 0.46 \mathrm{~cm}$ I.D.) obtained from Scientific Products \& Equipment (Concord, Ontario, Canada). The HPLC system used for the analyses was Beckman Gold (Beckman Instruments, San Ramon, CA, USA) using computerized integration and data handling (Beckman Model 126). The system was equipped with UV detector. The UV absorbance was monitored with a Beckman UV detector (Model 166). Injection was achieved through a Model 9095 automatic injector (Varian, Walnut Creek, CA, USA) fitted with a $50 \mu \mathrm{l}$ loop. HPLC analyses of the phenolic substrates and end-products were performed using a gradient elution system with a mixture of acetonitrile and water containing from $98 \%$ to $60 \%$ of water at a flow rate of $0.75 \mathrm{ml} / \mathrm{min}$ for $45 \mathrm{~min}$. UV detection was performed at $278,308,324$, 298 and $288 \mathrm{~nm}$, respectively, for catechin, vanillin, chlorogenic acid, $p$-aminophenol and hydroquinone.

\subsection{Capillary Electrophoresis (CE) Analyses}

The capillary electrophoresis system used was P/ACE System 5510 from Beckman Instrument Inc. (Beckman Instruments, Fullerton, CA). Electrophoresis separations were 
achieved using a capillary of $57 \mathrm{~cm} \times 50 \mu \mathrm{m}$ I.D., an applied voltage of $15 \mathrm{kV}$ and $\mathrm{UV}$ detection at $200 \mathrm{~nm}$ at a temperature setting of $20^{\circ} \mathrm{C}$. The running buffer was $100 \mathrm{mM}$ sodium phosphate buffer at 7.0 with $50 \mathrm{mM}$ sodium dodecyl sulfate (SDS) and samples were injected for $5.0 \mathrm{sec}$, using pressure of 20 psi. Each analysis lasted $10 \mathrm{~min}$. Between each analysis the capillary was washed with $0.1 \mathrm{M} \mathrm{NaOH}$ for $1 \mathrm{~min}$ followed by $1 \mathrm{~min}$ washing with water and $1 \mathrm{~min}$ with rinse buffer.

The phenolic substrates and their end-products, formed from tyrosinase biocatalysis in chloroform as described in Enzyme Assay, were first dried under a gentle stream of nitrogen and then dissolved in the running buffer at a concentration of $1 \mathrm{mg} / \mathrm{ml}$ each. 


\section{RESULTS AND DISCUSSION}

\subsection{Kinetics}

Commercially purified tyrosinases may contain contaminating oxidizing enzymatic activities, particularly laccase (Kermasha et al., 1993a). In order to determine the absence or presence of such contaminating activity, the commercially purified tyrosinase (Sigma Chemical Co.) was examined using two specific substrates for laccase activity: 3,5-dimethoxy-4hydroxybenzaldehyde azine "syringaldazine" and 2,6-dimethoxyphenol (Dubourdieu et al., 1984). The experimental results indicated that the commercially purified tyrosinase, used throughout this study, contained negligible laccase activity (0.03 - $0.4 \%$ ) (data not shown). Kermasha et al. (1993a) also indicated similar results on the purity of the commercially purified tyrosinase (Sigma Chemical Co.).

\subsubsection{Selection of Organic Solvent Medium}

The spectrophotometric scanning profiles of enzymatic end-products (Fig. 4), using catechin, vanillin, chlorogenic acid, $p$-aminophenol and hydroquinone as substrates, show that among methanol, ethanol, acetone, heptanol and chloroform, the last solvent was the most appropriate medium for tyrosinase activity for all the substrates. The results demonstrate that the use of chloroform as the reaction medium resulted in clear distinct absorbance peaks at 372,332 , 372,394 and $338 \mathrm{~nm}$ corresponding to the o-quinones of catechin, vanillin, chlorogenic acid, $p$ aminophenol and hydroquinone, respectively. The use of acetone, ethanol, methanol or heptanol as reaction media, however, resulted in no distinct peaks. On the basis of these findings, chloroform was selected as the most appropriate medium for tyrosinase biocatalysis throughout this study. The trend of these results is in agreement with that reported by Laane et al. (1987) who suggested that solvents having $\log \mathrm{P}<2$ are not suitable in biocatalytic systems, since they strongly distort the essential water-biocatalyst interactions, thereby inactivating or denaturing the biocatalyst. Our results show that heptanol, though with a relatively high $\log P$ value (2.4), was not appropriate for tyrosinase biocatalysis for the substrates. Estrada et al. (1991) also examined 


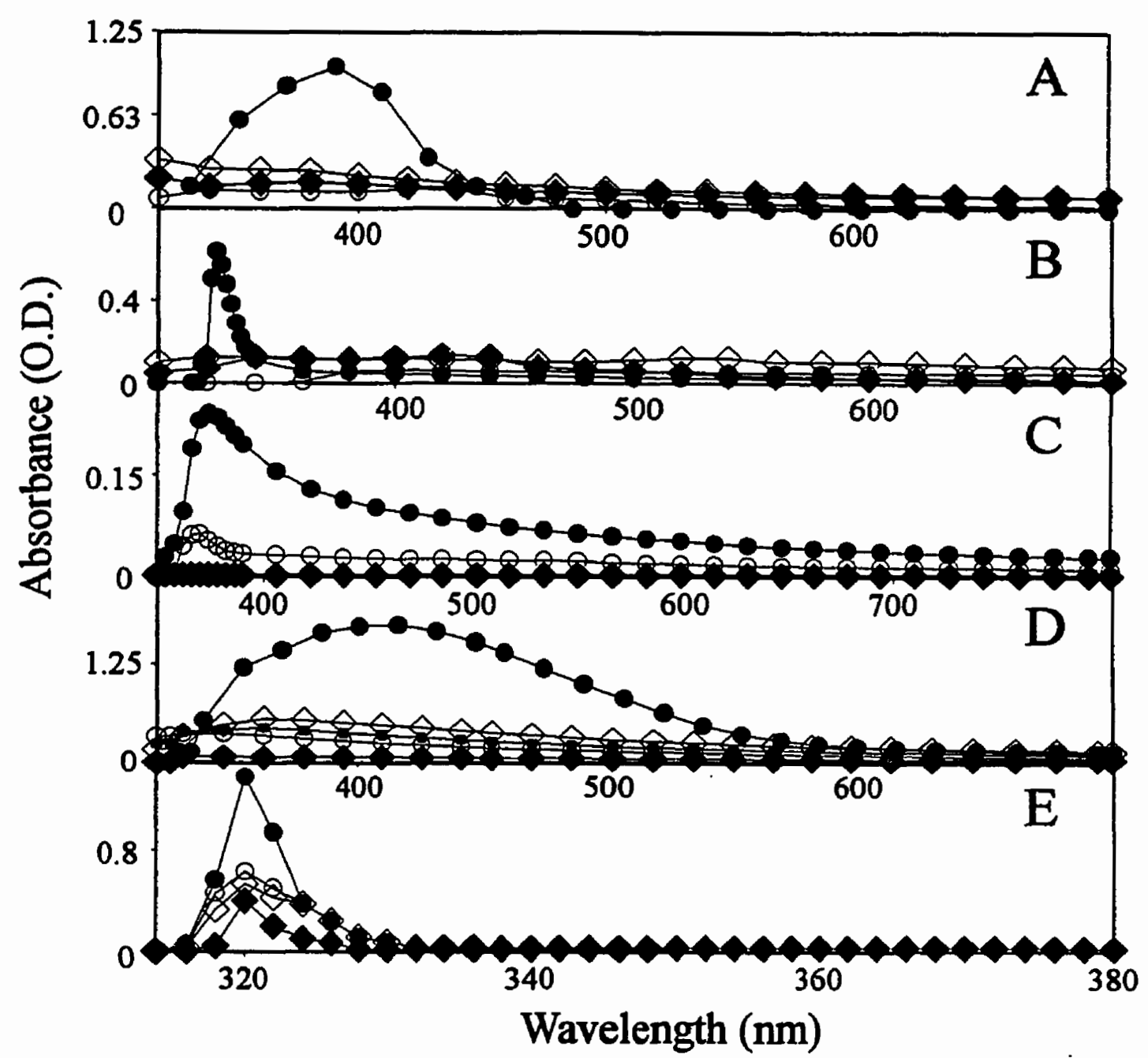

Figure 4. Spectrophotometric scanning profiles of tyrosinase enzymatic end-products formed in various organic solvent media: methanol $(\mathrm{O}-\mathrm{O})$, ethanol $(\longrightarrow \longrightarrow)$, acetone $(\diamond-\diamond)$, chloroform $(\bullet-)$ ) and heptanol $(\bullet-\bullet)$, using catechin (A), vanillin (B), chlorogenic acid (C), p-aminophenol (D) and hydroquinone $(E)$ as substrates. 
solvents with hydrophobicity values more than 2.5 , such as octanol (2.9), hexane (3.5), heptane (4.0), were not suitable for the biocatalysis of tyrosinase. Estrada et al. (1991) suggested that the low enzymatic activity may be due to the effect of the solvent polarity not only on the enzyme but also on the solubility of substrate and/or product.

\subsubsection{Effect of Enzymatic Protein on Tyrosinase Activity}

Figure 5 shows that the optimum amount of enzymatic protein for tyrosinase biocatalysis in chloroform. For both catechin and vanillin, the optimal enzyme concentration was found to be $44.0 \mathrm{mg}$ protein $/ \mathrm{L}$ whereas that for chlorogenic acid, $p$-aminophenol and hydroquinone was 31.6 , 180.5 and $90.3 \mathrm{mg}$ protein/L, respectively. These amounts were therefore selected as the amount of enzymatic protein for the subsequent enzyme assays. With catechin as substrate, the specific activity of tyrosinase increased steadily with increasing concentration of enzymatic protein until $44.0 \mathrm{mg}$ protein $/ \mathrm{L}$; with further increase in the protein concentration, tyrosinase specific activity was stabilized. With the other four substrates, the specific activity of tyrosinase increased steadily with increasing concentration of enzymatic protein until the optimum was reached; with further increase in the protein concentration, tyrosinase specific activity declined. This phenomenon might be due to the aggregation of enzyme molecules in chloroform since tyrosinase is not soluble in chloroform, resulting in reduced contact between enzyme and substrate, thus lowering the effectiveness of the enzyme (Kazandjian et al., 1986; Halling, 1992; Kamat et al., 1995).

\subsubsection{Determination of Water Activity $\left(a_{w}\right)$ in the Reaction Medium}

Under the optimized experimental conditions, water activity $\left(a_{w}\right)$ of the chloroform reaction mixture (Table 1) was found to be $0.674,0.594,0.550,0.776$ and 0.702 for catechin, vanillin, chlorogenic acid, $\boldsymbol{p}$-aminophenol and hydroquinone, respectively. The measurement of water activity reflects the importance of the presence of water for biocatalysis in anhydrous system. Alston and Freedman (1995) indicated that no truly anhydrous system can support biocatalysis because water is involved in enzyme structure. 


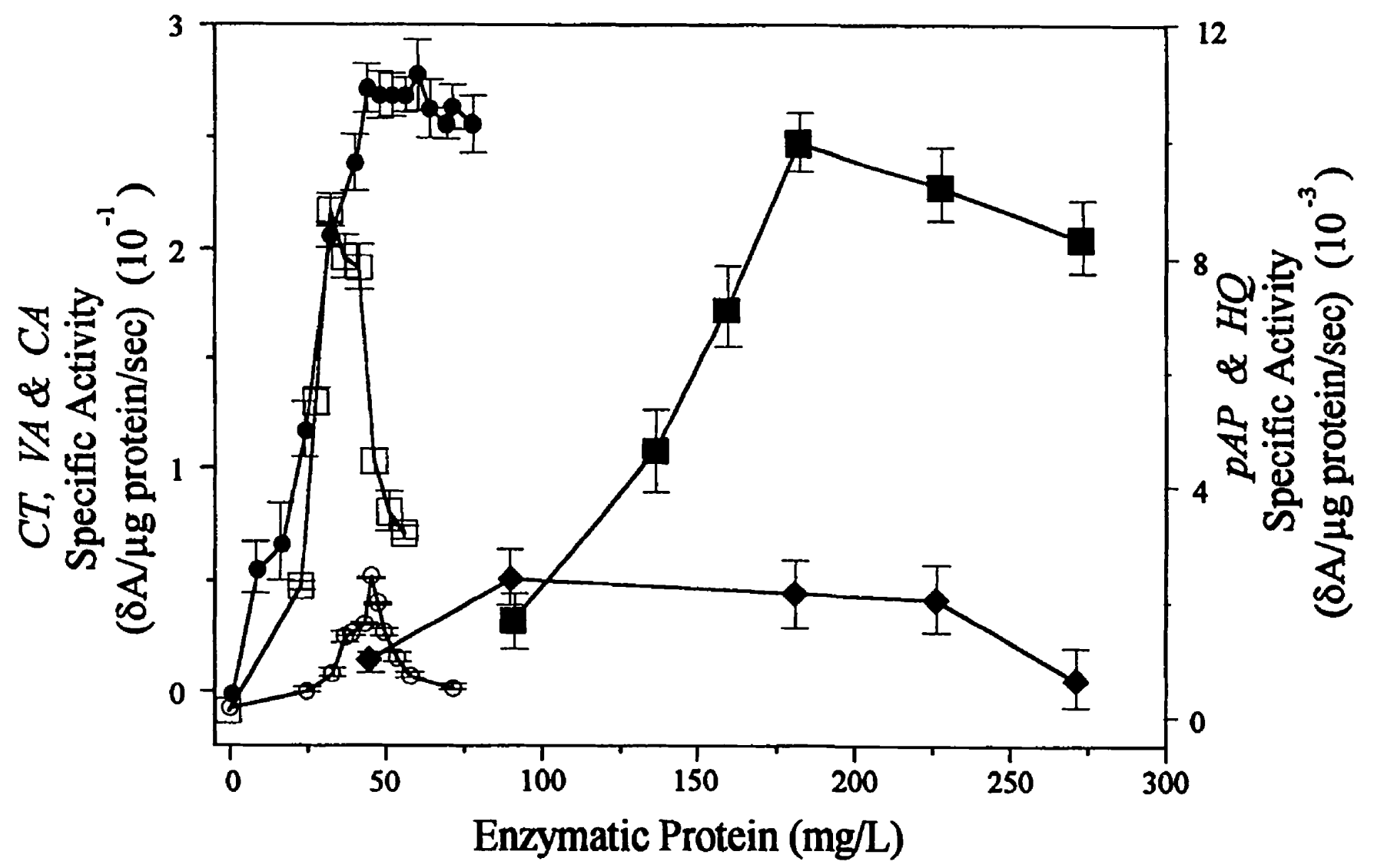

Figure 5. Effect of enzymatic protein concentration on tyrosinase activity in chloroform, using catechin (CT $\bullet-\bullet$ ), vanillin $(V$, chlorogenic acid (CA $\square-\square$ ), p-aminophenol (pAP - - ) and hydroquinone (HQ $\diamond$ ) as substrates; where $t$ activity was defined as the change in absorbance unit at $\lambda=372 \mathrm{~nm}$ for catechin, $332 \mathrm{~nm}$ for vanillin, $372 \mathrm{~nm}$ for $c$. acid, $394 \mathrm{~nm}$ for $p$-aminophenol and $338 \mathrm{~nm}$ for hydroquinone per $\mu \mathrm{g}$ protein per second. 
Table 1. Water activity measurement and the water content of the chloroform reaction mixture, using the phenolic substrates.

$\begin{array}{lll}\text { Substrate } & \text { Water Content }(\%)^{a} & \text { Water Activity }^{b}\end{array}$

Catechin

$0.674(0.009)^{c}$

Vanillin

0.55

$0.594(0.006)^{c}$

Chlorogenic Acid

0.45

$0.550(0.008)^{c}$

p-Aminophenol

2.0

$0.776(0.009)^{c}$

Hydroquinone

1.0

$0.702(0.011)^{c}$

${ }^{a}$ Water content (\%) was defined as the percent ratio (v/v) of the volume of the enzymebuffer suspension (in $\mu$ l) to the total reaction volume $(200 \mu \mathrm{l})$.

${ }^{b}$ Water activity was measured using a hygrometer (Hanna Instruments, Fisher Scientific, Pittsburgh, PA).

${ }^{c}$ The standard deviation for three replicate measurements. 


\subsubsection{Effect of Substrate Concentration on Tyrosinase Activity}

When tyrosinase suspension was added to chloroform containing the substrate followed by agitation, the resultant solution tumed bright yellowish orange (catechin and $p$-aminophenol end-products) or pale-yellow for vanillin and chlorogenic acid, or pale pink for hydroquinone end-products. However, in the absence of enzyme, no such products were detected by spectrophotometric scanning (data not shown); these findings indicated that the oxidation of the phenolic substrates in chloroform required the presence of the enzyme.

Figure 6 shows the spectrophotometric scanning of tyrosinase-catalyzed reaction using the five phenolic substrates, where the color intensity of the enzymatic end-products increased with respect to time at maximum absorbance of $372,332,372,394$ and $338 \mathrm{~nm}$ for catechin, vanillin, chlorogenic acid, $p$-aminophenol and hydroquinone, respectively.

For all five substrates, the enzymatic reactions obeyed Michaelis-Menten kinetics. Under the optimized experimental conditions, the specific activity of tyrosinase in chloroform (Table 2) was found to be $0.2034,0.0459,0.1529,0.0103$ and $0.2595 \times 10^{-3} \delta \mathrm{A}$ per $\mu \mathrm{g}$ protein per sec for catechin, vanillin, chlorogenic acid, $p$-aminophenol and hydroquinone, respectively, whereas that in aqueous media was $0.0102,0.0124,1.257 \times 10^{-3}, 0.2687 \times 10^{-3}$ and $2.395 \times 10^{-6} \delta \mathrm{A}$ per $\mu \mathrm{g}$ protein per sec for the five substrates in the above order.

The results in Table 2 also show that the $V_{\max }$ values of tyrosinase in chloroform and aqueous media for catechin were $0.1415,0.0042 \delta \mathrm{A}$ per $\mu \mathrm{g}$ protein per sec, respectively; the $V_{\max }$ values of the enzyme in the same media but with vanillin as substrate were 0.0250 and $0.0029 \delta \mathrm{A}$ per $\mu \mathrm{g}$ protein per sec, respectively. For chlorogenic acid as substrate, the $V_{\max }$ values in chloroform and in aqueous media were 0.1073 and $0.7462 \times 10^{-3} \delta \mathrm{A}$ per $\mu \mathrm{g}$ protein per sec, respectively; the $V_{\max }$ values of the enzyme in the same media but with $p$-aminophenol as substrate were $7.939 \times 10^{-3}$ and $0.1118 \times 10^{-3} \delta \mathrm{A}$ per $\mu \mathrm{g}$ protein per sec; whereas with hydroquinone as substrate, the $V_{\max }$ values were $0.1795 \times 10^{-3}$ and $1.114 \times 10^{-6} \delta \mathrm{A}$ per $\mu \mathrm{g}$ protein per sec, respectively. The values of both tyrosinase specific activity and $V_{\max }$ in 
substrates.

Tyrosinase exhibited a larger $K_{\mathrm{m}}$ value (3.970 $\mathrm{mM}$ ) for catechin in chloroform than that in buffer $(0.4915 \mathrm{mM})$, suggesting that catechin had higher affinity for the enzyme in aqueous solution than that in chloroform. Similar to catechin, chlorogenic acid also had a larger $K_{\mathrm{m}}$ value (3.492 $\mathrm{mM})$ in chloroform than that in buffer $(0.2151 \mathrm{mM})$. The $K_{\mathrm{m}}$ values of tyrosinase in chloroform and aqueous media with vanillin as substrate were 0.4125 and $1.469 \mathrm{mM}$, respectively, indicating that contrary to catechin and chlorogenic acid, vanillin had a much greater affinity for the enzyme in organic solvent than that in aqueous environment. The $K_{m}$ values of tyrosinase in chloroform and aqueous media with p-aminophenol as substrate were 0.9495 and $3.956 \mathrm{mM}$, respectively; showing $p$-aminophenol had a much greater affinity for the enzyme in organic solvent than that in aqueous environment. Similar to $p$-aminophenol, hydroquinone showed more affinity to tyrosinase in chloroform $(0.0427 \mathrm{mM})$ than in aqueous solvent ( $0.4284 \mathrm{mM})$. Examining the magnitude of $K_{\mathrm{m}}$ values of all the substrates in chloroform medium indicates a large discrepancy which may be due to the fact that catechin and chlorogenic acid, which are more hydrophobic than the other three substrates, partitioned more into the organic solvent; thus the substrate partitioning into the enzyme's active site was disrupted by the substrate hydrophobicity, giving rise to greater $K_{\mathrm{m}}$. On the other hand, vanillin, $p$-aminophenol and hydroquinone, which are less hydrophobic, partitioned themselves less into the organic solvents and more into the hydrophilic enzyme (Ryu and Dordick, 1989). Similar results were also obtained by Burton et al. (1993), using PPO as the biocatalyst in chloroform and varying the $p$-substituted phenolic substrates; as the hydrophobicity of the p-substituted phenolic substrate increased, the $K_{\mathrm{m}}$ value in chloroform correspondingly increased.

The catalytic efficiency, expressed as $V_{\max } / K_{\mathrm{m}}$ (Burton et al., 1993) was used to indicate the ability of tyrosinase to transform the substrate. The catalytic efficiency was much more higher in chloroform than that in aqueous medium for all the five phenolic substrates (Table 2). The acceleration factor, defined as the ratio of the catalytic efficiency in chloroform to that in aqueous medium, was also found much higher in chloroform (Table 2). The magnitude of the acceleration factor was generally correlated with the substrate hydrophobicity, the less hydrophobic the 
substrate (hydroquinone), the higher the acceleration factor, whereas the more hydrophobic the substrate was (catechin), the smaller the acceleration factor was. This phenomenon might also be explained by the fact that the less hydrophobic the substrate was, the less its partitioning into the enzyme active site in the organic solvent was disrupted by the organic solvent (Ryu and Dordick, 1989), giving rise to higher catalytic efficiency in chloroform and thus higher acceleration factor.

\subsubsection{Effect of $\mathrm{pH}$ on Tyrosinase Activity}

Figure 7 shows that the optimal $\mathrm{pH}$ for tyrosinase oxidation in chloroform was 6.0 for all the substrates. Tyrosinase was first prepared in buffer at $\mathrm{pH} 6.0$, which is the optimal $\mathrm{pH}$ of tyrosinase in aqueous media, followed by the suspension of the enzyme-buffer solution into the chloroform medium. Kermasha et al. (1993b) reported that the optimal $\mathrm{pH}$ for mushroom tyrosinase in aqueous solution, using chlorogenic acid as substrate, was also 6.0. Our results suggest that the presence of chloroform did not alter the optimal $\mathrm{pH}$ of tyrosinase. The present results (Fig. 7) can be explained in terms of the 'pH memory' where the enzyme exhibits in organic media its catalytic activity, characteristic of its optimal $\mathrm{pH}$ in aqueous media. This may be due to the fact that the enzyme's ionogenic groups acquire the corresponding ionization states at that particular $\mathrm{pH}$ which will then remain in the solid state (as suspension) or in organic solvents (Zaks and Klibanov, 1985). On the basis of our experimental findings (Fig. 7), phosphate citrate buffer at $\mathrm{pH} 6.0$ was used throughout this study for the preparation of the enzyme-buffer suspension.

\subsubsection{Effect of Temperature on Tyrosinase Activity}

Figure 8 shows that the optimal temperatures for catechin-tyrosinase oxidation in chloroform was found to be $30^{\circ} \mathrm{C}$. Estrada et al. (1991) reported that the optimal temperature for the phenol enzymatic oxidation in chloroform, using immobilized mushroom tyrosinase, was also $30^{\circ} \mathrm{C}$. The temperature coefficient $\left(\mathrm{Q}_{10}\right)$ for the catechin-tyrosinase oxidation in chloroform was found to be 1.91; this finding is close to that reported by Estrada and co-workers (1991) who indicated that the $Q_{10}$ value for the above phenol oxidation was 1.88 . The optimal temperatures 


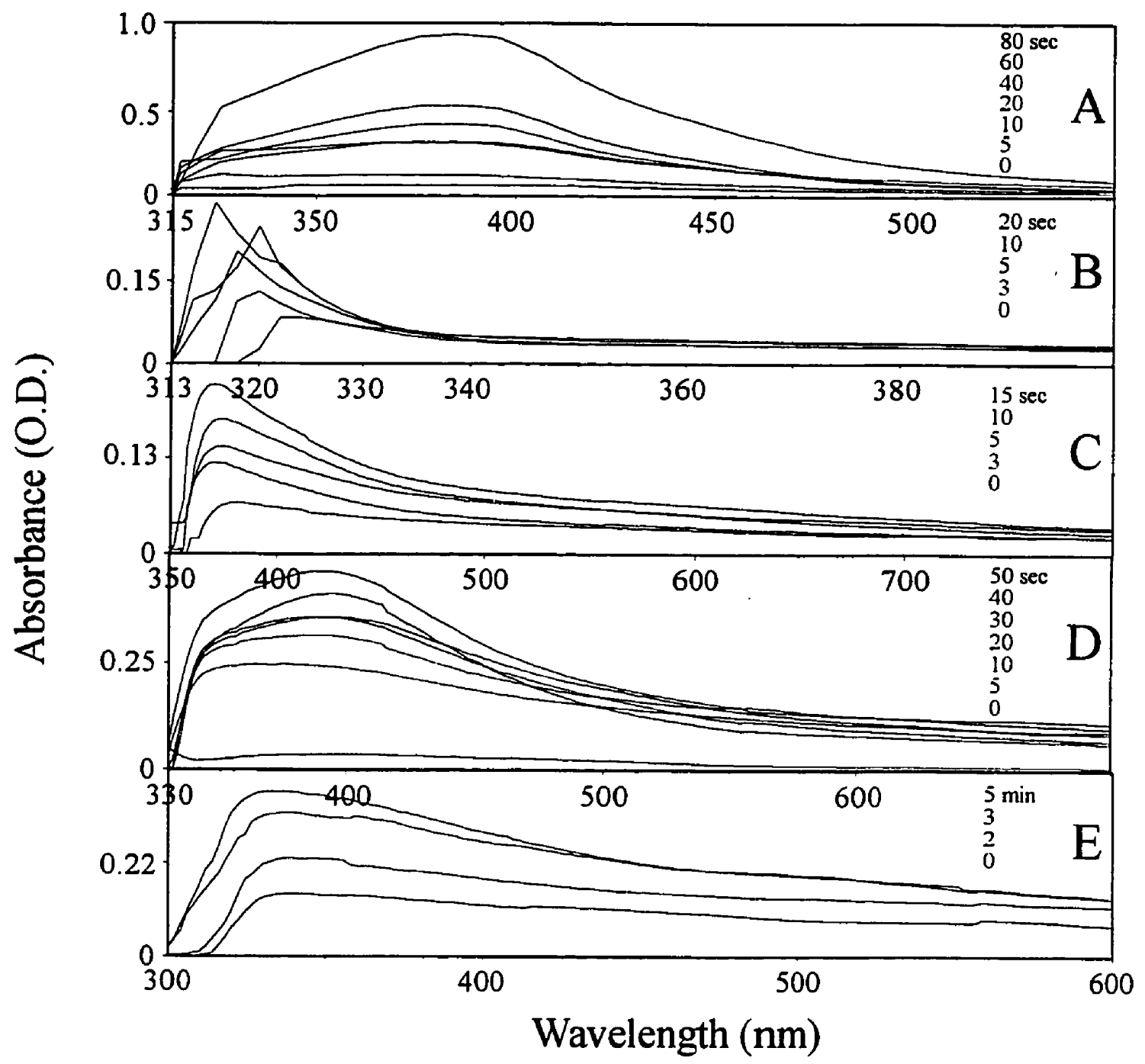

Figure 6. Spectrophotometric scanning profiles of tyrosinase biocatalysis in chloroform, using catechin (A), vanillin (B), chlorogenic acid (C), p-aminophenol (D) and hydroquinone $(E)$ as substrates at various intervals of time. 
Table 2: Kinetic parameters of tyrosinase biocatalysis in chloroform and aqueous media.

\begin{tabular}{|c|c|c|c|c|c|c|c|c|}
\hline \multirow[b]{2}{*}{ Substrate } & \multicolumn{2}{|c|}{ Specific Activity $^{a}$} & \multicolumn{2}{|c|}{$V_{\max }^{b}$} & \multicolumn{2}{|c|}{$K_{\mathrm{m}}$} & \multicolumn{2}{|c|}{$V_{\max } / K_{\mathrm{m}}{ }^{c}$} \\
\hline & $\begin{array}{l}\text { Chloroform } \\
\qquad(\delta \mathrm{A} / \mu \mathrm{g} \text { pr }\end{array}$ & $\begin{array}{l}\text { Aqueous } \\
\text { protein/sec) }\end{array}$ & $\begin{array}{l}\text { Chloroform } \\
\qquad(\delta \mathrm{A} / \mu \mathrm{g} \text { prc }\end{array}$ & $\begin{array}{l}\text { Aqueous } \\
\text { tein/sec) }\end{array}$ & Chloroform & $\begin{array}{l}\text { Aqueous } \\
\text { M) }\end{array}$ & Chloroform & Aqueous \\
\hline Catechin & 0.2034 & 0.0102 & 0.1415 & 0.0042 & 3.970 & 0.4915 & 0.0356 & 0.0085 \\
\hline Vanillin & 0.0459 & 0.0124 & 0.0250 & 0.0029 & 0.4125 & 1.469 & 0.0606 & 0.0020 \\
\hline Chlorogenic acid & 0.1529 & $1.257 \times 10^{-3}$ & 0.1073 & $0.7462 \times 10^{-3}$ & 3.492 & 0.2151 & 0.0307 & 0.0035 \\
\hline p-Aminophenol & 0.0103 & $0.2687 \times 10^{-3}$ & $7.939 \times 10^{-3}$ & $0.1118 \times 10^{-3}$ & 0.9495 & 3.956 & 0.0084 & $0.0283 \times 10^{-3}$ \\
\hline Hydroquinone & $0.2595 \times 10^{-3}$ & $2.395 \times 10^{-6}$ & $0.1795 \times 10^{-3}$ & $1.114 \times 10^{-6}$ & 0.0427 & 0.4284 & 0.0042 & $0.0026 \times 10^{-3}$ \\
\hline
\end{tabular}

${ }^{a}$ Specific activity of tyrosinase was expressed as the change in absorbance unit at the specific wavelength per $\mu \mathrm{g}$ enzymatic protein per sec

${ }^{b}$ The maximal enzymatic reaction rate was defined as the change in absorbance unit at a specific wavelength ( $372 \mathrm{~nm}$ for catechin, 3 vanillin, $372 \mathrm{~nm}$ for chlorogenic acid, $394 \mathrm{~nm}$ for $p$-aminophenol, and $338 \mathrm{~nm}$ for hydroquinone) per $\mu \mathrm{g}$ enzymatic protein per second.

${ }^{c}$ The catalytic efficiency was defined as the ratio of $V_{\max }$ to $K_{\mathrm{m}}$.

${ }^{d}$ Acceleration factor was defined as the ratio of $V_{\max } / K_{\mathrm{m}}$ in chloroform to that in aqueous media. 


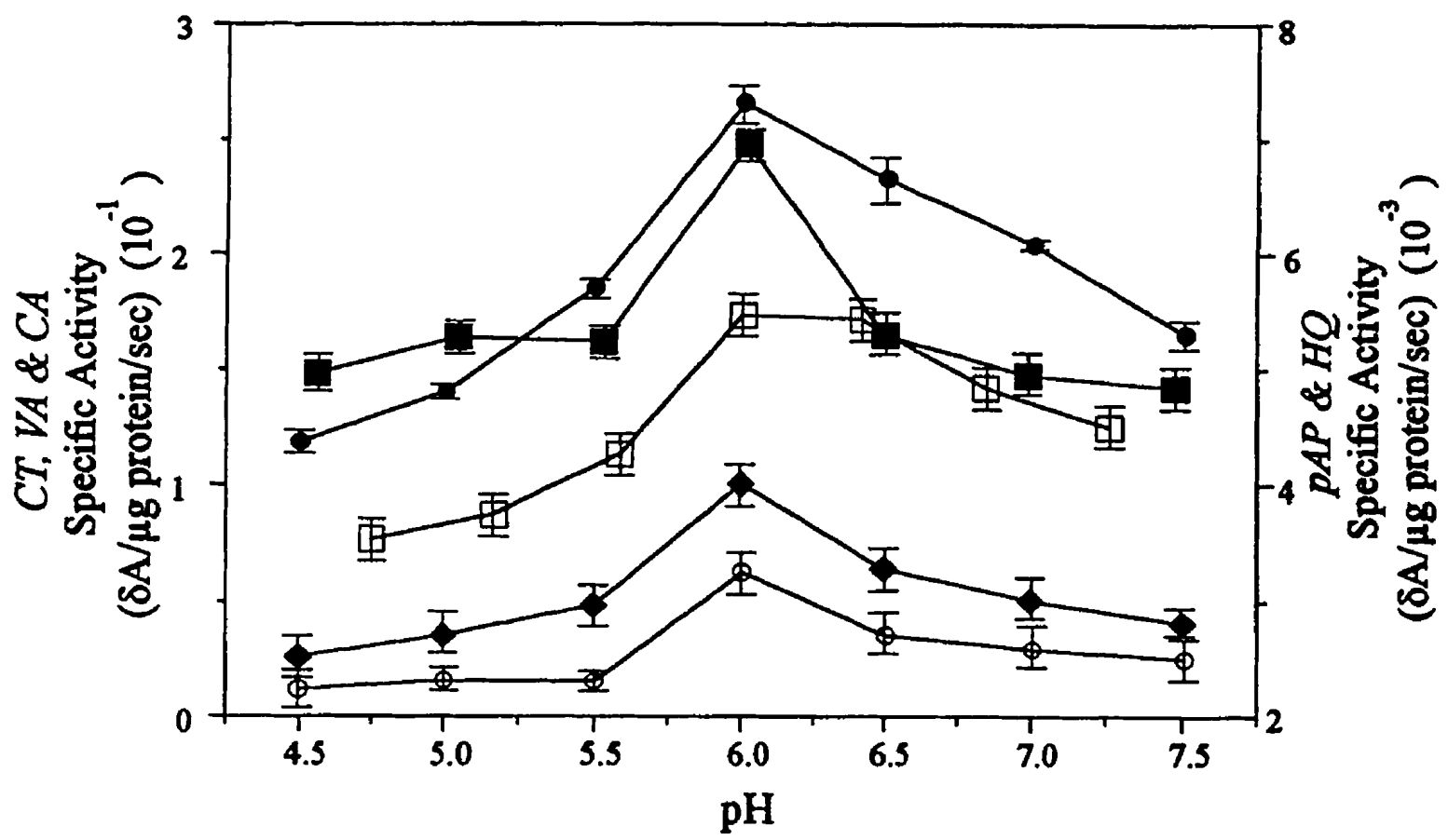

Figure 7. The effect of $\mathrm{pH}$ on tyrosinase biocatalysis in chloroform, using catechin (CT - -), vanillin (VA O-O), chlorogenic acid (CA $\square-\square)$ ), p-aminophenol $(p A P=)$ and hydroquinone (HQ $-\bullet)$ as substrates, where the specific activity was defined as the change in absorbance unit at $\lambda=372 \mathrm{~nm}$ for catechin, $332 \mathrm{~nm}$ for vanillin, $372 \mathrm{~nm}$ for chlorogenic acid, $394 \mathrm{~nm}$ for $p$-aminophenol and $338 \mathrm{~nm}$ for hydroquinone per $\mu \mathrm{g}$ protein per second. 


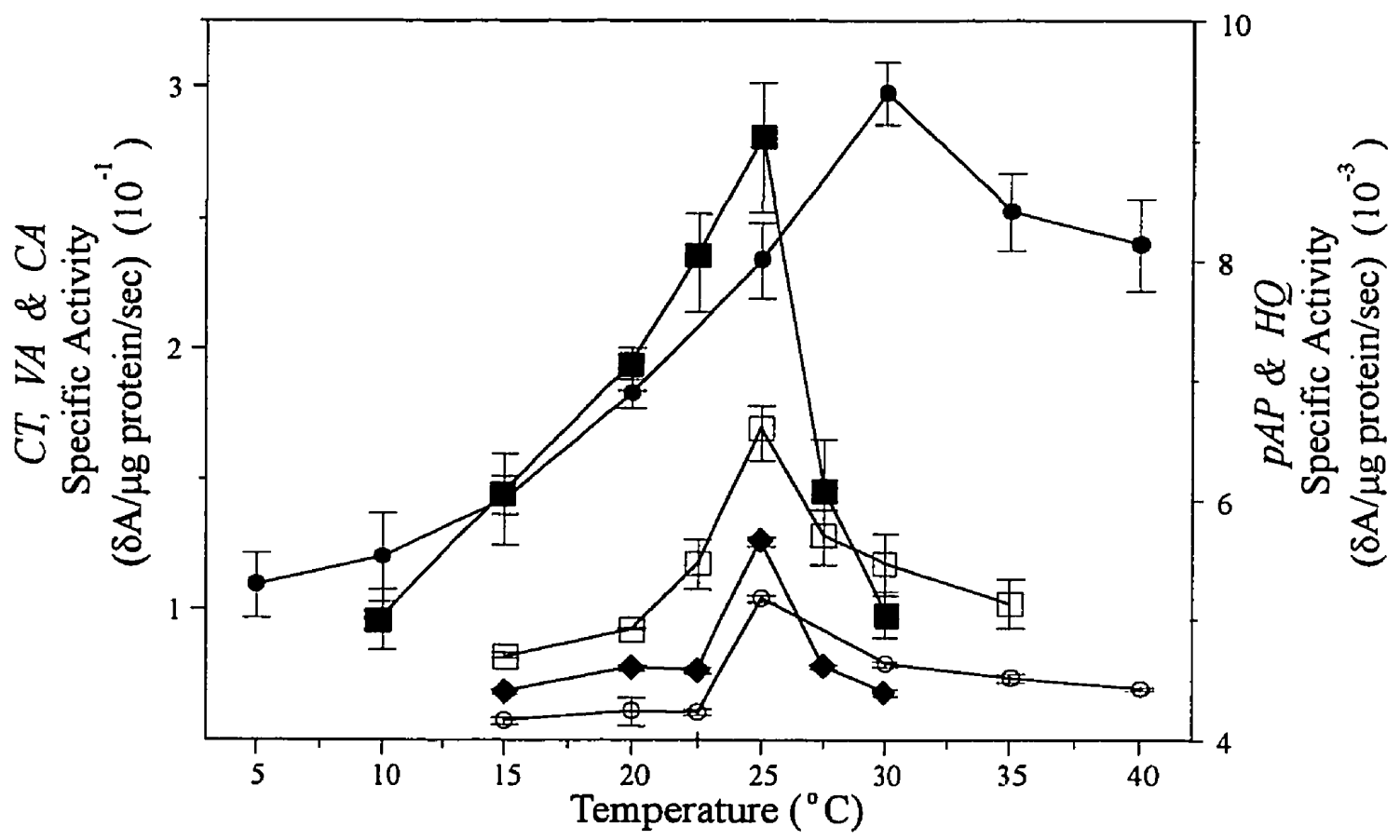

Figure 8. The effect of temperature on tyrosinase biocatalysis in chloroform, using catechin (CT ——), vanillin (VA O-O), chlorogenic acid (CA $\square-\square$ ), $p$-aminophenol $(p \mathrm{AP}-\square)$ and hydroquinone (HQ $-\bullet$ ) as substrates, where the specific activity was defined as the change in absorbance unit at $\lambda=372 \mathrm{~nm}$ for catechin, $332 \mathrm{~nm}$ for vanillin, $372 \mathrm{~nm}$ for chlorogenic acid, $394 \mathrm{~nm}$ for $p$-aminophenol and $338 \mathrm{~nm}$ for hydroquinone per $\mu \mathrm{g}$ protein per second. 
for vanillin-, chlorogenic acid-, p-aminophenol- and hydroquinone-tyrosinase oxidation in chloroform were all found to be $25^{\circ} \mathrm{C}$ (Fig. 8). The $Q_{10}$ value for vanillin-tyrosinase oxidation in chloroform was found to be 1.66 whereas that for chlorogenic acid-tyrosinase oxidation was $2.15,1.52$ for $p$-aminophenol and 1.26 for hydroquinone.

\subsubsection{Effect of Co-Solvent on Tyrosinase Activity}

\subsubsection{Effect of Acetone on Tyrosinase Activity}

Figure 9 shows that the addition of acetone, from 10.0 to $30.0 \%(v / v)$, inhibited tyrosinase activity by 19.4 to $92.1 \%$ when catechin was used as substrate. The inhibitory effect of acetone was much stronger with vanillin as substrate than that with catechin, since merely $2.5 \%$ of acetone per assay was sufficient to inhibit $65.9 \%$ of enzyme activity; a complete inhibition of tyrosinase activity was achieved with acetone at $25.0 \%(\mathrm{v} / \mathrm{v})$. The addition of acetone to the reaction medium exhibited an uncompetitive inhibitory effect towards tyrosinase activity for both catechin (Fig. 10A) and vanillin (Fig. 10B). The corresponding $V_{\text {maxapp }}$ and $K_{\text {mapp }}$ values (Table 3) for catechin were $0.0234 \delta \mathrm{A}$ per $\mu \mathrm{g}$ protein per sec and $1.241 \mathrm{mM}$, respectively, whereas those for vanillin were $0.0072 \delta \mathrm{A}$ per $\mu \mathrm{g}$ protein per $\sec$ and $0.1075 \mathrm{mM}$, respectively.

Figure 9 also demonstrates that the addition of acetone, from 0 to $12.5 \%$, somehow shows an activating effect on tyrosinase when chlorogenic acid was used as substrate, with $2.5 \%$ acetone giving the maximum enzyme activation (67.9\%); this may be due to two reasons. First, the enhanced solubility of the substrate by the presence of acetone in chloroform might have allowed more available substrates interacting with tyrosinase. Second, the observed enzyme activation might have been the "lubricating effect" of acetone to protein structure as suggested by Poole and Finney (1983). However, additional increase in acetone concentration resulted in an inhibitory effect on tyrosinase activity; with the maximal enzyme inhibition (42.9\%) obtained by $50.0 \%$ acetone. The trend of these results is in agreement with that reported by Almarsson and Klibanov (1996) in which the activity of the lyophilized protease subtilisin Carlsberg suspended in anhydrous acetonitrile was actually greatly enhanced by the addition of 10 to $50 \%$ of formamide; above $50 \%$, formamide irreversibly inactivated the enzyme. The addition of acetone to the reaction medium with chlorogenic acid as substrate exhibited a competitive inhibitory effect 
(Table 3). Therefore, in the case of chlorogenic acid, acetone could act as both enzyme activator and inhibitor depending on the relative amount used.

With $p$-aminophenol as substrate (Fig. 9), tyrosinase residual activity steadily decreased with the increasing concentration of acetone; with $95.0 \%$ acetone giving almost complete inhibition (88.8\%); acetone behaved as a competitive inhibitor to p-aminophenol-tyrosinase oxidation (Fig. 10D), with $K_{\text {mupp }}$ being $37.03 \mathrm{mM}$ (Table 3).

With hydroquinone as substrate (Fig. 9), merely $2.5 \%$ of acetone was enough to give the maximal enzyme inhibition (93.2\%); while increasing acetone concentration decreased and stabilized the enzyme inhibition to $30.0 \%$ (Fig. 9). Acetone acted as a mixed non-competitive inhibitor to hydroquinone-tyrosinase oxidation (Fig. 10E), with $V_{\operatorname{maxapp}}$ of $0.0746 \times 10^{-3} \delta \mathrm{A} / \mu \mathrm{g}$ protein/sec and $K_{\text {mupp }}$ of $0.0739 \mathrm{mM}$ (Table 3).

\subsubsection{Effect of Methanol on Tyrosinase Activity}

The concentration of methanol required for the highest enzyme activation (92.3\%), using catechin as substrate, was found to be $1.75 \%(v / v)$; however, further increase in the concentration of methanol (80.0\%) in the reaction mixture inhibited tyrosinase activity, with the maximum enzyme inhibition of $70.3 \%$ (Fig. 11A). The initial enzyme activation by methanol may be, as mentioned earlier in the case of chlorogenic acid, due to either the enhanced solubility of substrate in chloroform or the "lubricating effect" of methanol on the enzyme (Poole and Finney, 1983). The eventual enzyme inhibition by elevated amount of methanol was also observed by Almarsson and Klibanov (1996). The addition of methanol to the reaction medium when catechin was used as substrate exhibited a competitive inhibitory effect towards tyrosinase activity (Fig. $12 \mathrm{~A}$ ), with the corresponding $K_{\text {mapp }}$ value being $0.1023 \mathrm{mM}$ (Table 3).

Figure 11B shows, however, that using vanillin as substrate, the addition of 1.0 to $5.0 \%$ methanol decreased the residual enzyme activity drastically from 35.6 to $12.9 \%$; a complete inhibition of tyrosinase was obtained with $50.0 \%$ methanol. The addition of methanol to the reaction medium when vanillin was used as substrate exhibited a competitive inhibitory effect 
With chlorogenic acid as substrate, tyrosinase was sensitive to the addition of methanol, since only $5.0 \%(\mathrm{v} / \mathrm{v})$ of methanol inhibited the enzyme by $94.0 \%$. With further addition of methanol, the enzyme inhibition decreased and stabilized to around $50.0 \%$ (Fig. 11B). The addition of methanol to the reaction medium when chlorogenic acid was used as substrate exhibited a competitive inhibitory effect towards tyrosinase activity (Fig. 12C), with the corresponding $K_{\text {mapp }}$ value being $0.0955 \mathrm{mM}$ (Table 3).

With $p$-aminophenol as substrate, the addition of only $5.0 \%$ methanol enhanced the enzymatic activity by $88.6 \%$ while continuing addition of methanol decreased the enzyme activation. Additional increase in methanol concentration (92.5\%) in the reaction mixture acted as inhibitor to tyrosinase, with the maximum inhibition of $39.1 \%$ (Fig. 11A). Methanol in the reaction mixture when $p$-aminophenol was used as substrate behaved as an uncompetitive inhibitor to tyrosinase (Fig. 12D) with $V_{\text {maxapp }}$ of $2.140 \times 10^{-3} \delta \mathrm{A} / \mu \mathrm{g}$ protein/sec and $K_{\text {mapp }}$ of $0.1999 \mathrm{mM}$ (Table 3).

With hydroquinone as substrate, the enzyme inhibition increased steadily with the increasing concentration of methanol where the maximum enzyme inhibition (77.7\%) was achieved by $90.0 \%$ of methanol (Fig. 11B). The addition of methanol to the reaction medium when hydroquinone was used as substrate exhibited a mixed non-competitive inhibitory effect towards tyrosinase activity (Fig. 12E), with the corresponding $V_{\text {maxapp }}$ of $0.0726 \times 10^{-3} \delta \mathrm{A} / \mu \mathrm{g}$ protein $/ \mathrm{sec}, K_{\text {mapp }}$ of $0.1250 \mathrm{mM}$ (Table 3).

\subsubsection{Effect of Ethanol on Tyrosinase Activity}

Similarly, with $p$-aminophenol as substrate, the residual enzyme activity decreased steadily from 98.8 to $16.0 \%$ with the increasing concentration of ethanol from 5.0 to $95.0 \%$ (Fig. 13A). The addition of ethanol to the reaction medium when $p$-aminophenol was used as substrate exhibited a competitive inhibitory effect towards tyrosinase activity (Fig. 13B), with the corresponding $K_{\text {mapp }}$ value being $0.0188 \mathrm{mM}$ (Table 3). 


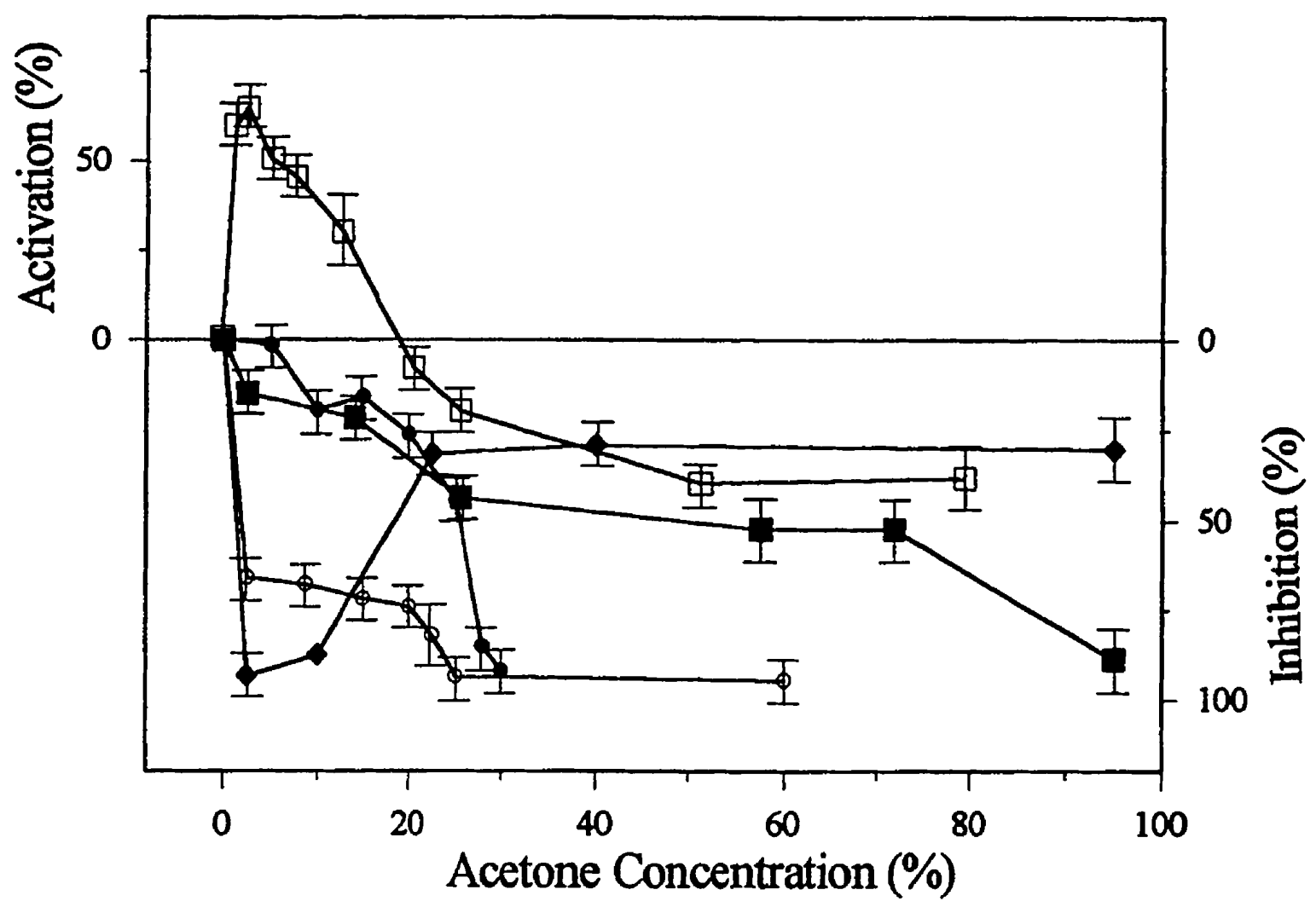

Figure 9. Effect of the presence of acetone on tyrosinase biocatalysis in chloroform, using catechin $(\bullet-)$, vanillin $(\mathrm{O}-\mathrm{O})$, chlorogenic acid $(\square-\square)$, p-aminophenol $(\square)$ and hydroquinone $(-\bullet)$ as substrates. The percentage of inhibition or activation of tyrosinase activity was defined as the decrease or increase in enzymatic activity relative to the initial value. 


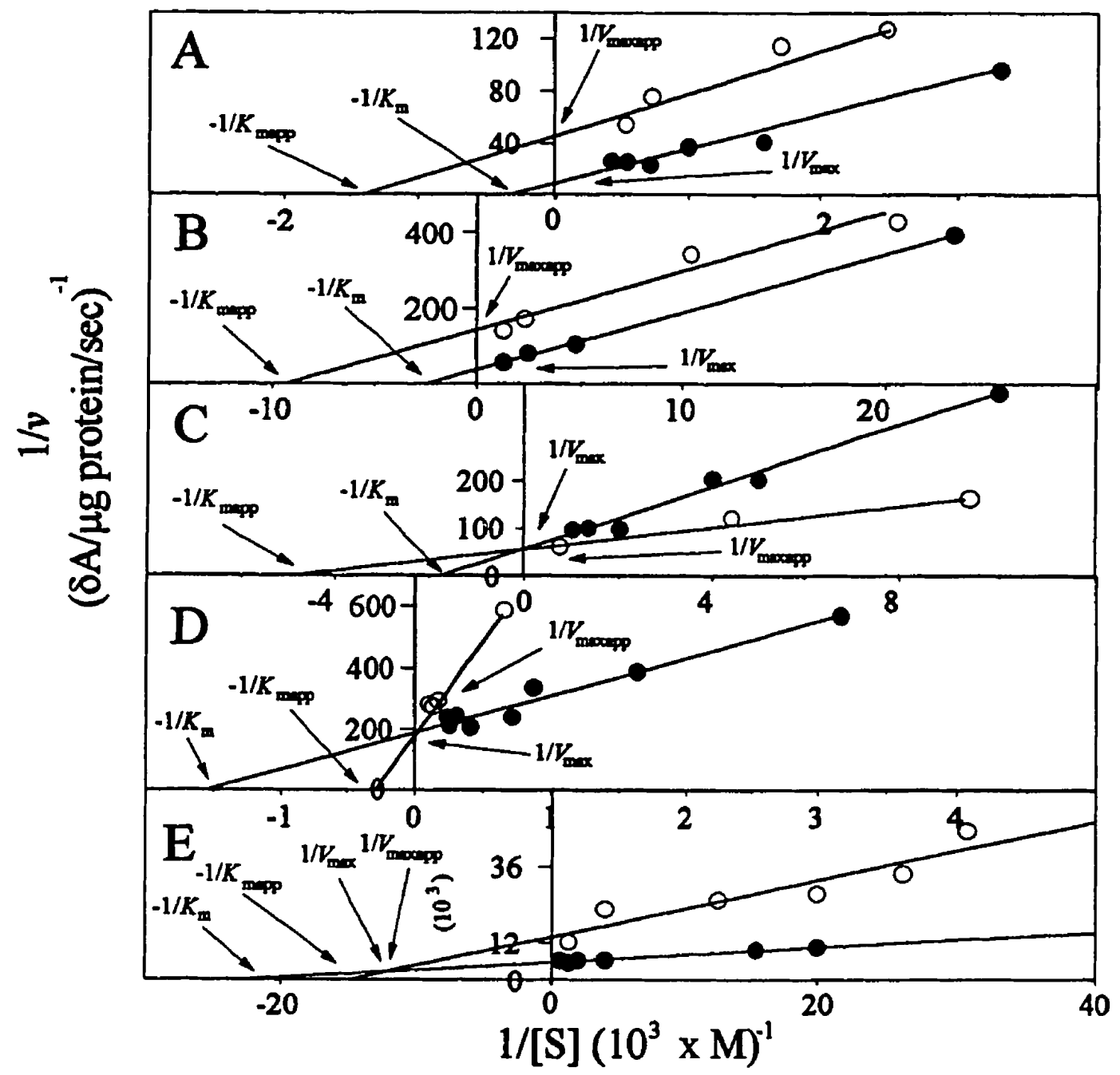

Figure 10. The Lineweaver-Burk plots of tyrosinase biocatalysis in chloroform without inhibitor $(-\bullet)$, and with acetone as inhibitor $(\mathrm{O}-0)$; $25 \%$ acetone $(\mathrm{v} / \mathrm{v})$ with catechin (A), $15 \%$ acetone with vanillin (B), $25 \%$ acetone with chlorogenic acid (C), $60 \%$ acetone with p-aminophenol (D), $20 \%$ acetone with hydroquinone $(E)$ as substrates, where the initial reaction rate was defined as the change in absorbance unit at $\lambda=372 \mathrm{~nm}$ for catechin, $332 \mathrm{~nm}$ for vanillin, 372 $\mathrm{nm}$ for chlorogenic acid, $394 \mathrm{~nm}$ for $p$-aminophenol and $338 \mathrm{~nm}$ for hydroquinone per $\mu \mathrm{g}$ protein per second. 


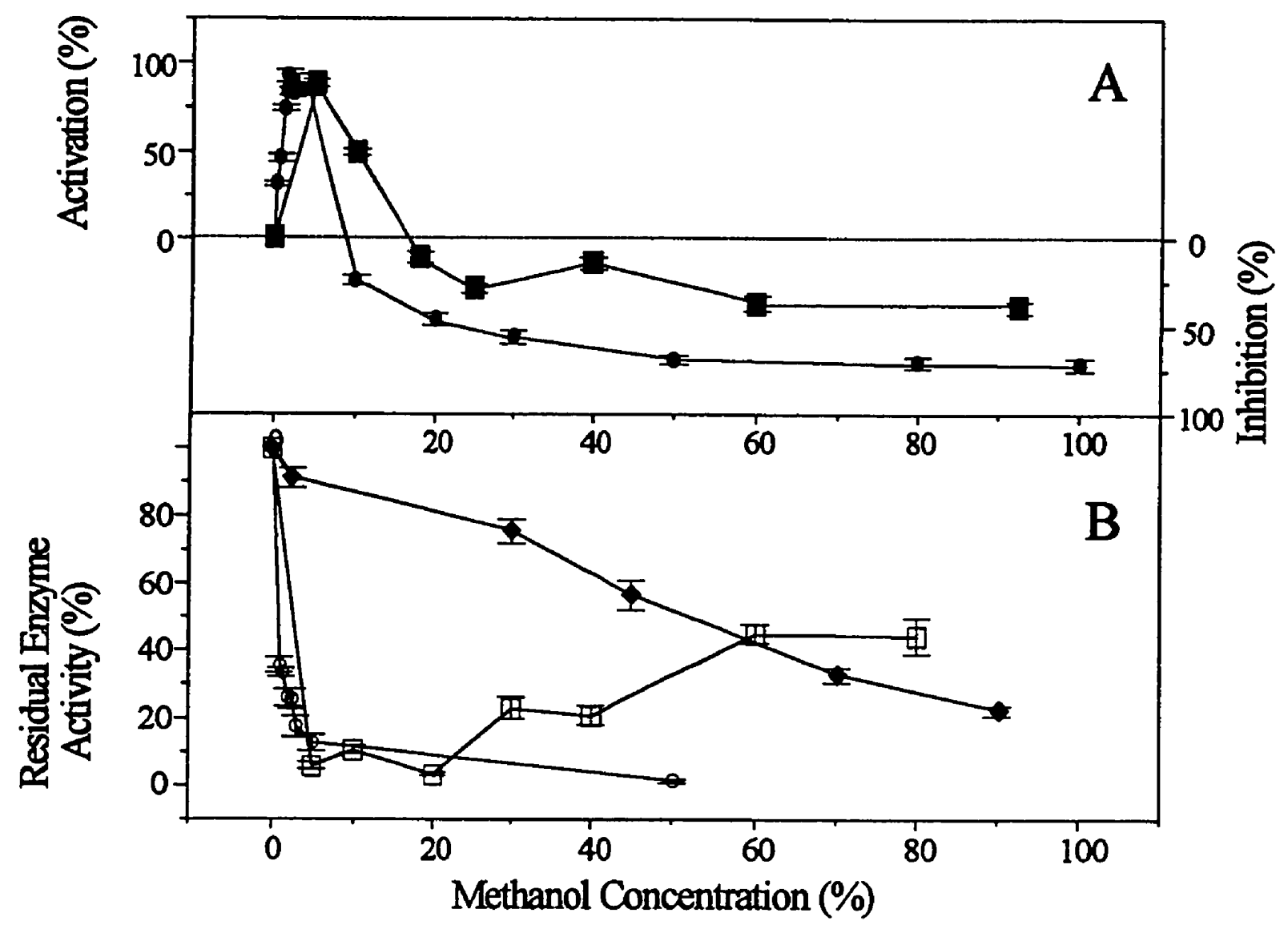

Figure 11. Effect of the presence of methanol on tyrosinase biocatalysis in chloroform, using catechin (๑), p-aminophenol ( $\square$ ) (A), vanillin (O-O), chlorogenic acid $(\square-\square)$, and hydroquinone $(-\bullet)$ as substrates (B). The percentage of activation or inhibition of tyrosinase activity was defined as the increase or decrease in enzymatic activity relative to the initial value and the residual enzyme activity was defined as the percentage of the ratio of residual enzyme activity to the initial value. 


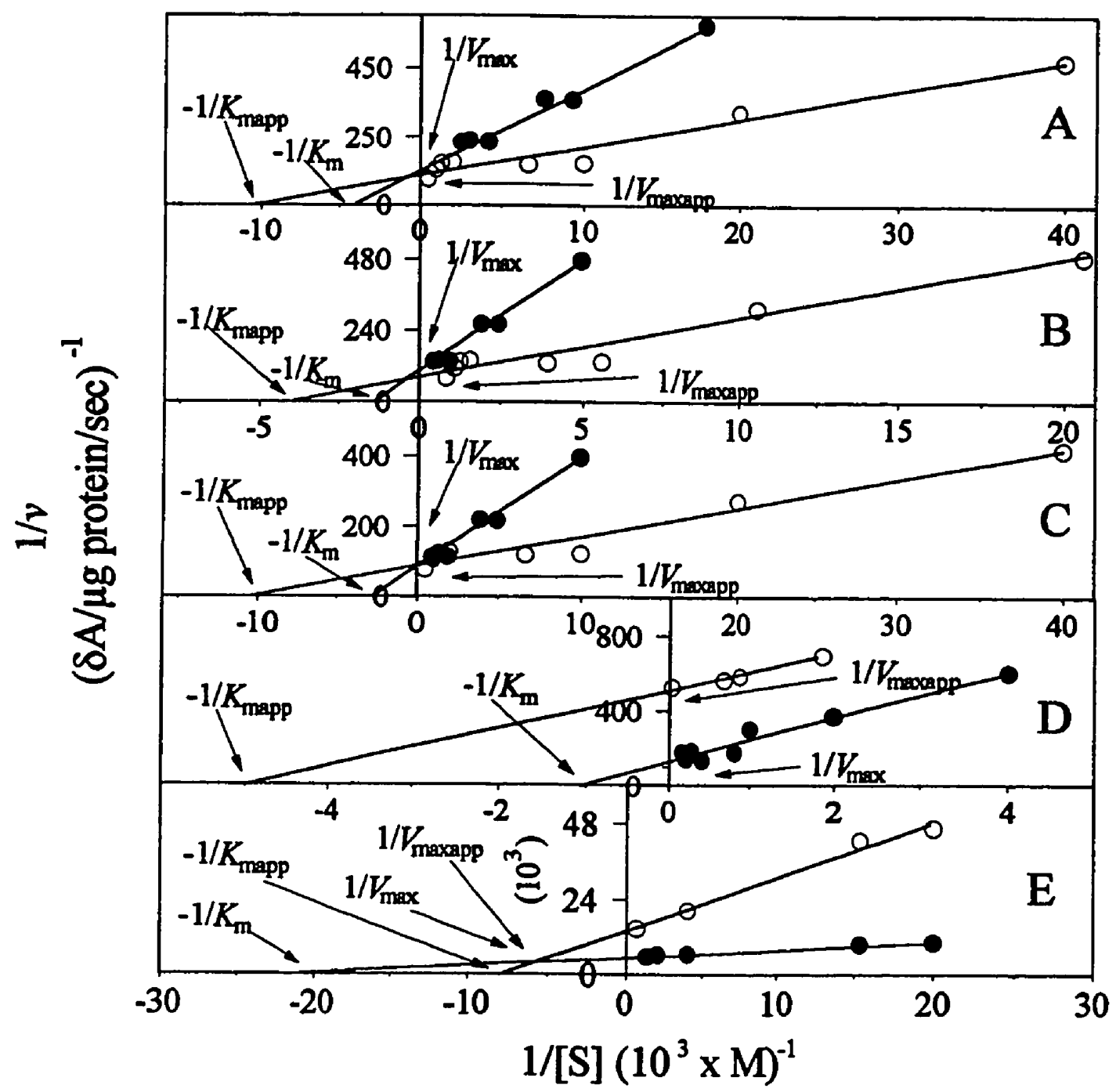

Figure 12. The Lineweaver-Burk plots of tyrosinase biocatalysis in chloroform without inhibitor $(\bullet)$, and with methanol as inhibitor $\left(\mathrm{O}_{-}-0\right)$; $50 \%$ methanol $(\mathrm{v} / \mathrm{v})$ with catechin (A), $5 \%$ methanol with vanillin (B), $60 \%$ methanol with chlorogenic acid (C), $25 \%$ methanol with $p$-aminophenol (D), $10 \%$ methanol with hydroquinone (E) as substrates, where the initial reaction rate was defined as the change in absorbance unit at $\lambda=372 \mathrm{~nm}$ for catechin, $332 \mathrm{~nm}$ for vanillin, $372 \mathrm{~nm}$ for chlorogenic acid, $394 \mathrm{~nm}$ for $p$-aminophenol and $338 \mathrm{~nm}$ for hydroquinone per $\mu \mathrm{g}$ protein per second. 


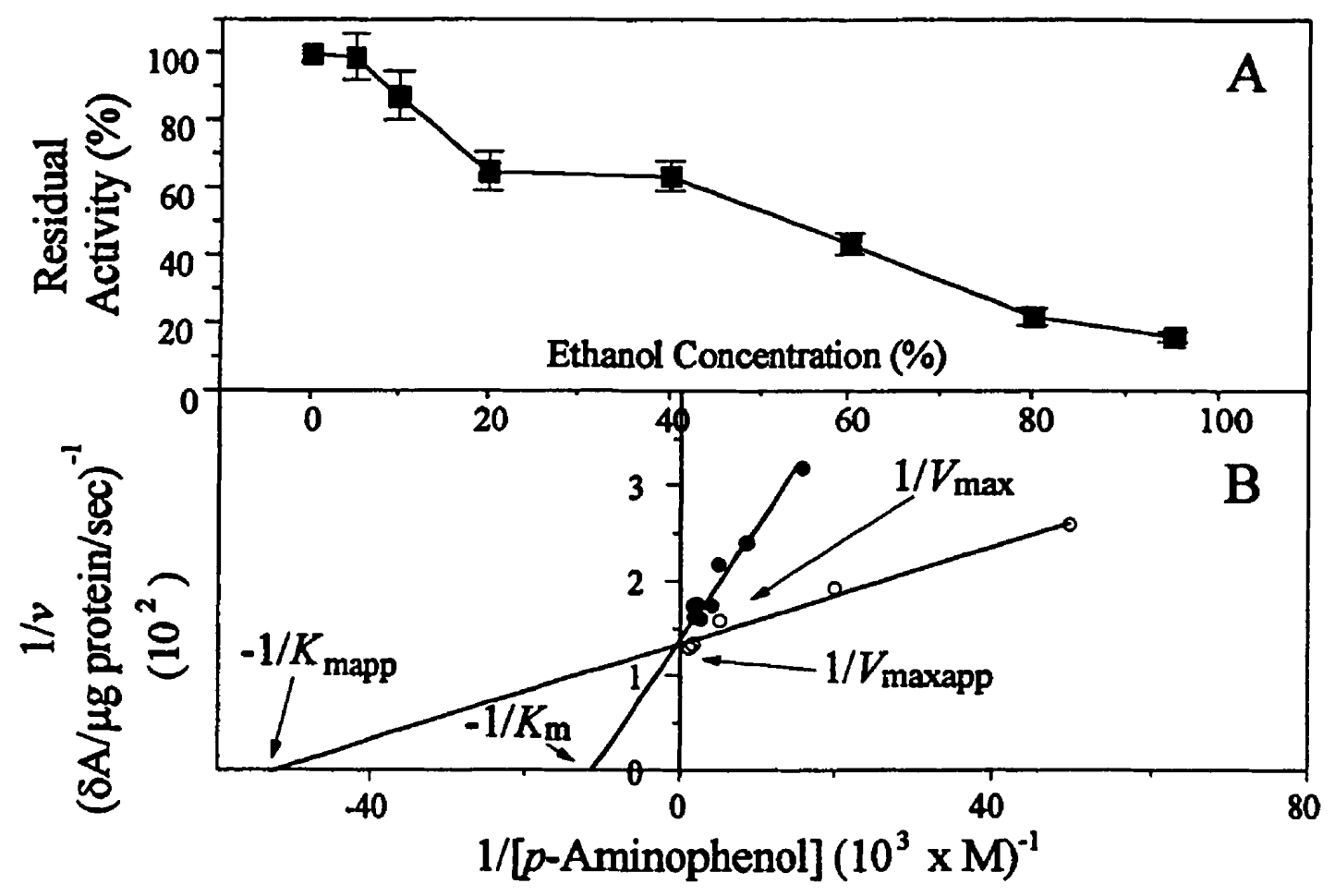

Figure 13. Effect of the presence of ethanol on tyrosinase biocatalysis in chloroform, using p-aminophenol (n-a) as substrate (A). The residual enzyme activity was defined as the percentage of the ratio of residual enzyme activity to the initial value. The Lineweaver-Burk plots of tyrosinase biocatalysis in chloroform without inhibitor (-), and with ethanol as inhibitor $(\mathrm{O}-\mathrm{O})$ (B); $40 \%$ ethanol ( $v / v)$ with $p$-aminophenol, where the initial reaction rate was defined as the change in absorbance unit at $\lambda=394 \mathrm{~nm}$ for $p$-aminophenol per $\mu \mathrm{g}$ protein per second. 
Table 3. Kinetic parameters of tyrosinase biocatalysis in chloroform with co-solvents as the inhibitor.

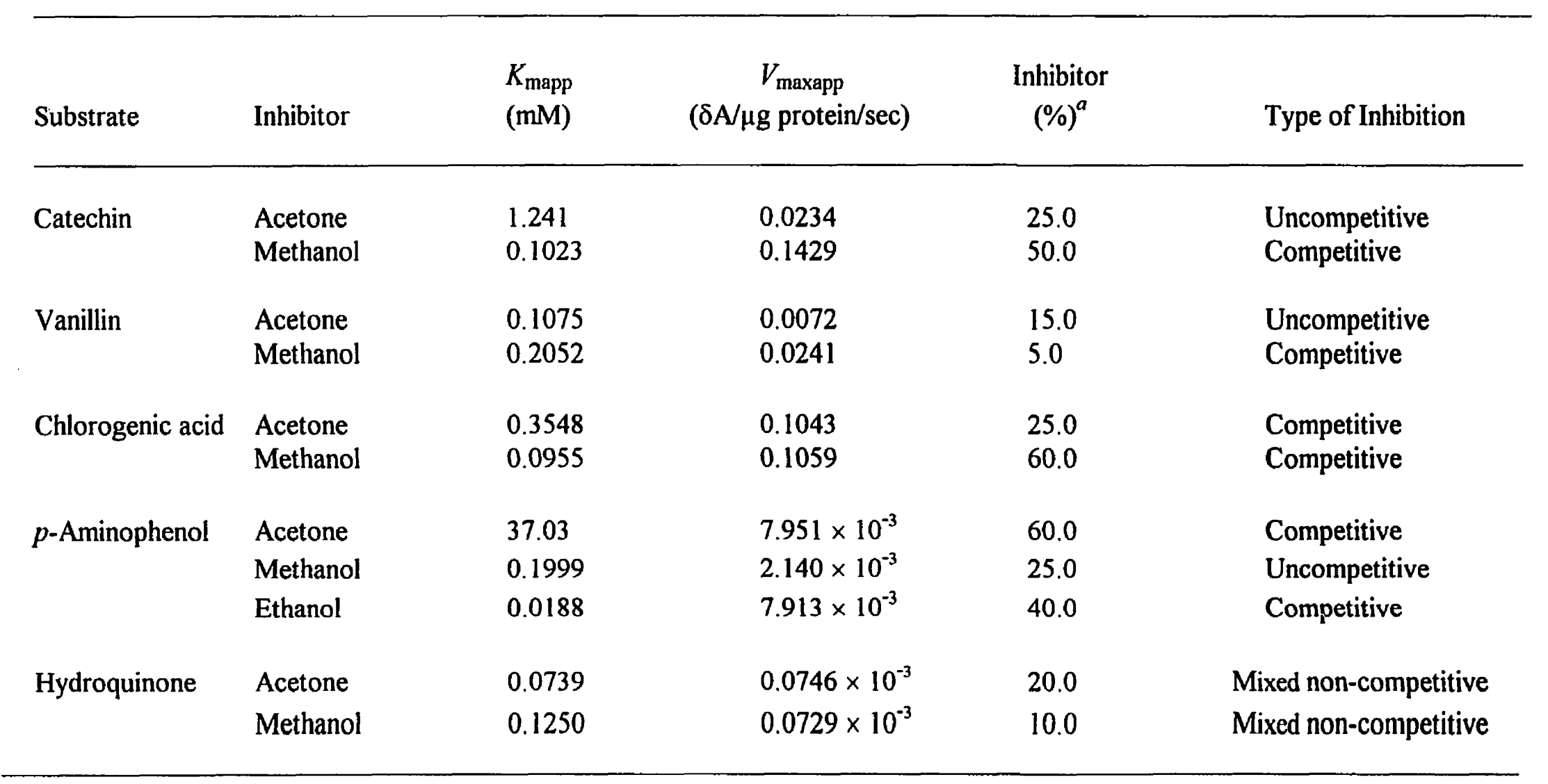

${ }^{a}$ The amount of co-solvent as the inhibitor for the determination of $V_{\text {maxapp }}$ and $K_{\text {mapp }}$ values. 


\subsubsection{Effect of Catechol on Tyrosinase Activity}

Results in Figure 14 show that although catechol was being oxidized itself, it had an activating effect on tyrosinase biocatalysis, using catechin and chlorogenic acid as substrates. The increase in catechol concentration from 0.335 to $1.25 \mathrm{mM}$ resulted in a concomitant increase in enzyme activation from 4.8 to $56.2 \%$, with catechin as substrate; however, the addition of higher amount of catechol $(4.0 \mathrm{mM})$ resulted in only $27.8 \%$ of enzyme activation. With chlorogenic acid as substrate, the increase in catechol concentration from 0 to $6.65 \mathrm{mM}$ resulted in a concomitant increase in enzyme activation from 0 to $267.2 \%$. Since catechol itself can also act as a substrate for tyrosinase, the increase in enzyme activity due to the presence of catechol alone was taken into account.

Bordner and Nelson (1939) reported that the enzymatic oxidation of L-tyrosine by polyphenol oxidase in aqueous media exhibited a lag period; these authors were able to overcome this phenomenon by using L-3,4-dihydroxyphenylalanine (L-DOPA) as an activator of tyrosinase. The elimination of the lag time may be due to the fact that L-DOPA was the immediate product of the substrate L-tyrosine and hence saturating the specific binding site on the enzyme. The lag time in tyrosinase oxidation reaction in chloroform medium, using phenol as substrate, was also reported by Estrada et al. (1991); these authors reduced the lag time by adding an enediol compound, such as catechol, as an inducer of the enzymatic reaction. Although in the present work catechol was not the immediate product of catechin enzymatic oxidation, it could still exert an activating effect. Our findings suggest that in order to activate tyrosinase biocatalysis, the activator does not have to be the immediate product of the reaction but rather must possess an enediol group.

Catechol $(0-7 \mathrm{mM})$, however, failed to show any effect on tyrosinase in chloroform when vanillin, $p$-aminophenol or hydroquinone was used as substrate. The comparison of $K_{\mathrm{m}}$ values for hydroquinone, vanillin, $p$-aminophenol and catechol indicates that the highest affinity of tyrosinase was for hydroquinone $\left(K_{\mathrm{m}}=0.0425 \mathrm{mM}\right)$, followed by that for vanillin $\left(K_{\mathrm{m}}=\right.$ $0.4125 \mathrm{mM}), p$-aminophenol $\left(K_{\mathrm{m}}=0.9495 \mathrm{mM}\right)$, and then for catechol $\left(K_{\mathrm{m}}=2.126 \mathrm{mM}\right)$. Bordner and Nelson (1939) suggested that in order for catechol to act as an activator for the tyrosinase-oxidation of $p$-cresol, the enzyme must first oxidize the $o$-dihydric phenol 


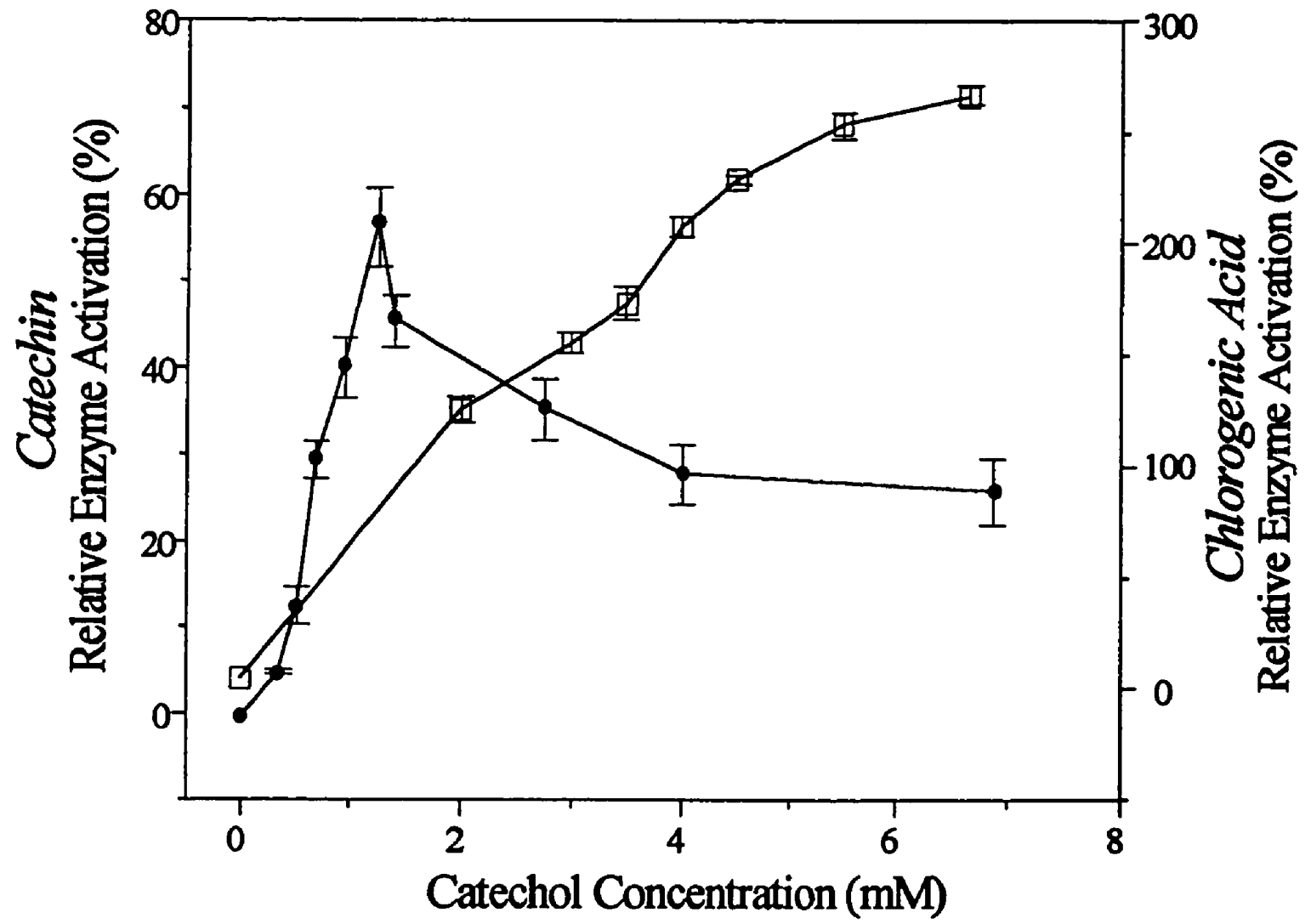

Figure 14. Effect of catechol on tyrosinase biocatalysis in chloroform, using catechin $(\bullet-)$ and chlorogenic acid $(\square-\square)$ as substrates. The percentage of activation of tyrosinase activity was defined as the increase in enzymatic activity relative to the initial value. 
(catechol in this case) before it can bring about the oxidation of mononydnc to 0 -ainyanc. ine failure of catechol to act as an activator for tyrosinase when vanillin, $p$-aminophenol or hydroquinone was used as substrate may be due to the higher enzyme affinity for the substrate rather than for catechol.

\subsubsection{Effect of EDTA on Tyrosinase Activity}

Figure 15A shows that ethylenediamine tetraacetic acid (EDTA) inhibited tyrosinase activity when catechin was used as substrate in chloroform. The decrease in residual tyrosinase activity from 92.5 to $60.1 \%$ was in concomitance with the increase of EDTA concentration from 0.90 to $6.15 \mathrm{mM}$. Likewise, EDTA had the highest enzyme inhibitory effect $(84.7 \%)$ at a concentration of $2.25 \mathrm{mM}$ when vanillin was used as substrate; however, an increase of EDTA concentration did not result in higher inhibition in enzyme activity. Similarly, EDTA exerted inhibitory effect on $p$-aminophenol; the decrease in residual tyrosinase activity from 100.0 to $33.0 \%$ was in concomitance with the increase of EDTA concentration from 0 to $5.39 \mathrm{mM}$ (Fig. 15A).

Figure 15B shows that increasing concentration of EDTA from 0.125 to $4.75 \mathrm{mM}$ activated tyrosinase activity, from $4.7 \%$ to $101.9 \%$, when chlorogenic acid was used as substrate. Similar to chlorogenic acid, EDTA activated tyrosinase when hydroquinone was used as substrate; with the maximal enzyme activation (115.9\%) by $1.60 \mathrm{mM}$ of EDTA. Additional increase in EDTA concentration up to $3.85 \mathrm{mM}$ decreased the enzyme activation to only $43.1 \%$ (Fig. 15B). These findings, using chlorogenic acid and hydroquinone as substrates, are in contrast to the effect of EDTA on tyrosinase activity in chloroform medium, using catechin, vanillin and p-aminophenol as substrates.

Results in Figure 16 show that EDTA exerted inhibitory effect on tyrosinase activity in aqueous solution for all the substrates. For catechin, the enzyme inhibition increased from 0 to $35.7 \%$ steadily with increasing EDTA concentration from 0 to $1.30 \mathrm{mM}$; when vanillin was used as substrate, the residual enzyme activity decreased from 100 to $25.5 \%$ with increasing concentration of EDTA from 0 to $1.35 \mathrm{mM}$. For chlorogenic acid, the residual enzyme activity decreased from 100.0 to $65.4 \%$ steadily with increasing EDTA concentration from 0 to 1.43 


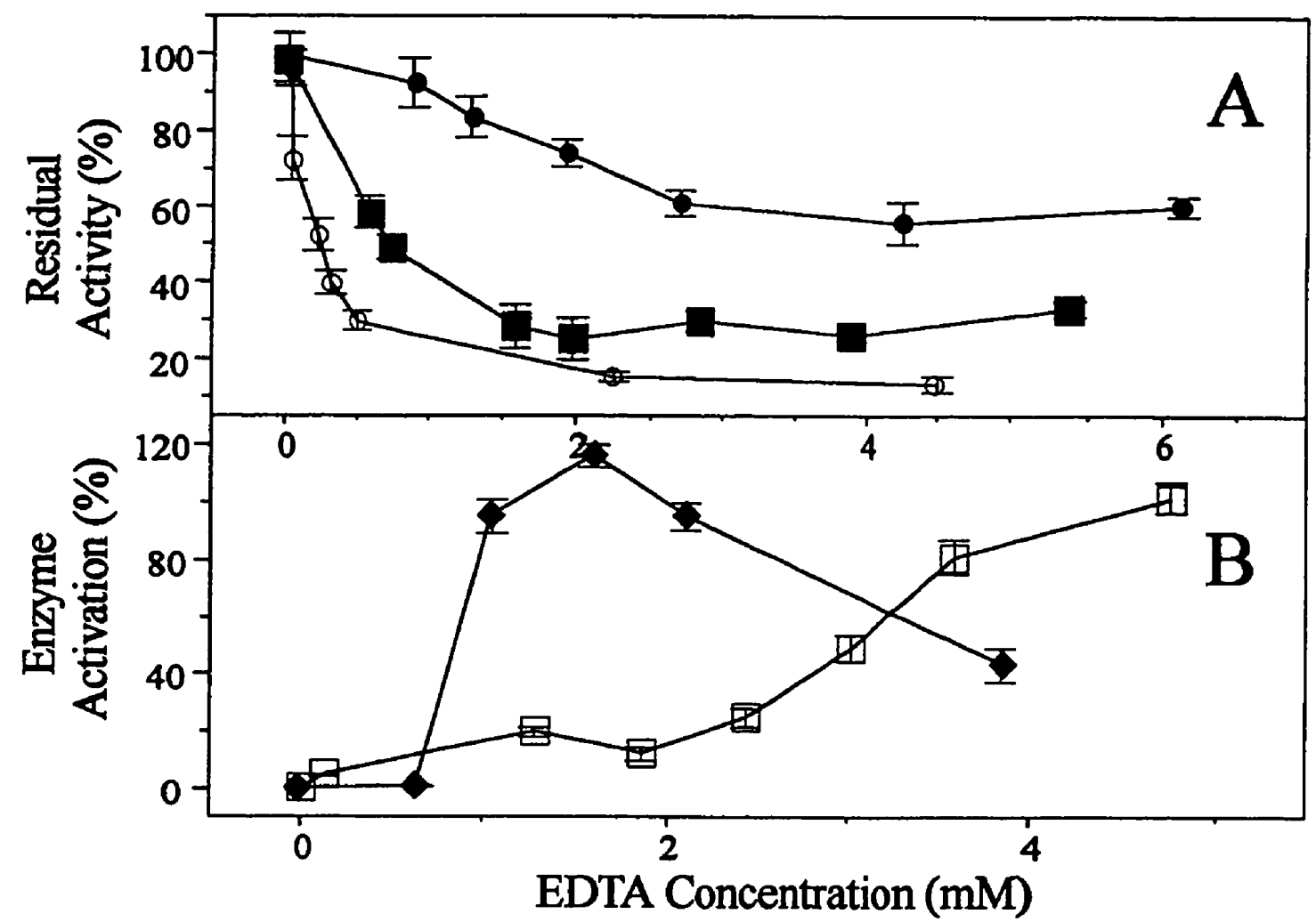

Figure 15. Effect of EDTA on tyrosinase biocatalysis in chloroform, using catechin ( $\bullet \bullet)$, vanillin $(\mathrm{O}-\mathrm{O})$, p-aminophenol ( $-\square)(\mathrm{A})$, chlorogenic acid $(\square-\square)$ and hydroquinone (- ) as substrates (B). The residual enzyme activity was defined as the percentage of the ratio of residual enzyme activity to the initial value and the percentage of activation of tyrosinase activity was defined as the increase in enzymatic activity relative to the initial value. 


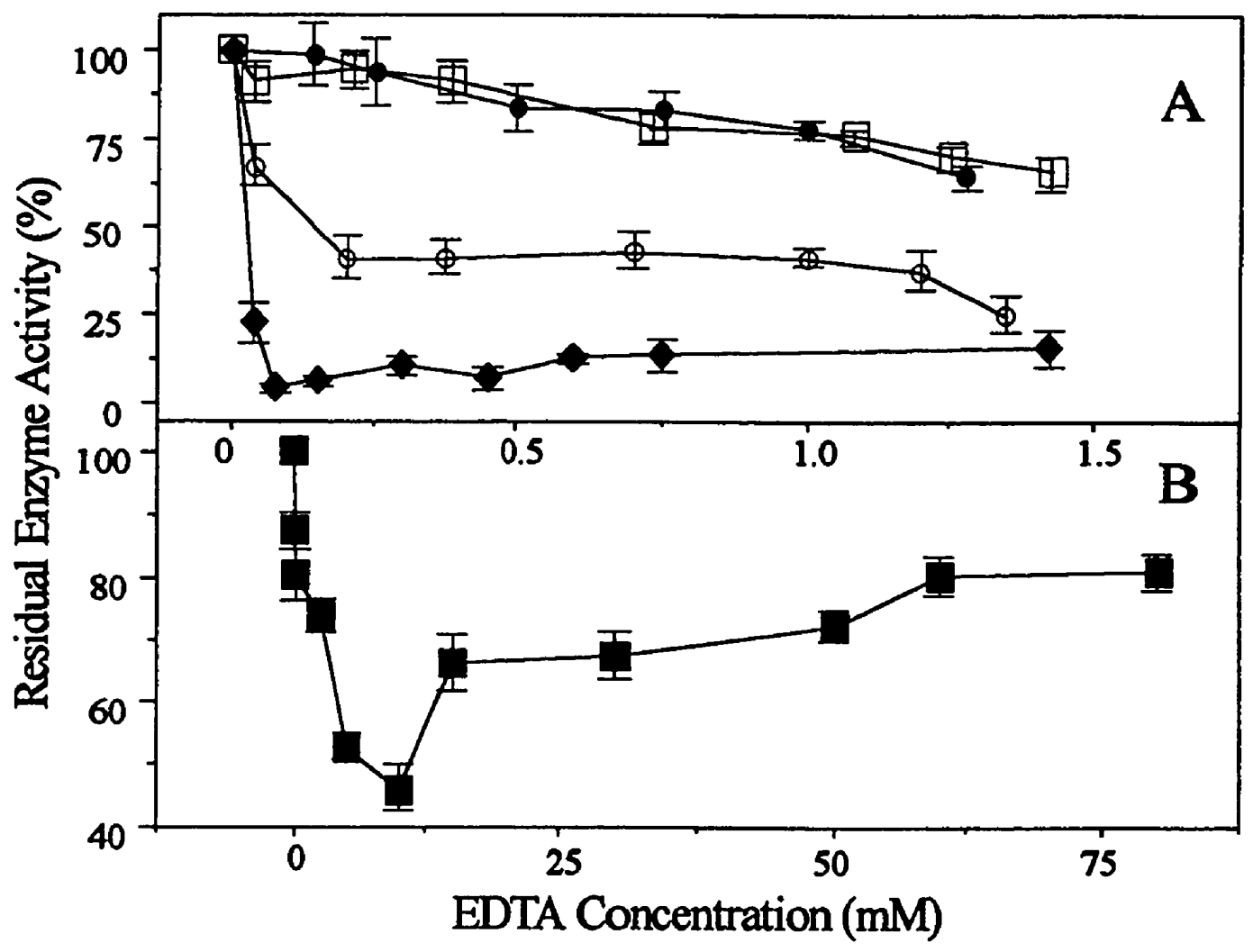

Figure 16. Effect of EDTA on tyrosinase biocatalysis in aqueous medium, using catechin $(\bullet-\bullet)$, vanillin $(\mathrm{O}-\mathrm{O})$, chlorogenic acid $(\square-\square)$, hydroquinone $(\diamond-\diamond)$ (A) and $p$-aminophenol (n- as substrates (B). The residual enzyme activity was defined as the percentage of the ratio of residual enzyme activity to the initial value. 
of $10.0 \mathrm{mM}$ maximally inhibited tyrosinase where the lowest residual enzyme activity was $46.4 \%$. Increasing EDTA concentration decreased and stabilized the enzyme activity to approximately $80.0 \%$ (Fig. 16B). With hydroquinone as substrate, the residual enzyme activity steadily decreased from $100.0 \%$ to $15.7 \%$ with the increasing concentration of EDTA from 0 to $1.43 \mathrm{mM}$ (Fig. 16A). Results in Figures 16A and 16B show clearly that for all the five substrates, EDTA exerted significant inhibitory effect on tyrosinase activity in aqueous media. It is believed that tyrosinase possesses copper at its active site (Lerch, 1987). EDTA might have exerted the inhibitory effect on tyrosinase via copper chelation.

\subsubsection{Use of Acetone for Quenching Enzymatic Reaction}

Due to the insolubility of the colored end-products of tyrosinase oxidation in chloroform, acetone was used to solubilize the end-products and to quench the enzymatic reaction. Figure 17 shows that the addition of acetone at $24.5 \%(\mathrm{v} / \mathrm{v})$ resulted in minimal residual enzyme activity (61.4\%) when catechin was used as substrate; however, for vanillin, $20.0 \%$ acetone resulted in $50.9 \%$ enzyme activity. For chlorogenic acid, the addition of acetone at $25.9 \%(\mathrm{v} / \mathrm{v})$ resulted in $47.9 \%$ of enzyme activity; whereas for p-aminophenol, the use of $24.52 \%$ acetone resulted in $20.9 \%$ enzyme activity. For hydroquinone, the use of $24.53 \%$ acetone resulted in $18.8 \%$ enzyme activity. The use of additional amounts of acetone did not result in any further inhibition, but rather lower its inhibitory effect. These findings suggest that the amount of water bound to the enzyme (measured as the water content), may "interfere" with the acetone inhibitory effect. Results in Figure 18A show that with catechin as substrate, the enzyme inhibition at $0.65 \%$ water content was 11 -fold higher than that at $0.50 \%$ water content at $54.5 \%$ acetone; while in the case of vanillin, the enzyme inhibition at $0.65 \%$ water content was almost 93 -fold higher than that at $0.50 \%$ water content at $33.3 \%$ acetone. With chlorogenic acid as substrate, the enzyme inhibition at $0.65 \%$ water content was 3 -fold higher than that at $0.35 \%$ water content at $29.8 \%$ acetone; while in the case of p-aminophenol, the enzyme inhibition at $2.5 \%$ water content was almost 1.2 -fold higher than that at $1.0 \%$ water content at $29.82 \%$ acetone. For hydroquinone, the enzyme inhibition at $2.0 \%$ water content was 10 -fold higher than at $0.75 \%$ at $23.08 \%$ acetone. 


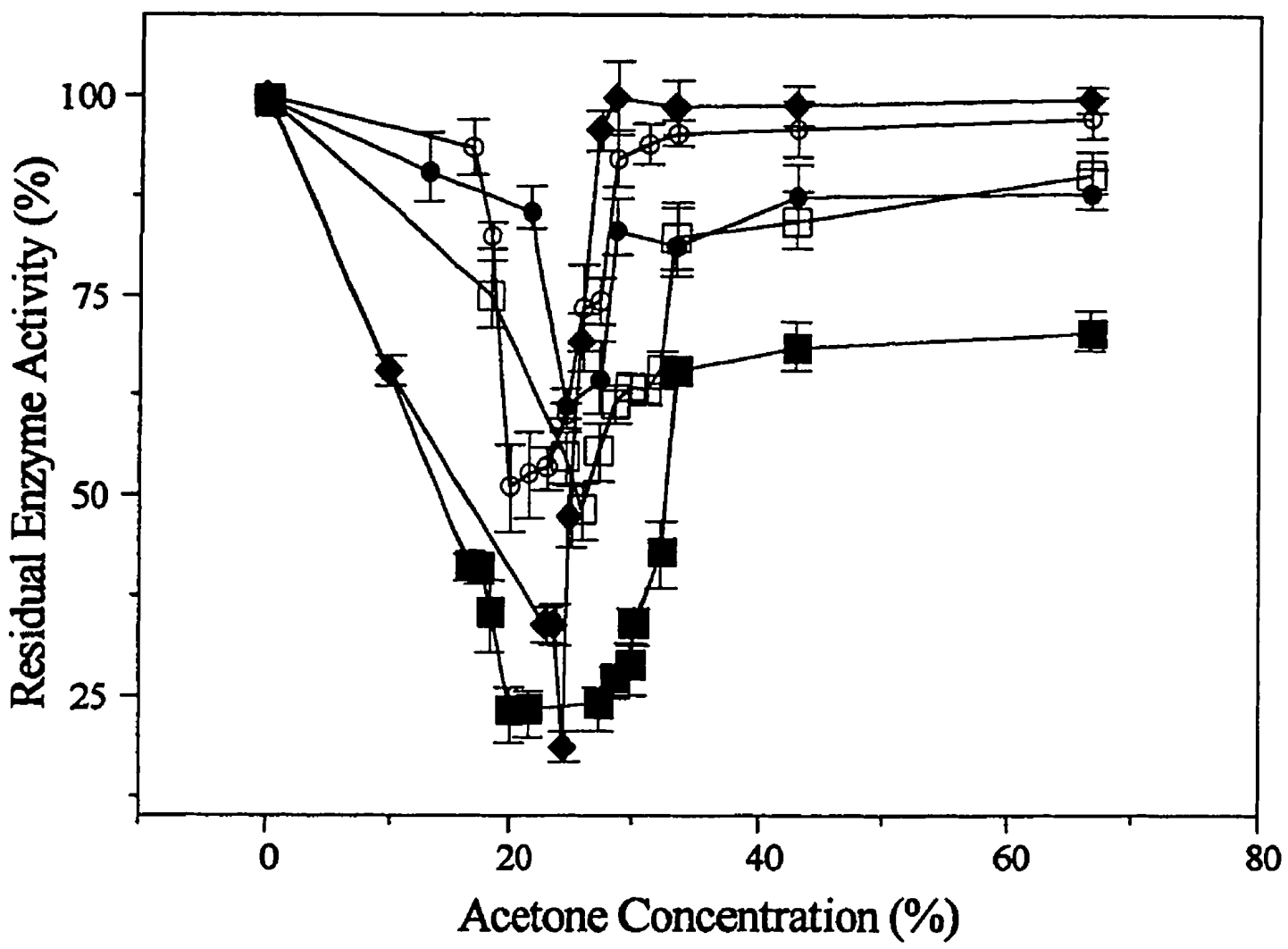

Figure 17. Use of acetone for quenching the enzymatic reaction, using catechin (-), vanillin ( $\mathrm{O}-\mathrm{O})$, chlorogenic acid $(\square-\square), p$-aminophenol $(\square-\square)$ and hydroquinone $(-)$ as substrates. The residual enzyme activity was defined as the percentage of the ratio of residual enzyme activity to the initial value. 


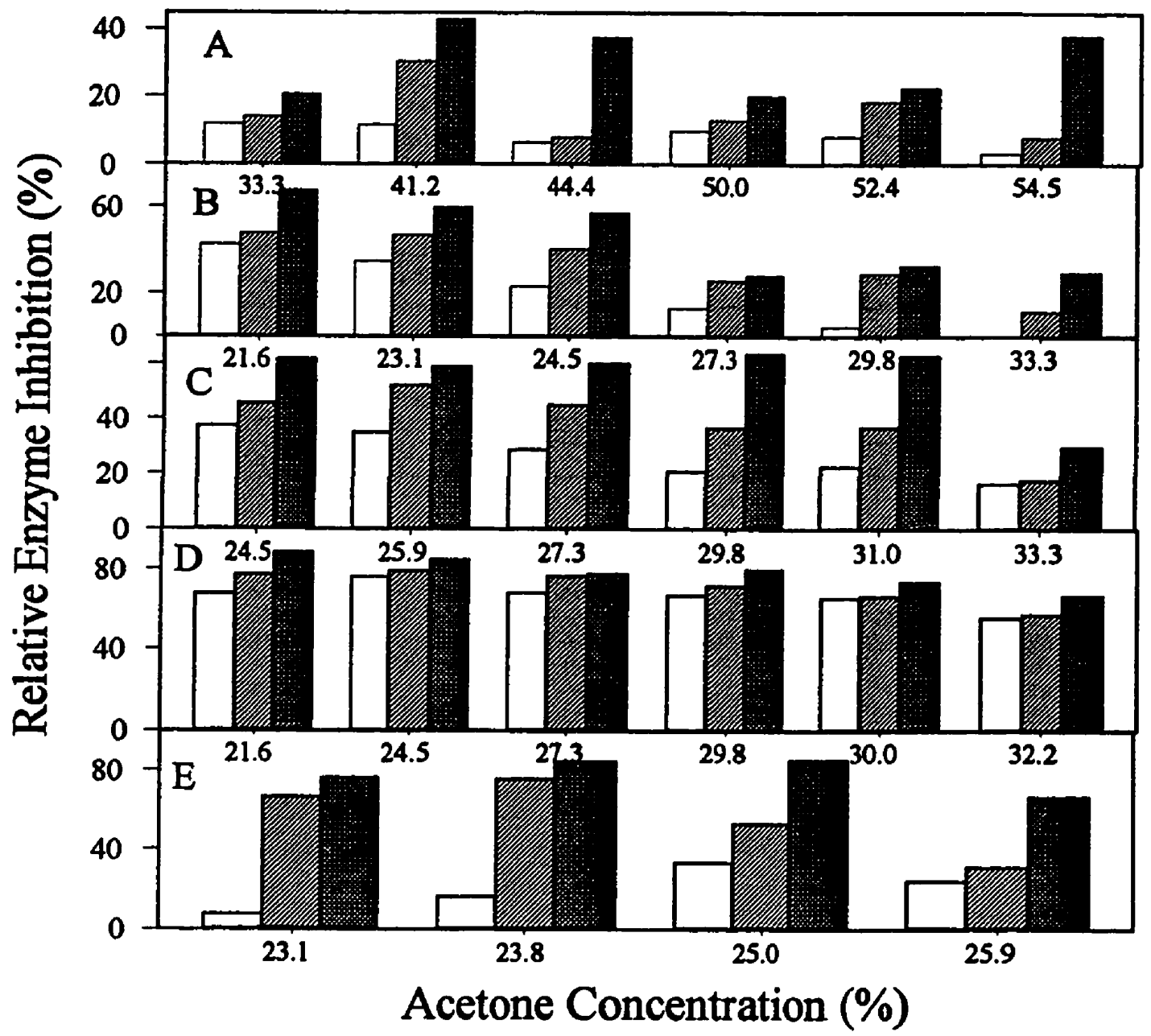

Figure 18. Tyrosinase inhibition by acetone at different water contents in chloroform reaction mixture: ( $\square$ ); ( and the highest water contents, respectively, using catechin (A) and vanillin (B) $(0.50,0.55$ and $0.65 \%$ water content), chlorogenic acid (C) $(0.35,0.45,0.65 \%$ water content), p-aminophenol (D) (1.0, 2.0 and $2.5 \%$ water content) and hydroquinone (E) $(0.75,1.0$ and $2.0 \%)$ as substrates. The percentage of inhibition of tyrosinase activity was defined as the decrease in enzymatic activity relative to the initial value. 
These results demonstrate that among tyrosinase preparations at different amount of water content, acetone demonstrated its highest inhibitory effect at highest \% water content while the least inhibition occurred with minimally hydrated enzyme.

\subsection{Characterization}

\subsubsection{Fourier Transform Infrared (FT-IR) Spectroscopy Study}

\subsubsection{Tyrosinase}

In aqueous environment of deuterium oxide $\left(D_{2} O\right)$, the FT-IR spectrum (Fig. 19) shows that tyrosinase exhibits a secondary structure which is predominately $\alpha$-helical in nature as indicated by the presence of a strong band at $1651 \mathrm{~cm}^{-1}$. A second band at $1640 \mathrm{~cm}^{-1}$ of comparable intensity may be attributed to the presence of a $3_{10}$ helix or turns (Susi and Byler, 1986; Surewicz et al., 1993). Two bands at 1614 and $1584 \mathrm{~cm}^{-1}$ may be attributed to side chain absorptions of arginine, while the band at $1515 \mathrm{~cm}^{-1}$ is assigned to tyrosine side chains. The band at $1550 \mathrm{~cm}^{-1}$ is assigned to the amide $\mathrm{I}$ band of non-exchanged amide $\mathrm{N}-\mathrm{H}$ groups. Likewise, the ATR/FT-IR spectrum of mushroom tyrosinase deposited as a dried film (after the complete evaporation of chloroform) on the ATR crystal shows prominent peaks at 1515, 1543, 1635 and $1651 \mathrm{~cm}^{-1}$, suggesting that the enzyme is mainly composed of $\beta$-sheet structure (figure not shown). Specifically, the peaks at 1635 and $1651 \mathrm{~cm}^{-1}$ demonstrate the existence of amide $\Gamma$ group whereas that at $1543 \mathrm{~cm}^{-1}$ indicating the presence of amide II group in the protein structure in chloroform environment. The peak at $1515 \mathrm{~cm}^{-1}$ also suggests the presence of tyrosine in the enzyme structure. Similarly, Klibanov et al. (1995) also reported a general pattern of enzyme conformation; upon protein dehydration (e.g. lyophilization), the $\alpha$-helix content drops with a concomitant increase in $\beta$-sheet conformation.

Figure 19 also shows the deconvoluted spectra of tyrosinase at different temperatures. Above $40^{\circ} \mathrm{C}$, the secondary structure of the protein begins to change with increasing temperature while at $45^{\circ} \mathrm{C}$ a new band at $1616 \mathrm{~cm}^{-1}$ appears and its intensity increases with time. The 1616 $\mathrm{cm}^{-1}$ band has been previously attributed to protein-protein aggregate formation (Holzbaur et al., 1996). Figures $20 \mathrm{~A}$ and $20 \mathrm{~B}$ show a plot of the increase in the intensity of the $1616 \mathrm{~cm}^{-1}$ band (aggregation band) as a function of time at a constant temperature of $45^{\circ} \mathrm{C}$ along with the 
seen to parallel the rate of decrease of the intensity of the amide $\boldsymbol{I}$ band. These findings suggest that as the protein began to unfold, hidden N-H groups buried within the protein were exposed to the solvent, and these groups rapidly underwent hydrogen-deuterium exchange, which resulted in the decrease in the intensity of the amide II band at $1550 \mathrm{~cm}^{-1}$. The unfolded protein underwent self-aggregation, forming a strong intermolecular hydrogen bonding network with $\beta$-sheet structure which has a characteristic amide I band at $1616 \mathrm{~cm}^{-1}$ (Holzbaur et al., 1996).

\subsubsection{Phenolic Substrates}

\section{(i) Catechin}

The FT-IR spectrum (Fig. 21A) of the substrate catechin shows peaks at 1550 and 1600 $\mathrm{cm}^{-1}$ due to the aromatic carbon double bonds in the catechin structure. The new peak at 1700 $\mathrm{cm}^{-1}$ in the spectrum of the catechin end-products formed in aqueous (Fig. 21B) and chloroform media (Fig. 21C) may be due to the carbonyl group of the quinone end-products. The presence of the 1550 and $1600 \mathrm{~cm}^{-1}$ bands in the spectrum of the end-products formed in aqueous and chloroform media is indicative of the presence of some residual substrate.

\section{(ii) Vanillin}

The FT-IR spectrum of the substrate vanillin (Fig. 22A) shows peaks at 1505 and 1583 $\mathrm{cm}^{-1}$ which are assigned to aromatic ring vibrations, as well as a strong band at $1660 \mathrm{~cm}^{-1}$, corresponding to the aldehyde function; two weak bands at 2737 and $2831 \mathrm{~cm}^{-1}$, attributed to an aldehydic C-H stretching vibration were also observed. The appearance of new peaks at 1709 and $1703 \mathrm{~cm}^{-1}$ in the spectrum of the vanillin end-products formed in aqueous (Fig. 22B) and chloroform media (Fig. 22C), respectively, may be due to the carbonyl group of the quinone structure. The absence of all the peaks characteristic of the substrate in the spectrum of the vanillin end-products formed in both aqueous and chloroform media indicates that the depletion of vanillin almost reached its completion. However, the absence of any absorptions from the aldehydic function may be indicative of the possibility that the end-products were unstable and 


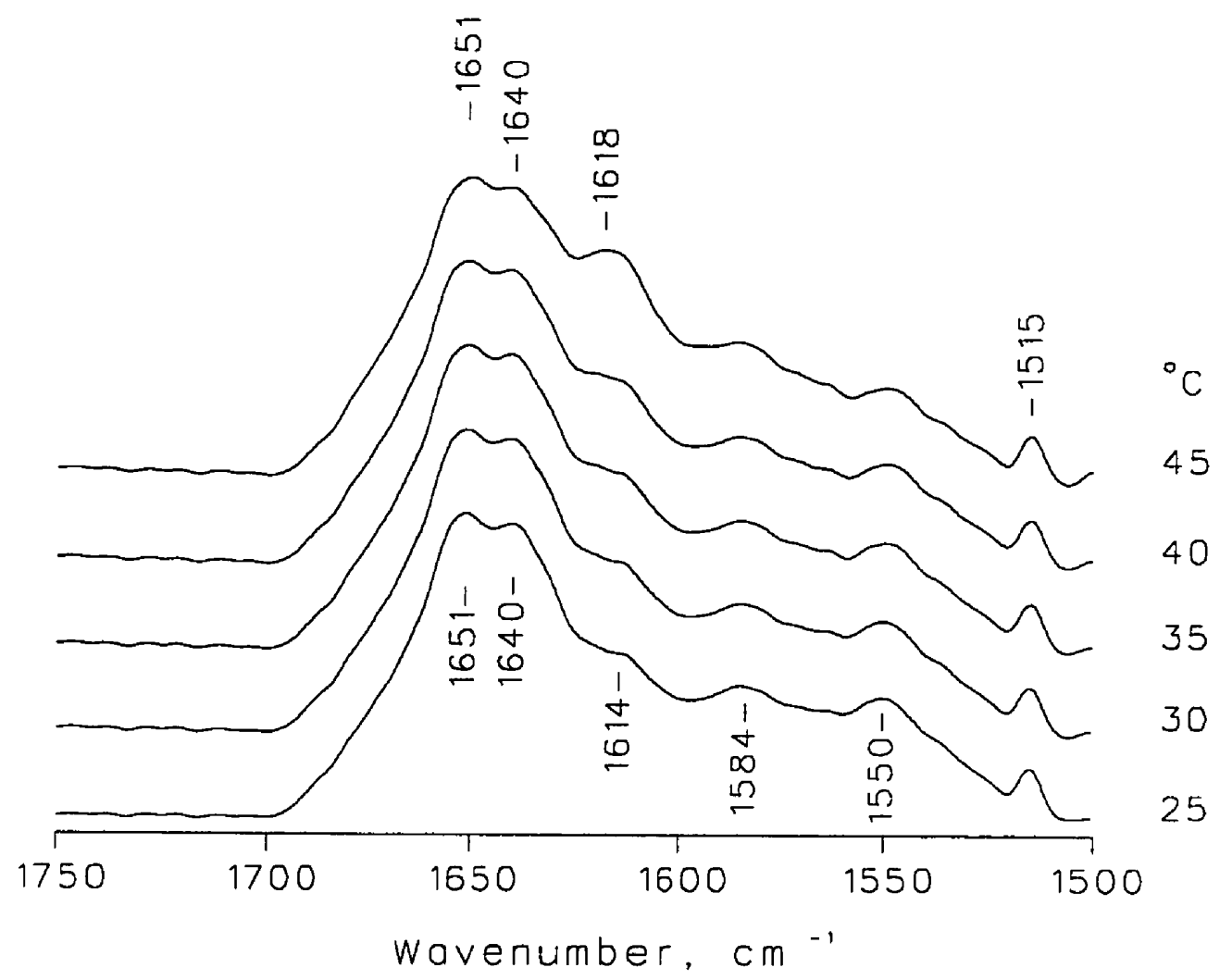

Figure 19. Stacked plot of deconvoluted spectra of tyrosinase in $\mathrm{D}_{2} \mathrm{O}$ in the amide $\mathrm{I}^{\prime}$ region as a function of temperature. Deconvolution was performed with a bandwidth of $13 \mathrm{~cm}^{-1}$ and a $\mathrm{k}$ factor of 2.4 . 


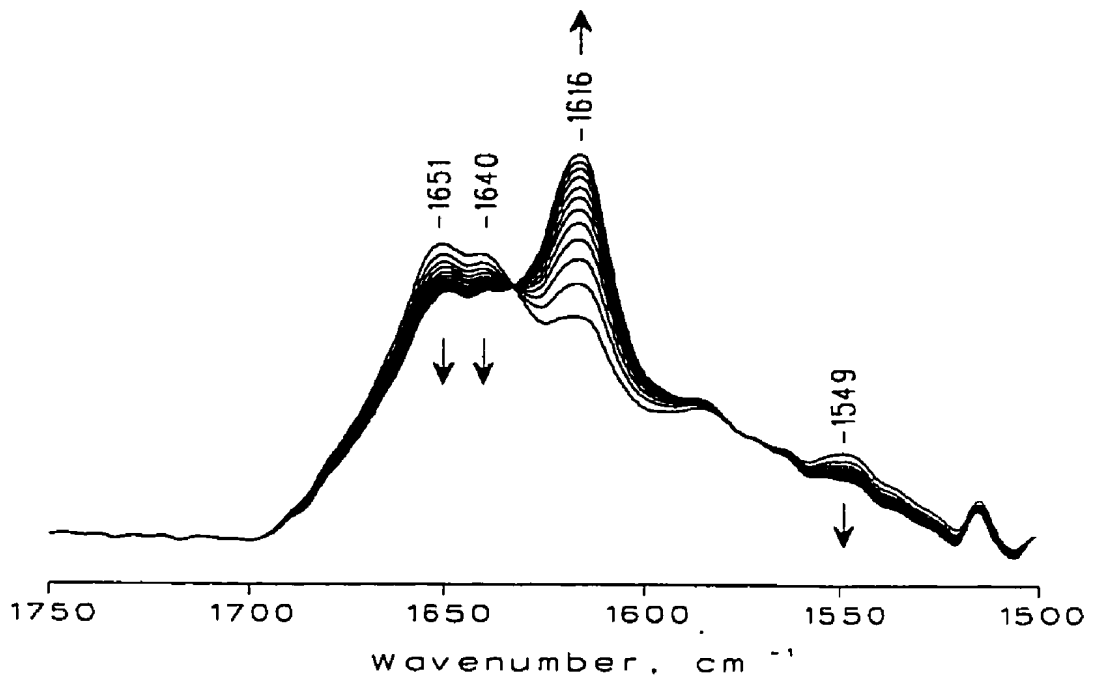

B

$$
\text { (•) } 1618 \mathrm{~cm}^{-1} \quad(+) 1550 \mathrm{~cm}^{-1}
$$

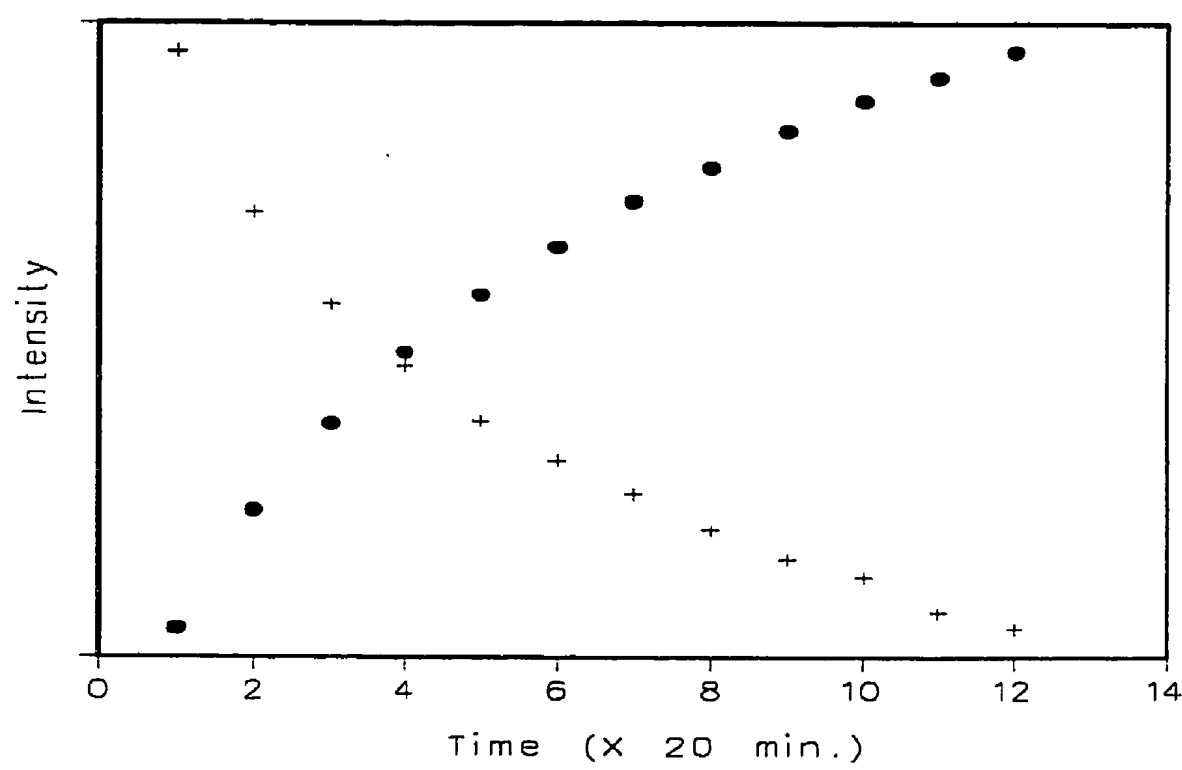

Figure 20. Overlaid spectra of the amide I' band of tyrosinase in $\mathrm{D}_{2} \mathrm{O}$ at $45^{\circ} \mathrm{C}(\mathrm{A})$ and plots of the increase in the intensity of the $1616 \mathrm{~cm}^{-1}(\bullet)$ and the decrease in the intensity of the $1550 \mathrm{~cm}^{-1}(+)$ bands as a function of time (B). 


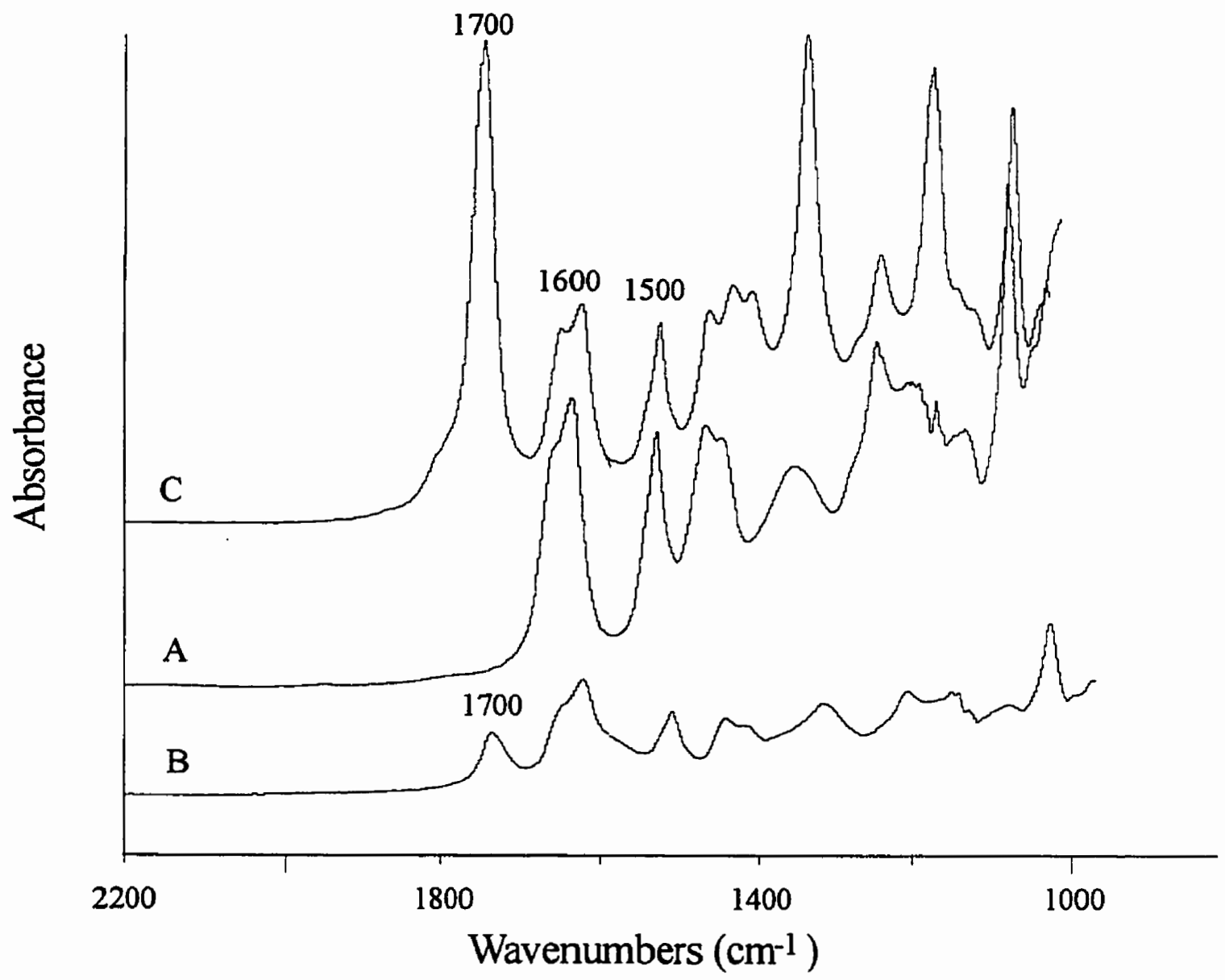

Figure 21. ATR/FT-IR spectra of dry films deposited onto the ATR crystal of the catechin substrate (A), and the enzymatic end-products of tyrosinase biocatalysis in aqueous (B) and chloroform media (C). 


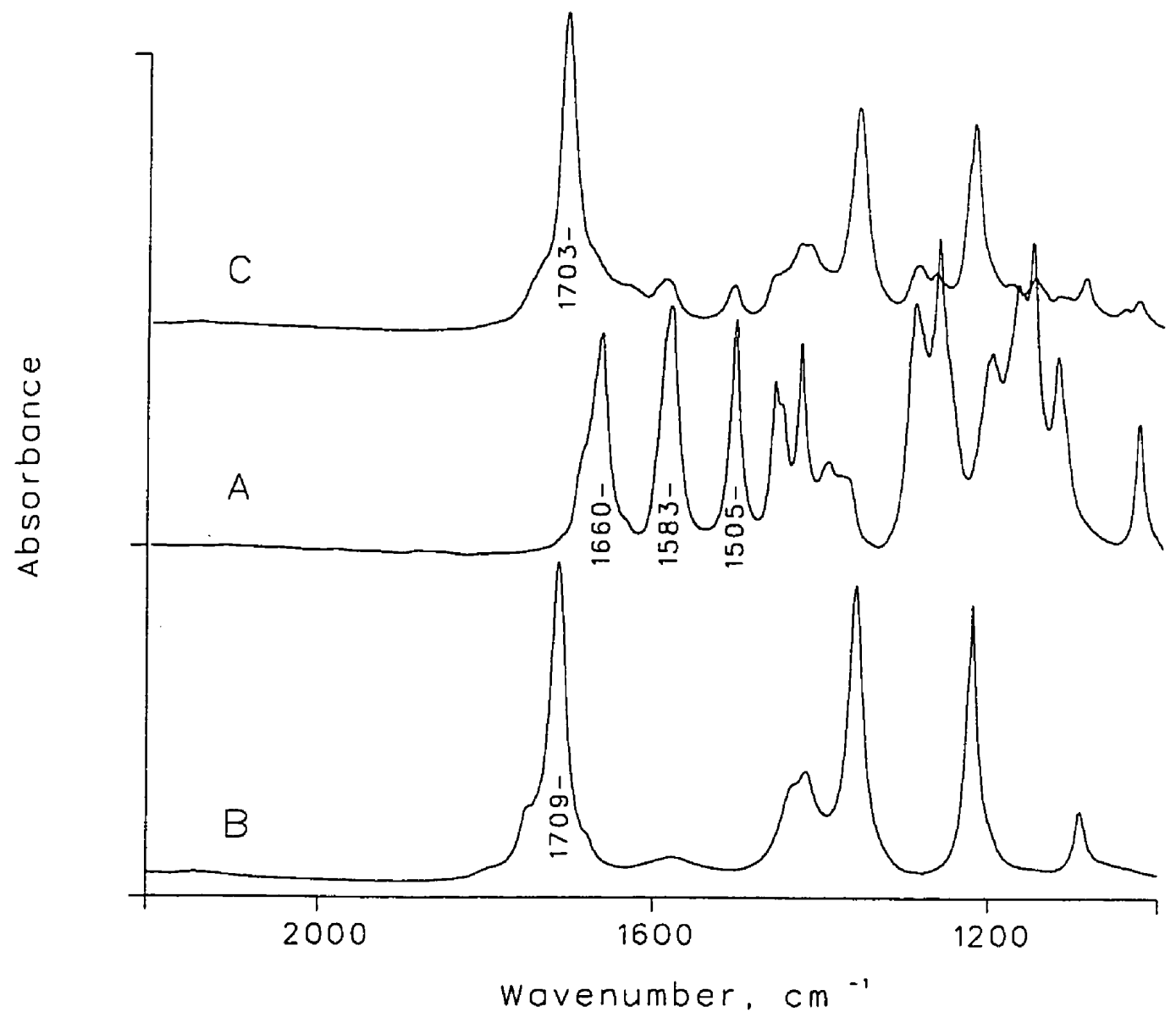

Figure 22. ATR/FT-IR spectra of dry films deposited onto the ATR crystal of the vanillin substrate (A), and the enzymatic end-products of tyrosinase biocatalysis in aqueous (B) and chloroform media (C). 


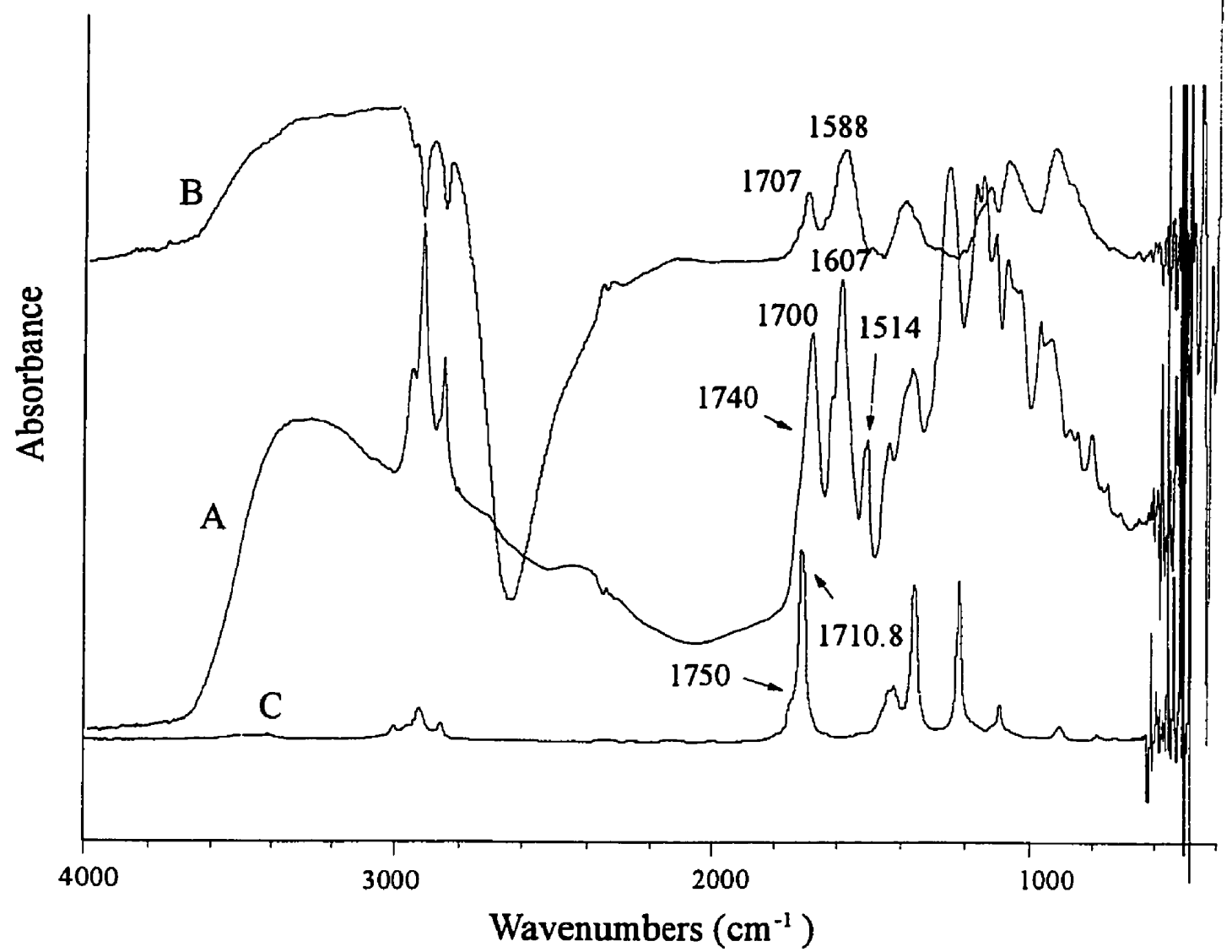

Figure 23. ATR/FT-IR spectra of dry films deposited onto the ATR crystal of the chlorogenic acid substrate (A), and the enzymatic end-products of tyrosinase biocatalysis in aqueous (B) and chloroform media (C). 


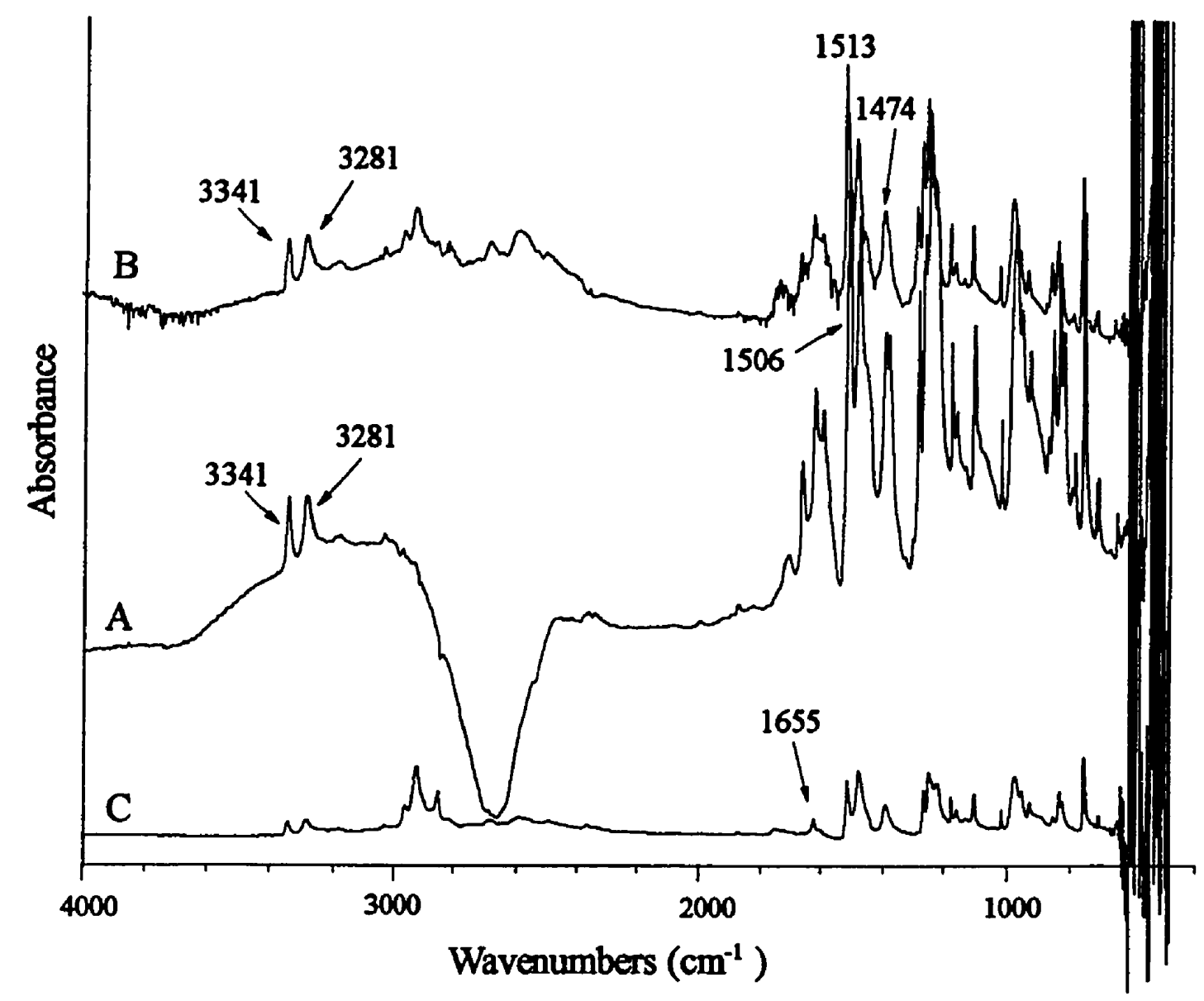

Figure 24. ATR/FT-IR spectra of dry films deposited onto the ATR crystal of the paminophenol substrate (A), and the enzymatic end-products of tyrosinase biocatalysis in aqueous (B) and chloroform media (C). 


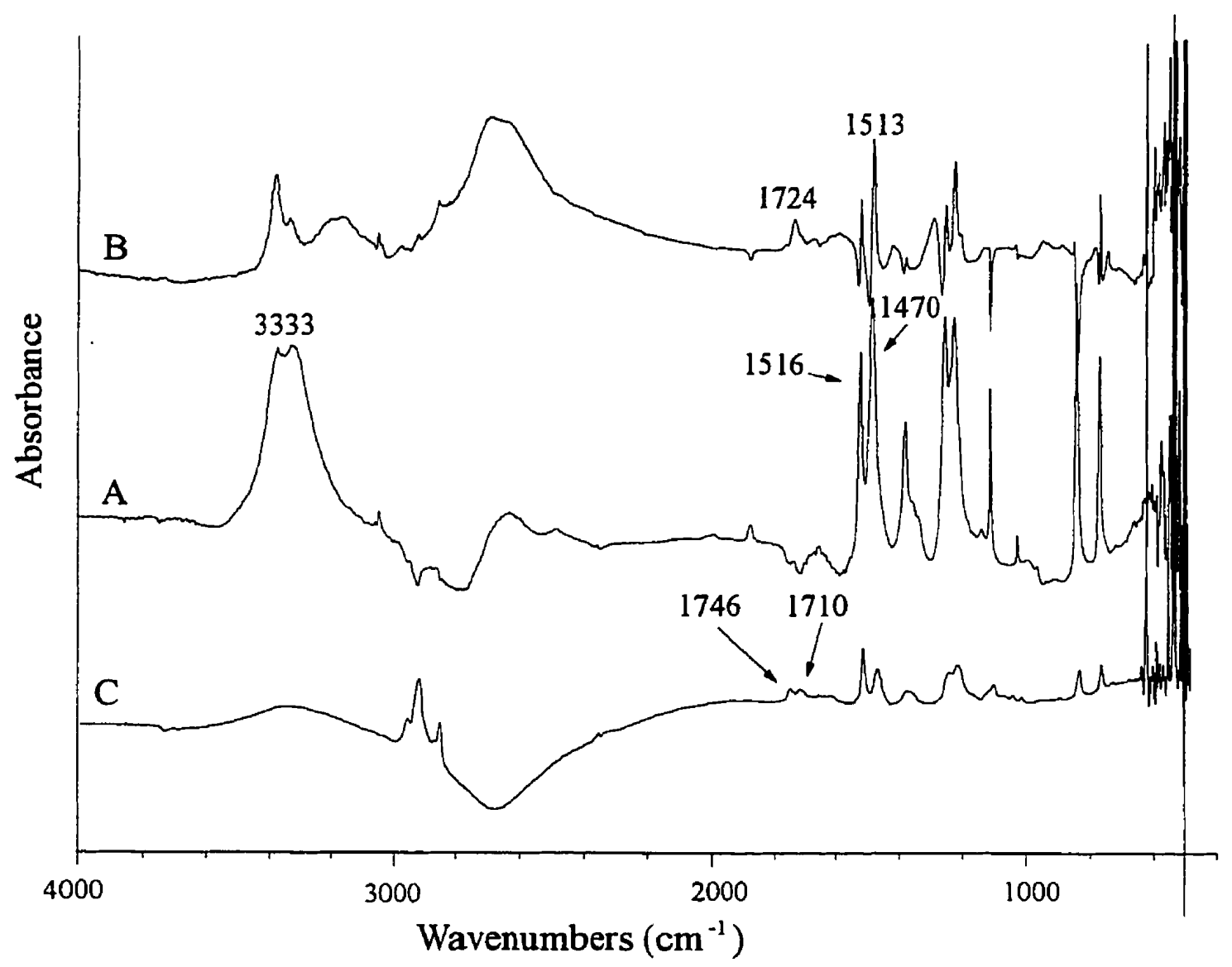

Figure 25. ATR/FT-IR spectra of dry films deposited onto the ATR crystal of the hydroquinone substrate (A), and the enzymatic end-products of tyrosinase biocatalysis in aqueous (B) and chloroform media (C). 
underwent decomposition. For example, the end-products o-quinones can react with anothermolecule of the parent phenol, leading to the formation of dimers. These dimers have been suggested to undergo further oxidation, yielding larger oligomers with different color intensities (Singleton, 1987; Rouet-Mayer et al., 1990).

\section{(iii) Chlorogenic Acid}

The FT-IR spectrum (Fig. 23A) of the substrate chlorogenic acid shows peak at 1514 $\mathrm{cm}^{-1}$ which was due to the phenolic $\mathrm{OH}$ vibrations, whereas that at $1607 \mathrm{~cm}^{-1}$ corresponded to the vibrations of the aromatic carbon double bonds in the benzene ring of the substrate structure. The peak at $1700 \mathrm{~cm}^{-1}$ was due to the acid group $(-\mathrm{COOH})$ while that at $1740 \mathrm{~cm}^{-1}$ may be due to the ester group in the structure. The new peak at $1707 \mathrm{~cm}^{-1}$ in the spectrum of the chlorogenic acid end-products formed in aqueous medium (Fig. 23B) may be due to the diketone functional group in the product while the peak at $1588 \mathrm{~cm}^{-1}$ might be due to the $\mathrm{C}=\mathrm{C}$ bond in the structure. Figure $23 \mathrm{C}$ shows the spectrum of the chlorogenic acid product formed in chloroform; the peak at $1750 \mathrm{~cm}^{-1}$ could be due to the diketone group of the $o$-quinone product whereas that at 1710.8 $\mathrm{cm}^{-1}$ might be due to the acid group of the cyclohexane ring. In addition, the absence of the peak at $1514 \mathrm{~cm}^{-1}$ in the spectrum of the chlorogenic acid products formed in chloroform (Fig. 23C) suggests that the mass transfer in chloroform almost went to completion. However, the absence of the peak at 1607 and $1740 \mathrm{~cm}^{-1}$, which are due to the ester group and the $\mathrm{C}=\mathrm{C}$ bond vibrations, in the spectrum of the end-products (Fig. 23C) implies that no benzene ring and ester groups were present in the end-products, suggesting that decomposition might have occurred upon the formation of end-products.

\section{(iv) p-Aminophenol}

The FT-IR spectrum (Fig. 24A) of the substrate p-aminophenol shows peaks at $1506 \mathrm{~cm}^{-1}$ due to the phenolic $\mathrm{OH}$ vibrations in the structure. The peaks at 3341 and $3281 \mathrm{~cm}^{-1}$ were due to the amine group. The presence of the peak at $1513 \mathrm{~cm}^{-1}$ which might have been due to the phenolic $\mathrm{OH}$ vibrations suggests that the bioconversion in aqueous medium was not quantitative (Fig. 24B). The new peak at $1655 \mathrm{~cm}^{-1}$ in the spectrum of the p-aminophenol end-products formed in chloroform (Fig. 24C) may be due to the imine functional group which might have 
been produced trom the interaction of the carbonyl group of the o-quinone product with the amine group of the parent substrate since $o$-quinones are known for its instability.

\section{(v) Hydroquinone}

The peak at $3333 \mathrm{~cm}^{-1}$ of the spectrum of hydroquinone was due to the $\mathrm{OH}$ group in the benzene ring whereas those at 1516 and $1470 \mathrm{~cm}^{-1}$ were due to the phenolic $\mathrm{OH}$ group and $\mathrm{C}=\mathrm{C}$ group in the benzene ring, respectively (Fig. 25A). Figure 25B shows the peak at $1724 \mathrm{~cm}^{-1}$ which might be due to diketone group in the products formed in aqueous medium whereas the presence of the peak at $1513 \mathrm{~cm}^{-1}$ suggests the existence of $\mathrm{OH}$ group in the structure of the endproducts. The two peaks at 1710 and $1746 \mathrm{~cm}^{-1}$ in the spectrum of the end-products formed in chloroform (Fig. 25C) show the presence of the diketone group, providing strong evidence that the $o$-quinone products were formed.

\subsubsection{High Performance Liquid Chromatography (HPLC) Analyses}

\subsubsection{HPLC Scanning of Phenolic Substrates}

The UV maximum absorbance of the five selected phenolic substrates were measured by the diode array. The results (Table 4) indicate that catechin exhibited two specific maxima absorbance $\left(\lambda_{\max }\right)$ at 204 and $278 \mathrm{~nm}$, whereas vanillin demonstrated four specific $\lambda_{\max }$ 's at 206 , 230, 280 and $308 \mathrm{~nm}$. For chlorogenic acid, three specific $\lambda_{\max }$ 's were shown, 216, 240 and 324 $\mathrm{nm}$ whereas that of $p$-aminophenol were 234 and $300 \mathrm{~nm}$ and that of hydroquinone were 222 and $288 \mathrm{~nm}$. Kermasha et al. (1995) reported that the $\lambda_{\max }$ 's for catechin were 241 and $278 \mathrm{~nm}$ whereas those of chlorogenic acid were 246, 304 and $325 \mathrm{~nm}$. On the basis of these findings, one wavelength absorbance of each substrate was selected for the HPLC analyses. The wavelength absorbance chosen were 278, 308, 324, 298 and $288 \mathrm{~nm}$ for catechin, vanillin, chlorogenic acid, $p$-aminophenol and hydroquinone, respectively.

\subsubsection{UV Detection of Phenolic Substrates and Their Bioconversion}

Figure 26 demonstrates the HPLC chromatograms of the phenolic substrates using UV detection. Table 4 shows the retention time as well as the maxima absorbance of each phenolic substrate. The overlaid HPLC chromatograms showing the bioconversion of the five substrates 
during the biocatalysis are presented in Figure $2 \%$. The results show a signincant decrease in ine height of the substrate peak, implying high bioconversion by tyrosinase in chloroform. Figure 28A demonstrates the extent of substrate bioconversion at various reaction time during tyrosinase biocatalysis; it is apparent that for all the substrates, the maximal substrate bioconversion occurred within the first $10 \mathrm{sec}$ of the reaction after which the reaction slowed down and reached the equilibrium. For catechin, $94.4 \%$ of the total substrate utilization was completed within the first $10 \mathrm{sec}$ of the reaction whereas that for vanillin, $49.1 \%$ of the total substrate consumption occurred in the first $5 \mathrm{sec}$. With chlorogenic acid as substrate, $92.8 \%$ of the total substrate reduction lied on the first $3 \mathrm{sec}$ of the reaction, while that for $p$-aminophenol and hydroquinone, $70.2 \%$ and $99.5 \%$ of the total substrate utilization was completed within the first 5 and $15 \mathrm{sec}$ of the reaction, respectively (Fig. 28A).

\subsubsection{Capillary Electrophoresis (CE) Analyses}

The electropherograms of substrates and migration times of each substrate are presented in Figure 29 and Table 4, repsectively. Overlaid chromatograms showing a typical time course of the phenolic substrate oxidation are presented in Figure 30, illustrating a decrease in the height of the substrate peak with respect to the reaction time. The plot showing the reducing substrate concentration with increasing reaction time is shown in Figure 28B. In comparison to the results obtained in HPLC analyses, the maximal substrate bioconversion in chloroform detected by CE occurred within the first $20 \mathrm{sec}$ of the reaction after which the reaction slowed down and reached the equilibrium. Even substrate consumption occurred with catechin during the biocatalysis (Fig. 28B). For vanillin, however, the highest substrate utilization, which accounted for $42.2 \%$ of the total substrate consumption, occurred within the first $3 \mathrm{sec}$ of the reaction. Likewise, with chlorogenic acid as substrate, $95.4 \%$ of the total substrate utilization was completed within the first 3 sec. With $p$-aminophenol as substrate, however, $46.6 \%$ of the substrate utilization was within 10 to $20 \mathrm{sec}$ of the reaction whereas for hydroquinone as substrate, $80.8 \%$ of the total substrate consumption was within the first $15 \mathrm{sec}$.

CE has become an excellent separation technique owing to its speed and high resolution. The separation of the phenolic compounds by CE was achieved within $10 \mathrm{~min}$ whereas that by HPLC lasted $45 \mathrm{~min}$. In addition to its high speed, using CE system offers greater sensitivity 
since efficient separation can be achieved using small amount of samples. In the analysis of phenolic compounds, only $0.18 \mathrm{nmol}$ of sample was taken for the actual injection in CE while that in HPLC, $2.4 \mu \mathrm{mol}$ of samples was needed, demonstrating that CE was over 10,000-fold more sensitive than HPLC. 


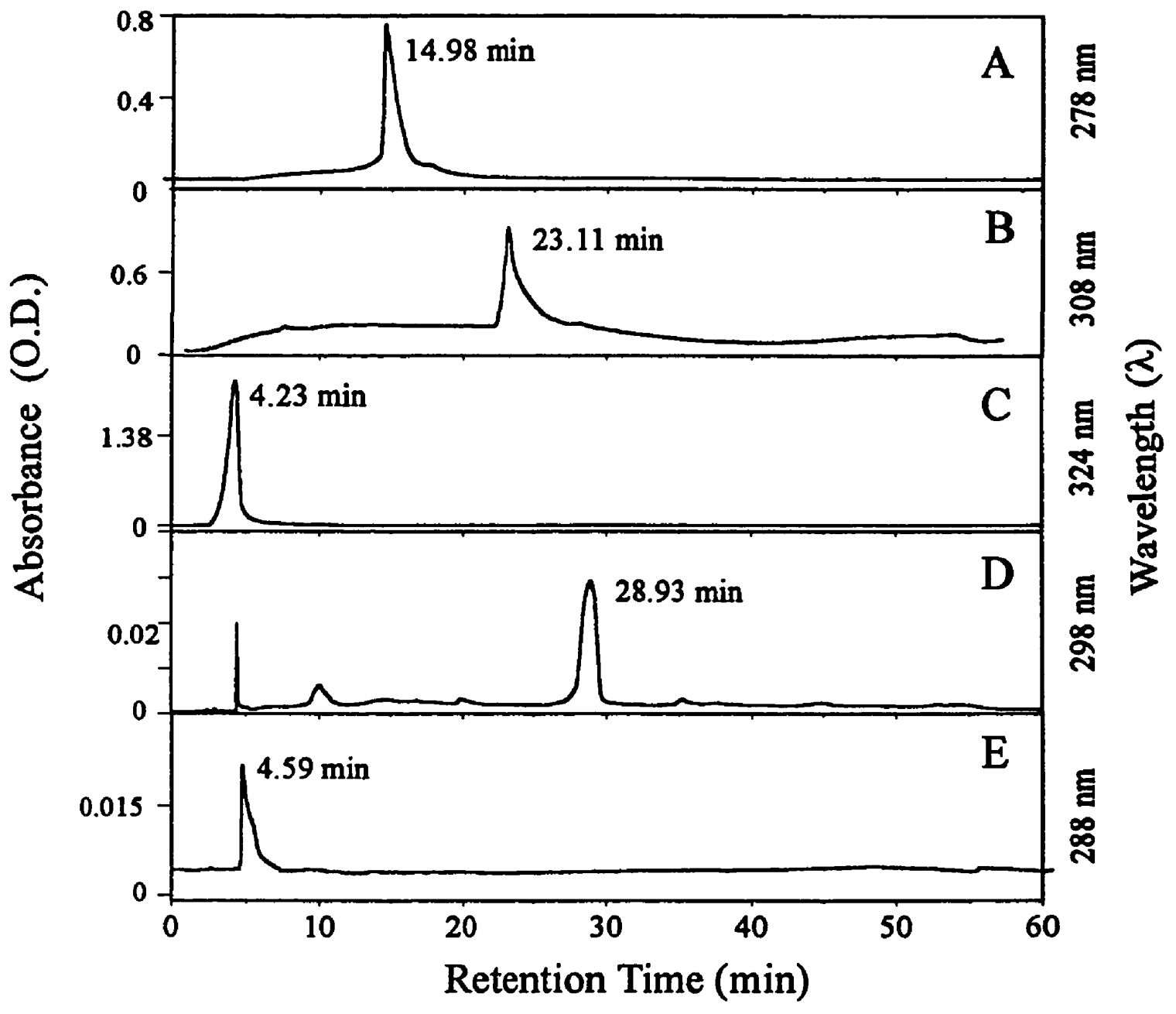

Figure 26. HPLC chromatograms of the five selected phenolic substrates using UV detection; (A) catechin, (B) vanillin, (C) chlorogenic acid, (D) p-aminophenol and $(E)$ hydroquinone. 


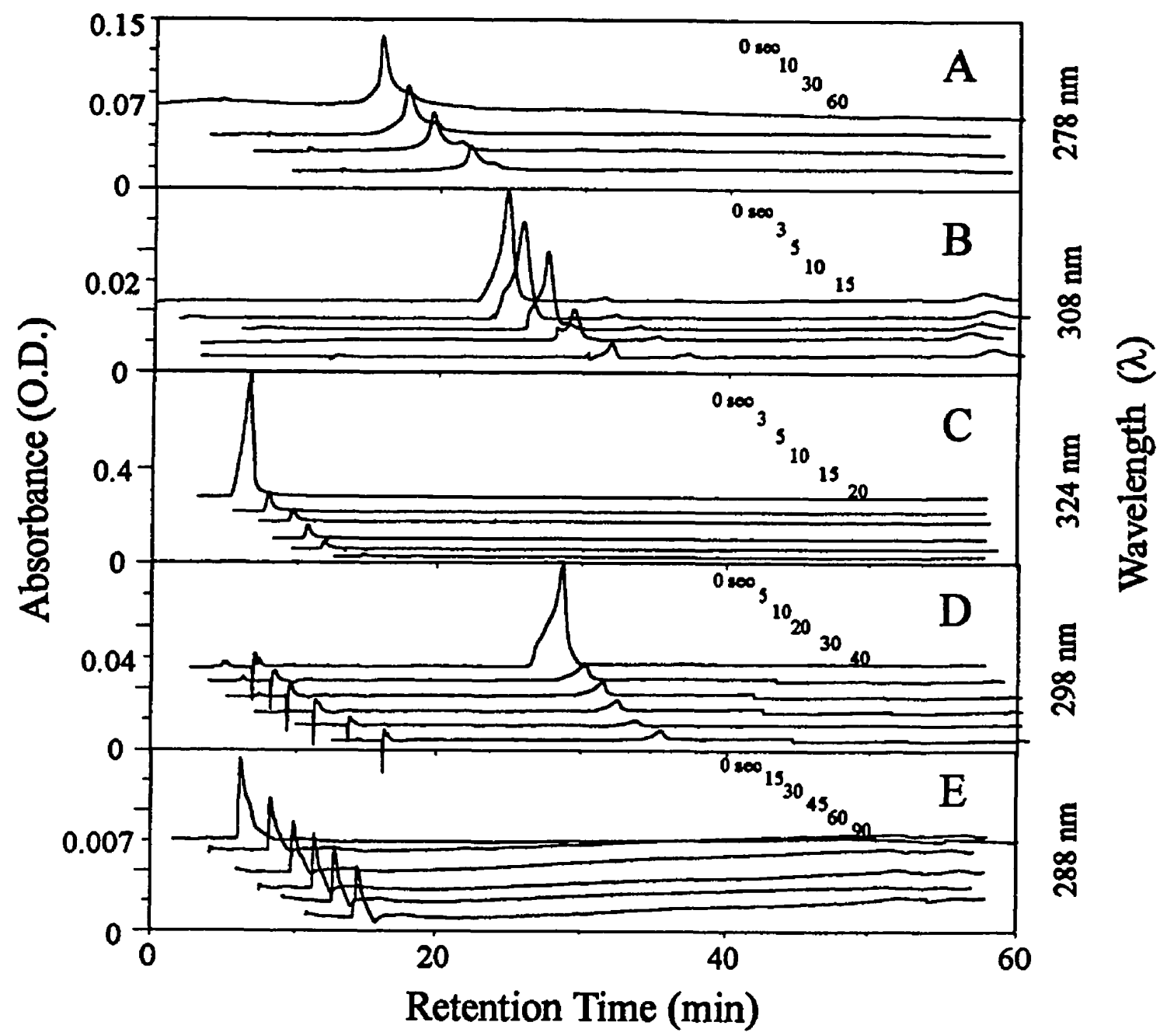

Figure 27. Overlaid HPLC chromatograms of the five phenolic substrate bioconversion with respect to reaction time during tyrosinase biocatalysis using $U V$ detection, (A) catechin, (B) vanillin, (C) chlorogenic acid, (D) p-aminophenol and (E) hydroquinone. 


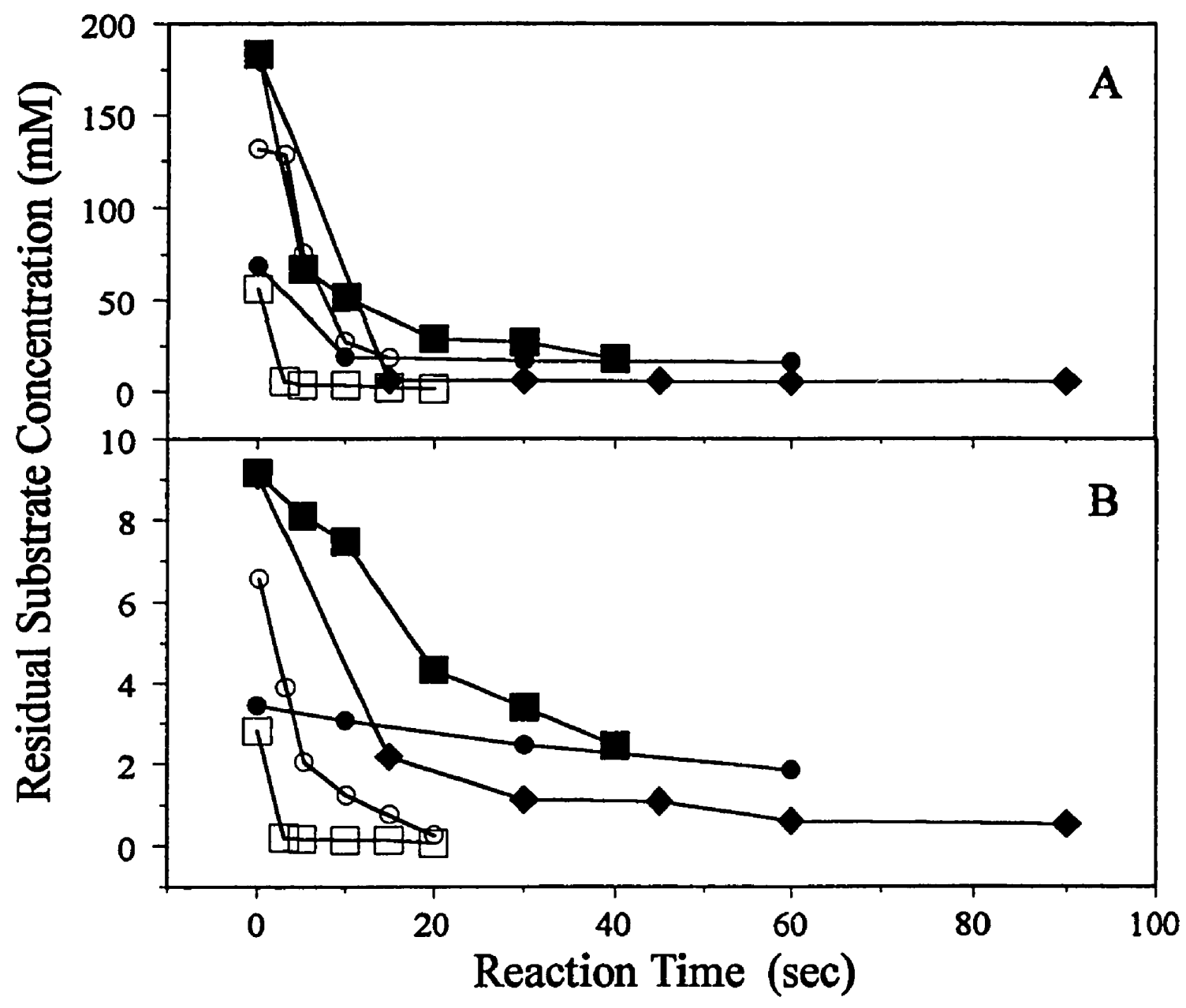

Figure 28. Substrate bioconversion at various reaction time, measured in the HPLC analyses (A) and CE analyses (B), using catechin ( $-\bullet$ ), vanillin ( $\mathrm{O}-\mathrm{O}$ ), chlorogenic acid $(\square-\square)$, $p$-aminophenol $(\square-\square)$ and hydroquinone $(\diamond-\diamond)$ as substrates. 


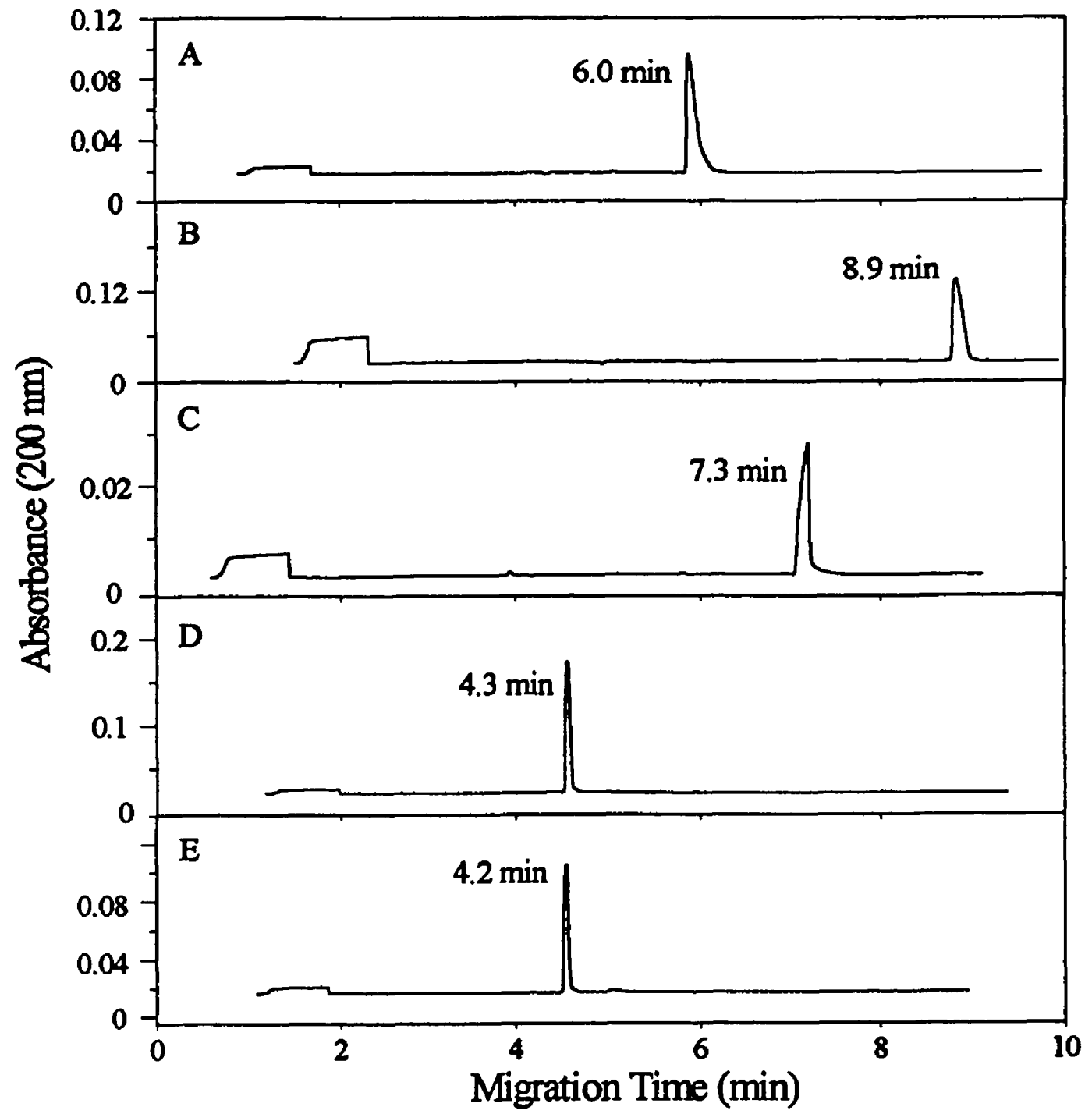

Figure 29. CE electropherograms of the five selected phenolic substrates using UV detection; (A) catechin, (B) vanillin, (C) chlorogenic acid, (D) p-aminophenol and $(E)$ hydroquinone. 


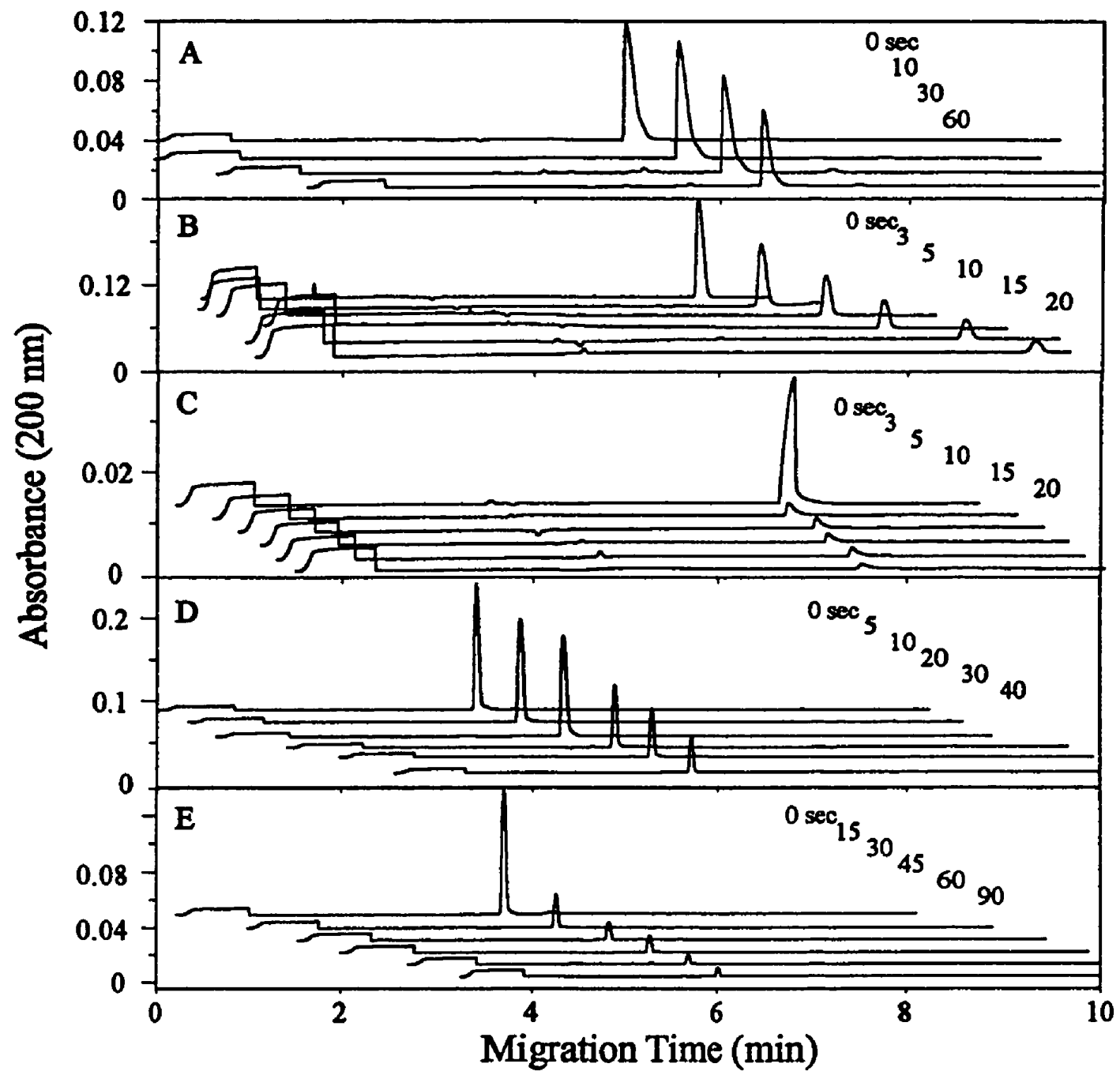

Figure 30. Overlaid CE electropherograms of the five phenolic substrate bioconversion with respect to reaction time using $\mathrm{UV}$ detection, (A) catechin, (B) vanillin, (C) chlorogenic acid, (D) p-aminophenol and (E) hydroquinone. 
Table 4. The retention time, migration time and the maxima absorbance wavelengths of the five phenolic substrates.

\begin{tabular}{lcccc}
\hline Substrate & $\begin{array}{c}\text { Retention Time } \\
(\mathrm{min})\end{array}$ & $\begin{array}{c}\text { Migration Time } \\
(\mathrm{min})\end{array}$ & $\begin{array}{c}\text { Maxima Absorbance }(\lambda) \\
\text { in Acetonitrile } \\
(\mathrm{nm})\end{array}$ & $\begin{array}{c}\text { Maxima Absorbance }(\lambda)_{\text {in Aqueous Medium }^{d}} \\
(\mathrm{~nm})\end{array}$ \\
\hline Catechin & 15.0 & 6.0 & $204,222,278$ & $234,294,484$ \\
Vanillin & 23.1 & 8.9 & $206,230,280,308$ & 234,335 \\
Chlorogenic Acid & 4.2 & 7.3 & $216,240,324$ & $232,292-368$ \\
p-Aminophenol & 28.9 & 4.3 & 234,300 & $234,272-306$ \\
Hydroquinone & 4.6 & 4.2 & 222,288 & 288 \\
\hline
\end{tabular}

${ }^{a}$ Retention times of the phenolic substrates in the HPLC analyses.

${ }^{b}$ Migration times of the phenolic substrates in the CE analyses.

${ }^{c}$ Maxima of aborbances were determined by the scan of each phenolic substrate at $20 \mathrm{~g} / \mathrm{L}$ in acetonitrile, using the UV-diode-arr detector, in the HPLC analyses.

${ }^{d}$ The substrates at $20 \mathrm{~g} / \mathrm{L}$ were prepared in $0.1 \mathrm{M}$ phosphate citrate buffer at $\mathrm{pH} 6.0$, using UV-Visible spectrophotometer. 


\section{CONCLUSION}

The results gathered in this study showed that the activity of the commercially purified mushroom tyrosinase was enhanced in chloroform, using catechin, vanillin, chlorogenic acid, $p$-aminophenol and hydroquinone as substrates, compared to that in aqueous media. Both the values of $V_{\max }$ and the catalytic efficiency of tyrosinase were found higher in chloroform than that in aqueous media. Minute amount of such "denaturing" solvent as methanol or acetone activated tyrosinase activity in chloroform while elevated amounts in the reaction mixture exhibited inhibitory effect on tyrosinase. Catechol was able to activate tyrosinase with catechin or chlorogenic acid as substrate, but no such enzyme activation was found with vanillin, paminophenol or hydroquinone. EDTA inhibitory effect in chloroform was found to be substratedependent while that in aqueous medium was not.

The FT-IR spectroscopic analyses suggested that native mushroom tyrosinase is predominately of $\alpha$-helical conformation; while those in chloroform the enzyme is mainly composed of $\beta$-pleat structure, which may account for the difference in the enzymatic activity. In addition, the FT-IR analyses confirmed the formation of $o$-quinones from the bioconversion in chloroform for all the substrates and suggested the possibility of further interaction of these $a$ quinones with the parent phenolic substrate in the case of vanillin and $p$-aminophenol while for chlorogenic acid, ring cleavage upon the formation of o-quinones might have occurred.

HPLC and CE analyses demonstrated the phenolic substrate bioconversion while the spectrophotometric scanning illustrated the formation of enzymatic products with respect to reaction time. HPLC and CE analyses also illustrated the extent of the substrate bioconversion with increasing reaction time and suggested that the maximal substrate bioconversion occurred within the first 10 to $20 \mathrm{sec}$ of the reaction. In addition to the high speed and separation efficiency, CE was found to be over 10,000-fold more sensitive than HPLC.

The development and optimization of tyrosinase biocatalysis in organic solvent media could be an assess for future investigations aimed at potential applications of tyrosinase in the formation of natural stable colors. 
Tse, M., Kermasha, S. and Ismail, A. A. (1997). Biocatalysis by tyrosinase in organic solvent media; a model system using catechin and vanillin as substrates. J. Mol. Catalysis B: Enzymatic 2(4), p. xx-xx.

Madani, W., Kermasha, S., Goetghebeur, M. and Tse, M. (1996). Partial purification and characterization of a polyphenol esterase from Aspergillus niger. Process Biochem. 32, 6169.

Tse, M. and Kermasha, S. (1996). Biocatalysis of tyrosinase in chloroform medium, using chlorogenic acid, p-aminophenol and hydroquinone as substrates. Biotech. Bioeng. (submitted)

Tse, M. and Kermasha, S. (1996). Comparative analyses of the phenol bioconversion by tyrosinase, using high-performance liquid chromatography (HPLC) and capillary electrophoresis (CE). J. Chromatogr. (submitted)

Tse, M. and Kermasha, S. (1996). Biocatalysis of polyphenol oxidase in organic solvent media. (to be submitted) 


\section{REFERENCES}

Almarsson, O. and Klibanov, A. M. (1996). Remarkable activation of enzymes in non-aqueous media by denaturing organic co-solvents. Biotech. Bioeng. 49, p. 87-92.

Alston, M. and Freedman, R. B. (1995). The importance of water to biocatalysis in organic solvents. Biochem. Soc. Trans. 23, 70.

Ayala, G., Gomez-Puyou, M. T., Gomez-Puyou, A. and Daarszon, A. (1986). Thermostability of membrane molecule enzymes in organic solvents. FEBS Lett. 203, 41-43.

Bordner, A. and Nelson, J. M. (1939). On the oxidation of p-cresol by means of tyrosinase. $J$. Am. Chem. Soc. 61, 1507-1513.

Bretscher, M. (1981). Water disposal in the chemical industry. In Microbial Degradation of Xenobiotics and Recalcitrant Compounds, T. Leisinger, R. Huetter, A. M. Cook, J. Nueesch (Eds.), Academic Press, Orlando, FL, pp. 65-74.

Brink, L. E. S. and Tramper, J. (1986). Modeling the effects of mass transfer on kinetics of propene epoxidation of immobilized mycobacterium. 1. Pseudo-one-substrate conditions and negligible products inhibition. Enzyme Microb. Technol. 8, 281-288.

Burton, S. G., Duncan, J. R., Kaye, P. T. and Rose, P. D. (1993). Activity of mushroom polyphenol oxidase in organic medium. Biotech. Bioeng. 42, 938-944.

Cabanes, J., Garcia-Canovas, F. and Garcia-Carmona, F. (1987). Chemical and enzymic oxidation of 4-methylcatechol in the presence or absence of serine. Spectrophotometric determination in intermediates. Biochim. Biophys. Acta 914, 190-197.

Careri, G., Gratton, E., Yang, P. H. and Rupley, J. A. (1980). Correlation of IR spectroscopic, heat capacity, diamagnetic susceptibility and enzymatic measurements on lysozyme powder. Nature (London) 284, 572-573. 
Carrea, G. (1984). Biocatalysis in water-organic solvent two-phase systems. Trends Biotechnol. 2, 102-106.

Carrea, G. (1987). Biocatalysis in water-organic solvent two-phase systems. In Biocatalysis in Organic Media, C. Lanne, J. Tramper and M. D. Lilly (Eds.), Elsevier, Amsterdam, pp.157168.

Cheynier, V., Basire, N. and Rigaud, J. (1989). Mechanism of trans-caffeoyltartaric acid and catechin oxidation in model solutions containing grape polyphenoloxidase. J. Agric. Food Chem. 37, 1069-1071.

Cheynier, V. F., Trousdale, E. K., Singleton, V. L., Salgues, M. J. and Wilde, R. J. (1986). Characterization of 2-S-glutathionylcaftaric acid and its hydrolysis in relation to grape wines. J. Agric. Food Chem. 34, 217-221.

Cooper, D. R, Marrel, C., Van de Waterbeemd, H., Testa, B., Jenner, P. and Marsden, C. D. (1987). L-DOPA esters as potential prodrugs: Behavioral activity in experimental models of Parkinson's desease. J. Pharm. Pharmacol. 39, 627-635.

Crecchio, C., Ruggiero, P. and Pizzigallo, M. D. R. (1995). Polyphenoloxidases immobilized in organic gels: Properties and applicataions in the detoxification of aromatic compounds. Biotech. Bioeng. 48, 585-591.

Desnuelle, P. (1972). The lipases. In The Enzymes, Vol. 7, $3^{\text {rd }}$ ed., P. D. Boyer (Ed.), Academic Press, New York, pp. 575-616.

Dordick, J. S. (1989). Enzymic catalysis in monophasic organic solvents. Enz. Microb. Technol. 11, 194-211.

Dubourdieu, D., Grassin, C., Deruche, D. and Ribereau-Gayon, P. (1984). Rapid determination of laccase activity in musts and wines by the syringaldazine method. Application to evaluating the sanitary condition of grape harvests. Conn. Vigne Vin 18, 237-252. 
Esaki, N., Tanaka, H., Miles, E. W. and Soda, k. (1983). Enzymatic synthesis of Se-substituted L-selenocysteine with tryptophan synthase. FEBS Lett. 161, 207-209.

Estrada, P., Baroto, W., Castillon, M. P., Acebal, C. and Arche, R. (1993). Temperature effects on polyphenol oxidase activity in organic solvents with low water content. J. Chem. Tech. Biotechnol. 56, 59-65.

Estrada, P., Sanchez-Muniz, R., Acebal, C., Arche, R and Castillon, M. P. (1991). Characterization and optimization of immobilized polyphenol oxidase in low-water organic solvents. Biotechnol. Appl. Biochem. 14, 12-20.

Fennema, O. R. (1996). Water and ice. In Food Chemistry, O. R. Fennema (Ed.), $3^{\text {th }}$ ed. Marcel Dekker, Inc., New York, pp. 42-47.

Fukui, S., Ahmed, S. A., Omata, T. and Tanaka, A. (1980). Bioconversion of lipophilic compounds in non-aqueous solvent. Effect of gel hydrophobicity on diverse conversions of testosterone by gel-entrapped Nocardia rhodocrous cells. Eur. J. Appl. Microbiol. Biotechnol. 10, 289-301.

Gorman, L. A. S. and Dordick, J. S. (1992). Organic solvents strip water off enzymes. Biotech. Bioeng. 39, 392-397.

Halling, P. J. (1992). Salt hydrates for water activity control with biocatalysts in organic media. Biotechnol. Tech. 6, 271-276.

Hammond, D. A., Karel, M., Klibanov, A. M. and Krukonis, V. J. (1985). Enzymatic reactions in supercritical gases. Appl. Biochem. Biotechnol. 11, 393-400.

Hirose, Y., Kariya, K., Sasaki, I., Kurono, Y., Ebiike, H. and Achiwa, K. (1992). Drastic solvent effect on lipase-catalyzed enantioselective hydrolysis of prochiral 1,4-dihydropyridines. Tetrahedron Lett. 33, 7157-7160. 
Holzbaur, I. E., English, A. M. and Ismail, A. A. (1996). FTIR study of the thermal denaturation of horseradish and cytochrome $c$ peroxides in $\mathrm{D}_{2} \mathrm{O}$. Biochem. 35, 5488-5494.

Hwang, S. O. and Park, Y. H. (1994). Ethyl acetate production in the gas phase. Biotechnol. Lett. 16, 379-384.

Jones, J. B. (1986). Enzymes in organic synthesis. Tetrahedron 42, 3351-3403.

Kamat, S., Beckman, E. J. and Russell, A. J. (1995). Enzyme activity in supercritical fluids. Crit. Rev. Biotechnol. 15, 41-71.

Kazandjian, R. Z. and Klibanov, A.M. (1985). Regioselective oxidation of phenols catalyzed by polyphenol oxidase in chloroform. J. Am. Chem. Soc. 107, 5448-5450.

Kazandjian, R. Z., Dordick, J. S. and Klibanov, A.M. (1986). Enzymatic analyses in organic solvents. Biotech. Bioeng. 28, 417-421.

Kearney, P. C., Karns, J. S. and Mulbry, W. W. (1987). Engineering soil microorganisms for pesticide degradation. In Pesticide Science and Biotechnology, R. Greenhalgh and T. M. Roberts (Eds.), Blackwell Scientific, Boston, MA, pp. 591-596.

Kermasha, S., Goetghebeur, M., Dumont, J. and Couture, R. (1995). Analyses of phenolic and furfural compounds in concentrated and non-concentrated applce juices. Food Res. International 28, 245-252.

Kermasha, S., Goetghebeur, M., Monfette, A., Metche, M. and Rovel, B. (1993a). Inhibitory effects of cysteine and aromatic acids on tyrosinase activity. Phytochem. 34, 349-353.

Kermasha, S., Goetghebeur, M., Monfette, A, Metche, M. and Rovel, B. (1993b). Studies on inhibition of mushroom polyphenol oxidase using chlorogenic acid as substrate. J. Agric. Food Chem. 41, 526-531. 
Kirchner, G., Scollar, M. P. and Klibanov, A. M. (1985). Resolution of racemic mixtures via lipase catalysis in organic solvents. J. Am. Chem. Soc. 107, 7072-7076.

Klibanov, A. M. (1983). Stabilization of enzymes against thermal inactivation. Adv. Appl. Microbiol. 29, 1-28.

Klibanov, A. M. (1986). Enzymes that work in organic solvents. Chemtech 6, 354-359.

Klibanov, A. M., Desai, U. R. and Griebenow, K. (1995). In Enzyme Engineering XIII, San Diego, CA, October 15-20.

Klibanov, A. M., Samokhin, G. P., Martinek, K. and Berezin, I. V. (1977). A new approach to preparative enzymatic synthesis. Biotech. Bioeng. 19, 1351-1361.

Lanne, C., Boeren, S., Vos, K. and Veeger, C. (1987). Rules for optimization of biocatalysis in organic solvents. Biotech. Bioeng. 30, 80-87.

Lee, C. Y. and Whitaker, J. R. (1995). In Enzymatic Browning and Its Prevention, Lee, C. Y. and Whitaker, J. R. (Eds.), American Chemical Society, Washington, DC, pp. 11-12.

Lerch, K. (1987). Molecular and active site structure of tyrosinase. Life Chem Reports 5, 221234.

Lilly, M. D. (1982). Two-liquid phase biocatalytic reactions. J. Chem. Tech. Biotechnol. 32, 162169.

Lilly, M. D., Brazier, A. J., Hocknull, M. D., Williams, A. C. and Woodley, J. M. (1987). Biological conversions involving water-insoluble organic compounds. In Biocatalysis in Organic Solvent, C. Lanne, J. Tramper and M. D. Lilly (Eds.), Elsevier, Amsterdam, pp. 318.

Linke, W. F. (1958). In Solubilities: Inorganic and Metal-Organic Compounds, Vol. 2, $4^{\text {th }}$ ed., American Chemical Society, Washington, D.C. 
Margolin, A. L. and Klibanov, A. M. (1987). Peptide synthesis catalyzed by lipases in anhydrous organic solvents. J. Am. Chem. Soc. 109, 3802-3804.

Margolin, A. L., Tai, D. F. and Klibanov, A. M. (1987). Incorporation of D-amino acids into peptides via enzymatic condensation in organic solvents. J. Am. Chem. Soc. 109, 7885-7887.

Marini, M. A. and Martin, C. A. (1971). Chymotrypsin catalysis in the presence of formaldehyde. The $\mathrm{pH}$ dependence of ester hydrolysis. Eur. J. Biochem. 19, 153-161.

Matheis, G. and Whitaker, J. R. (1984). Modification of proteins by polyphenol oxidase and peroxidase and their products. J. Food Biochem. 8, 137-162.

Mayer, A. M. (1987). Polyphenol oxidases in plants: Recent progress. Phytochem. 26, 11-20.

Nicolas, J., Richard-Forget, F., Goupy, P., Amiot, M. J. and Aubert, S. (1994). Enzymatic browning reactions in apple and apple products. Crit. Rev. Food Sci. Nutri. 34, 109-157.

Oszmianski, J. and Lee, C. Y. (1990). Enzymatic oxidation reaction of catechin and chlorogenic acid in a model system. J. Agric. Food Chem. 38, 1202-1204.

Overbeek, J. T. G., De Bruyen, P. L. and Verhoeckx, F. (1984). Microemulsions. In Surfactant, T. F. Tadros (Ed.), Academic Press, London, pp. 111-132.

Poole, P. L. and Finney, J. L. (1983). Hydration-induced conformational changes in lysozyme at low water content. Int. J. Biol. Macromol. 5, 308-310.

Reed, R. L. and Healy, R. N. (1977). Some physiochemical aspects of microemulsion flooding: A review. In Improved Oil Recovery by Surfactant and Polymer Flooding, D. O. Shah and R. S. Schechter (Eds.), Academic Press, Inc., New York, pp. 383-437.

Rekker, R. F. and de Kort, H. M. (1979). The hydrophobic fragmental constant: An extension to a 1000 data point set. Eur. J. Med. Chem. - Chimica Therapeutica 14, 479-488. 
Richard-Forget, F., Amiot, M. J., Goupy, P. and Nicolas, J. (1995). Evolution of chiorogenic acid o-quinones in model solutions. In Enzymatic Browning and Its Prevention, C. Y. Lee and J. R. Whitaker (Eds.), American Chemical Society, Washington, D.C., pp. 144-159.

Richard-Forget, F., Rouet-Mayer, M. A., Goupy, P., Philippon, J and Nicolase, J. (1992). Oxidation of chlorogenic acid, catechin and 4-methylcatechol in model solutions by apple polyphenol oxidase. J. Agric. Food Chem. 40, 2114-2122.

Rouet-Mayer, M. A., Philippon, J. and Ralambosa, J. (1990). Roles of o-quinones and their polymers in the enzymic browning of apples. Phytochem. 29, 435-440.

Rubio, E., Fernandez-Mayorales, A. and Klibanov, A. M. (1991). Effect of the solvent on enzyme regioselectivity. J. Am. Chem. Soc. 113, 695-696.

Russell, A. J., Trudel, L. J., Skipper, P. L., Groopman, J. D., Tannenbaum, S. R. and Klibanov, A. M. (1989). Antibody-andigen binding in organic solvents. Biochem. Biophys. Res. Commun. 158, 80-85.

Ryu, K. and Dordick, J. S. (1989). Free energy relationships of substrate and solvent hydrophobicities with enzymatic catalysis in organic media. J. Am. Chem. Soc. 111, 80268027.

Sakurai, T., Margolin, A. L., Russell, A. J. and Klibanov, A. M. (1988). Control of enzyme enantioselectivity by the reaction medium. J. Am. Chem. Soc. 110, 7236-7237.

Sánchez-Ferrer, A., Perez-Gilabert, M. and Garcia-Carmona, F. (1992). Catalysis of polyphenol oxidase in a ternary system of reverse vesicles in organic solvents. In Biocatalysis in NonConventional Media; Progress in Biotechnology, Vol. 8, J. Tramper, M. H. Vermüe, H. H. Beektink and U. von Stockar (Eds.), Elsevier Science Publishers, B. V., Amsterdam, pp. 755-760. 
Schwartz, R. D. and McCoy, C. J. (1977). Prooxidation of 1,7-octadiene by Pseudomonas oleovorans: Fermentation in the presence of cyclohexane. J. Appl. Environ. Microbiol. 34, 47-49.

Singleton, V. L. (1987). Oxygen and phenols and related reactions in must, wines, and model systems; Observations and practical implications. Am. J. Enol. Vitic. 38, 69-77.

Solomon, E. I. (1990). Tyrosinase. In Copper Proteins, Vol. 3, T. G. Spiro (Ed.), Wiley, New York. pp. 91-98.

Stenius, P. (1984), Micelles and reversed micelles: A historical overview. In Reversed Micelles: Biological and Technological Relevance of Amphiphilic Structures in Apolar Media, P. L. Luisi and B. E. Straub (Eds.), Plenum Press, New York, pp. 1-20.

Surewicz; W. K., Mantsch, H. H. and Chapman, D. (1993). Determination of protein secondary structure by Fourier Transform Infrared Spectroscopy: A critical assessment. Biochem. 32, 389-394.

Susi, H. and Byler, D. M. (1986). Resolution-enhanced Fourier Transform Infrared Spectroscopy of enzymes. Methods Enzymol. 130, 290-311.

Wescott, C. R. and Klibanov, A. M. (1994). The solvent dependence of enzyme specificity. Biochim. Biophys. Acta 1206, 1-9.

Wheeler, C. J. and Croteau, R. (1986). Communication: Terpene cyclase catalysis in organic solvent/minimal water media: Demonstration and optimzation of $(+)-\alpha$-pinene cyclase activity. Arch. Biochem. Biophys. 248, 429-434.

Yamada, H. and Kumagai, H. (1978). Microbial and enzymatic processes for amino acid production. Pure Appl. Chem. 50, 1117-1127. 
Yang, F. and Russell, A. J. (1996). The role of hydration in enzyme activity and stability: 2. Alcohol dehydrogenase activity and stability in a continuous gas phase reactor. Biotech. Bioeng. 49, 709-716.

Yang, Z., Robb, D. A. and Halling, P. J. (1992). Variation of tyrosinase activity with solvent at a constant water activity. In Biocatalysis in Non-Conventional Media; Progress in Biotechnology, Vol. 8, J. Tramper, M. H. Vermüe, H. H. Beektink and U. von Stockar (Eds.), Elsevier Science Publishers, B. V., Amsterdam, pp. 585-592.

Zaks, A. and Klibanov, A. M. (1984). Enzymatic catalysis in organic media at $100^{\circ} \mathrm{C}$. Science 224, 1249-1251.

Zaks, A. and Klibanov, A. M. (1985). Enzyme-catalyzed processes in organic solvents. Proc. Natl. Acad. Sci. USA 82, 3192-3196.

Zaks, A. and Klibanov, A. M. (1986). Substrate specificity of enzymes in organic solvents vs. water is reversed. J. Am. Chem. Soc. 108, 2767-2768.

Zaks, A. and Klibanov, A. M. (1988a). The effect of water on enzyme action in organic media. $J$. Biol. Chem. 263, 8017-8021.

Zaks, A. and Klibanov. A. M. (1988b). Enzymatic catalysis in nonaqueous solvents. J. Biol. Chem. 263, 3194-3201.

Zaks, A. and Russell, A. J. (1988). Enzymes in organic solvents: Properties and applications. $J$. Biotechnol. 8, 259-270. 

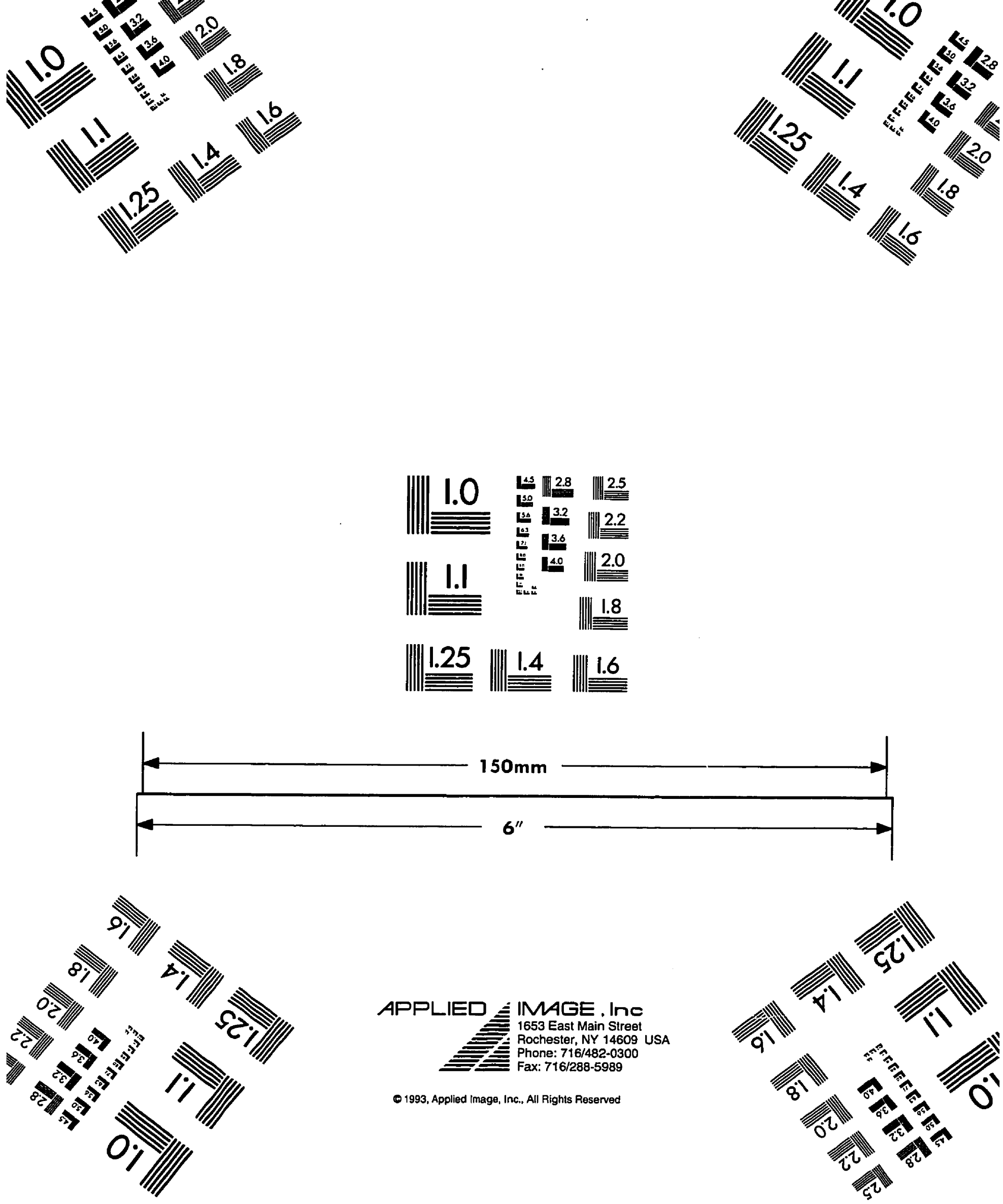

APPLIED Ë IMAGE . Ine

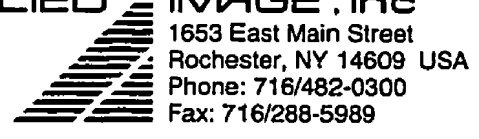

- 1993, Applied Image, Inc., All Rights Reserved

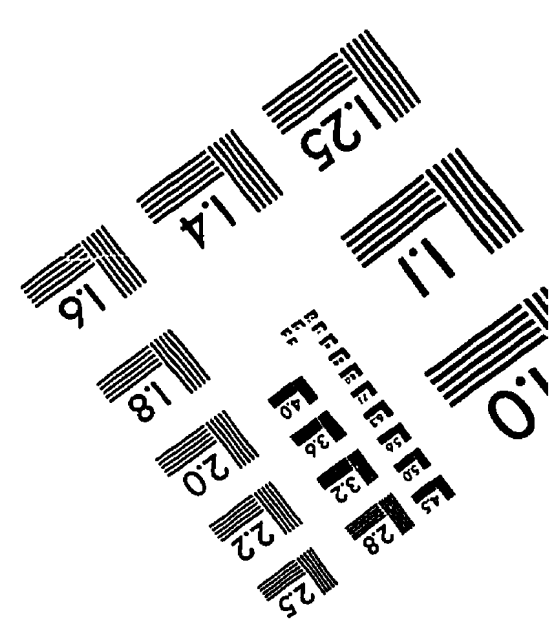

